\title{
Slope Stability and Alternative Design Methodology for Highway Rock Cut Slopes in West Virginia
}

\author{
Michael A. Kulbacki
}

Follow this and additional works at: https://researchrepository.wvu.edu/etd

\section{Recommended Citation}

Kulbacki, Michael A., "Slope Stability and Alternative Design Methodology for Highway Rock Cut Slopes in West Virginia" (2014). Graduate Theses, Dissertations, and Problem Reports. 6021.

https://researchrepository.wvu.edu/etd/6021

This Thesis is protected by copyright and/or related rights. It has been brought to you by the The Research Repository @ WVU with permission from the rights-holder(s). You are free to use this Thesis in any way that is permitted by the copyright and related rights legislation that applies to your use. For other uses you must obtain permission from the rights-holder(s) directly, unless additional rights are indicated by a Creative Commons license in the record and/ or on the work itself. This Thesis has been accepted for inclusion in WVU Graduate Theses, Dissertations, and Problem Reports collection by an authorized administrator of The Research Repository @ WVU. For more information, please contact researchrepository@mail.wvu.edu. 


\title{
Slope Stability and Alternative Design Methodology for Highway Rock Cut Slopes in West Virginia
}

\author{
Michael A. Kulbacki \\ Thesis submitted to the \\ Benjamin M. Statler College of Engineering and Mineral Resources \\ at West Virginia University \\ in partial fulfillment of the requirements for the degree of \\ Master of Science \\ in \\ Civil and Environmental Engineering \\ John D. Quaranta, Ph.D., P.E., Chair \\ Hema Siriwardane, Ph.D., P.E. \\ John Zaniewski, Ph.D. \\ Department of Civil and Environmental Engineering \\ Morgantown, West Virginia \\ 2014
}

KEYWORDS: Cut slopes, benching, planar, highway design, back slope angle, rock fall Copyright 2014 Michael A. Kulbacki 


\section{ABSTRACT \\ Slope Stability and Alternative Design Methodology for Highway Rock Cut Slopes in West Virginia}

\section{Michael A. Kulbacki}

This report presents the findings of numerical modeling analyses on rock cut slopes sites in Hardy County (U.S. Route 48) and Raleigh County (U.S. Route 121), West Virginia, and investigates the feasibility of design alternation in lieu of current cut slope practices performed by West Virginia Department of Highways. The scope of this research was to provide a new design process (i.e. flow charts and design charts) for rock cut slope design with respect to geotechnical bench reduction with the aid of numerical modeling.

The numerical modeling involved evaluations of current cut slopes and the investigation of design alternatives in various locations in West Virginia. The modeling software suite used for this analysis was SoilVision Systems ${ }^{\mathrm{TM}}$. The comprehensive modeling entailed slope stability analysis within the program module SVSlope ${ }^{\circledR}$. Various failure criterion methods were assessed, in addition to multiple stability analysis approaches. It was found that the Hoek-Brown failure criterion provides the most accurate representation of fractured rock behavior, due to the consideration of fracture assessment on the exposed slope face. The stability analysis method used in the calculations was the General Limit Equilibrium.

The bench reduction process conducted on U.S. Route 121 was performed in a friable, less desirable geological composition. The analysis yielded the elimination of one geotechnical bench during the redesign trials which lead to the increase in slope stability in three of the four redesign cases. Trial three of the reduction process showed an increase in stability by approximately $24 \%$. This would not only allow for a greater structural integrity is will allow for lower excavation quantities to be left in place, lowering the overall construction cost.

The bench reduction on U.S. Route 48 encountered hard competent rock material. The analysis illustrated that geotechnical bench elimination possible. The initial assessment on this route illustrate an over designed slope with bench implementation. One of the bench reductions performed lowered the factor of safety from the initial evaluation; however the calculated stability results exceeded the minimum requirement of 1.25 by approximately $20 \%$. This result deemed the bench reduction process a success for this case study.

The cumulative analysis of the alternative design approach yielded factors of safety that met or exceeded the minimum requirement of 1.25 stated with WVDOH regulations. The predicted failure locations were shallow non-circular failures near the surface of the back slopes. The results showed that alternative designs with regards to continuous vertical heights exceeding 50 vertical feet are plausible within the geology formations in West Virginia. It is possible that some small slope failure may occur with the weathering of exposed rock, it is believed that this material will be captured mid-slope on the geotechnical benches given the intended use. 


\section{EXECUTIVE SUMMARY}

The aim for this research focused on investigating the following items:

1. Literature review of rock cut slope practices with specific regards to back slope angle, bench widths, and continuous planar cut sections.

a. Critical review of West Virginia Department of Highways Design Directive: 403 (DD-403) (WVDOH, 2006).

b. Investigation into failure criterion which best represents rock type. In addition to failure criterion, the Method of Slices analysis technique appropriate for factor of safety calculation was also addressed.

2. Development of design charts for new slope design based on computer modeling.

3. Examination of bench reduction resulting in continuous planar sections exceeding 50 vertical feet, while maintaining a minimum factor of safety requirement of 1.25 . This was analyzed through computer aided modeling.

Summary of Findings:

\section{Literature Review}

This review is presented in section 2.0 of the report. It focused on a critical review of current procedures practiced by various state agencies; including failure mode criterion and stability analysis. I identified the key concepts and of rock cut slope construction and consideration from blasting, geologic formations, erosion and geometric optimization. Designs should optimize slope stability, geometric restrictions, rock fall attenuation, and ensure public safety. It is unrealistic to approach a rock cut design with the intention to stop all rock fall from occurring.

The DD-403 document is specifically for cut slope construction in bedrock. Rock cut slope construction begins with the subsurface exploration to observe and test the geologic stratum that will be encountered. Material testing is a vital step in the pre-design process. There are no current specific guidelines listed in DD-403 on subsurface exploration and material testing. A list of material classification was obtained through this literature review. The classification list was found to be inadequate for specific strength values and allowed too large of a range in strength values. Site specific tested data adds confidence and further ensuring a suitable design was achieved. 
I identified the following parameters to be consistently tested from preliminary slope design for rock cut slopes.

i. Determination of modulus of elasticity

ii. Determination of Poissons ratio

iii. Slake Durability Index ranges

iv. Layer thicknesses

v. Any attainable information regarding the lithography of the strata such as its strike, dip, and discontinuities.

vi. Unconfined Compressive Strength

vii. Presence of infilling of clay or any other material.

Obtaining these parameters and geological occurrences the designer will remove uncertainties on what will be encountered with regards to planning for excavation and design.

Geometric design method listed within DD-403 requires that rock cut slope be constructed with a maximum back slope vertical height of $50 \mathrm{ft}$. It states that larger heights may be used in certain situations with approval. Benching requirements set forth in the document mandate a minimum bench width of $20 \mathrm{ft}$. (horizontal) with a sloped ratio of $15 \mathrm{H}: 1 \mathrm{~V}$ away from the back slope to minimize water infiltration on the slope. In addition the minimum factor of safety requirement set forth in DD-403 is 1.25 .

Geometric design cannot be restricted to a specific guidance due to the anomalies which can encounter in geological formations. The design process includes a numerical modeling analysis to assess the factor of safety of the proposed slope. The Mohr-Coulomb is the most widely used criterion in geotechnical engineering. Mohr-Coulomb relies on the cohesion and friction with direct relation between normal stress and shear stress on intact media. Blasting practices fracture the exposed rock resulting in non-intact disturbed rock features. An alternative failure criterion, Hoek-Brown, was evaluated. The Hoek-Brown failure criterion was developed for the use in rock excavation for tunnels and small scale geotechnical slopes.

I determined that the Hoek-Brown failure criterion adequately represents the analysis of rock slope stability with the consideration of fractured material on the exposed slope face. This method includes stability with regards to fracture disturbances, unconfined compressive strength, unit weight, geological strength parameters and a rock mass constant. The Hoek-brown criterion 
is used for fractured rock. Fracture propagation into the exposed rock face leaves instability which leads to rock fall toppling events as seen in field observations.

The stability examination process evaluated three methods of analysis. The three methods considered were; Simplified Janbu, Simplified Bishop, and General Limit Equilibrium. Through literature findings and modeling validation I found the General Limit Equilibrium analysis method most adequately determined the factor of safety with consideration in summation of moments and summation of forces used in the calculative process.

\section{Sensitivity Analysis and Design Charts}

A sensitivity analysis was conducted on an idealized slope constructed within the geometric requirements in DD-403 to illustrate the estimated behavior an individual input variable has on the factor of safety. This process resulted in two outcomes: 1.) The intended sensitivity analysis and 2.) Design charts based upon material strength for the four most prevalent slope back slope angles that were seen in the field and proposed in DD-403. Completion of the sensitivity analysis and design charts required the assessment of 159 individual models.

The Hoek-Brown failure criterion was applied in this analysis. All the variable input parameters values were obtain through literature finding from tested data and scholarly sources.

I found that the three most influential parameters with respect to slope performance are: Unconfined Compressive Strength, Disturbance Factor, and Geological Strength Index. Disturbance factor determination is based upon the blasting effects and can only be determined post excavation. The geological strength index is determined through the discontinuities and faults within a geologic layer and is difficult to determine through borehole examination. The unconfined compressive strength is the only testable and obtainable parameter prior to slope construction with regards to the Hoek-Brown criterion, thus leading to the basis of the new slope design charts.

I developed design charts based upon the most prevalent back slope angles found within the DD403 and observed in current use through field observations. The design charts are equipped with a flow chart that provides a step-by-step procedure on the use and selection of the appropriate back slope angle.

Completion of the design charts illustrated unexpected results. The factor of safety deceased at the slope angle increased until it met a convergence angle around $60^{\circ}$. This finding required an addition analysis of back slope angle with respect to the factor of safety. This analysis required nine models which varied the back slope angle from $10^{\circ}$ to $90^{\circ}$. Conclusive evidence illustrated a decline in the factor of safety calculation from $10^{\circ}$ to $60^{\circ}$. The response after $60^{\circ}$ began to increase until the completion of the runs. 


\section{Salient Findings of Bench Reduction Analysis}

The work presented in section 4 of this report addresses the current slope stability performance and the feasibility of reducing benches throughout rock cut slope profiles. This work was conducted through numerical modeling of rock cut slopes and field visitations to evaluate slope behavior. Site selection was done based up on geologic orientation throughout the state of West Virginia. It was necessary to evaluate a high strength material in addition to a less desirable weak material. The first site that was selected was along U.S. Route 121 located in Raleigh County. The second slope was along U.S. Route 48 located with Hardy County. The bench reduction process was a five step method: including an initial trial to establish a base factor of safety, and four slope bench reduction trials. The four trials assessed bench removal at various locations throughout the slope profiles. Strength values used within this process were obtained through literature findings in addition to the other criteria necessary for the Hoek-Brown criterion.

Site \#1 located along U.S. 121 was comprised mainly of intermittent siltstone and sandstone layers. The siltstone showed more severe signs of weathering than the sandstone. The siltstone was very friable, highly erodible and exhibited a high frequency of falling siltstone. Large piles of accumulated siltstone material were found on all the benches, at the interface of the back slope and bench. The average recorded material was found to be gravel to sand sized particle ( 0.01 to 2.5 inch). There were some instances of fallen siltstone debris reaching two feet in diameter. The third bench showed the highest accumulation of fallen debris. With the majority of the material throughout the slope being highly fractured, it has left the slope very susceptible to aggressive raveling of material and further detrimental rock fall events.

Numerical modeling of the slope for the bench reduction was a five step process. Initial assessment was conducted on the slope with material strength at the 50 percent of the maximum value. This value was selected to ensure an initial factor of safety above 1.25 was met. The initial factor of safety calculation was found to be 1.254 , meeting the requirement set forth in DD-403. The bench reduction process conducted on U.S. Route 121 was performed in a weak less desirable geological composition. The analysis yielded the elimination of one geotechnical bench which lead to the increase is slope stability in three of the four redesign cases. Through the analysis I found that trial three of the reduction process showed an increase in the calculated factor of safety by approximately $24 \%$. This would not only allow for a greater structural integrity and higher factor of safety that will allow for lower excavation quantities to be left in place, lowering the overall construction cost. 
Site \#2 located along U.S. 48 was comprised of two distinct geologic zones of sandstone and limestone. Both the rock types appeared to be withstanding the weathering affects well and there was minimal sign of eroded material. The structure was large blocky uniform masses with minimal sporadic fracturing of the rock. All sign of fallen rock present on the slope was of minimal size, it is what would be expected to be found mid slope or at toe of slope. The vast majority of debris was cobble sized (3 to 12 inch) with the average size around 6 inches.

Similar to the analysis performed on U.S. 121 the bench reduction process performed on U.S. Route 48 was a five step procedure. Initial assessment of the slope to attain a stability result yielded current calculated factor of safety at 2.090 which was significantly greater than 1.25 , which leads to the belief that the slope has been over designed with benches at 50 percent of the maximum value material strength value. This left an ideal opportunity for a bench reduction assessment. Conclusive evidence shows bench reduction process in these instances is neither beneficial nor plausible to create increased slope stability. The bench reduction did in fact show the possibility to remove a bench while still achieving the minimum factor safety requirement of 1.25 (Trial 2); however, a decline in stability was the result which is satisfactory. The fourth trial of the reduction process yielded a factor of safety slightly below the requirement; it would be left to the geotechnical engineer discretion if design was acceptable for use. 


\section{CONCLUDING REMARKS AND RECOMMENDATIONS}

I found that conclusive evidence tends to indicate that the reduction in benches is possible for implementation throughout the state of West Virginia in both weak and strong strata. The slope stability evaluation results showed that it is possible to place continuous planar cut section within a slope profile and have an increase in the factor of safety, given certain stipulations. Conclusive evidence showing the increase in the stability of the slope with the reduction of benches illustrates that it is possible for rock cut slopes to be constructed with back slope portions exceeding the vertical $50 \mathrm{ft}$. restriction of DD-403. When benches are eliminated the designer can increase bench widths to allow for large material volumes to resist driving forces. This is an iterative process; several designs should be evaluated during this procedure.

I recommend the designer(s) use a modeling software that has the capability in analyzing rock cut slope with the Hoek-brown failure criterion. It was found that the Hoek-Brown failure criterion based up on its design and intent as well as modeling results provides the most accurate representation of the stability performance of fractured rock as compared to the Mohr-Coulomb criterion.

I feel that this study's findings presented herein are intended for a new approach in rock cut slope design, and do not encompass all the permutations and anomalies found within geological occurrences which may inhibit continuous planar section in rock cut slopes at times. 


\section{ACKNOWLEDGEMENTS}

I would first like to thank Dr. John Quaranta for this gracious opportunity to attend graduate school in the pursuit of a master's degree in civil engineering. His guidance, background, and support were second to none in aid and collaboration with this research project. In addition I wish to thank Dr. Hema J. Siriwardane and Dr. John Zaniewski for being in my advisory committee.

I wish to thank Mr. Harold Russell, Mr. Matthew Idleman, and Mr. Justin Pentz for assistance in field exploration as well as computer modeling.

I also would like to thank the engineers and staff from the West Virginia Department of Highways for their assistance throughout this research project.

I would like to dedicate this thesis to my parents Mike and Toni Kulbacki, brother Aaron Kulbacki, girlfriend Meredith Edwards, my grandparents and closest friends for their support throughout my academic career. This entire process would not have been attainable without the encouragement and motivation to overcome obstacles that were encountered thought this journey; and for that I thank all of you. 


\section{TABLE OF CONTENTS}

Abstract ii

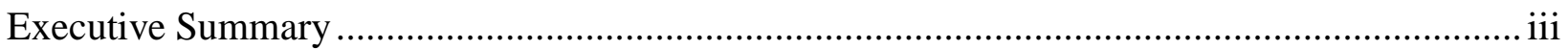

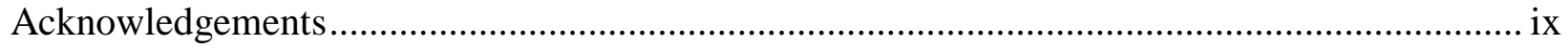

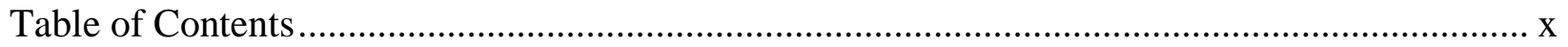

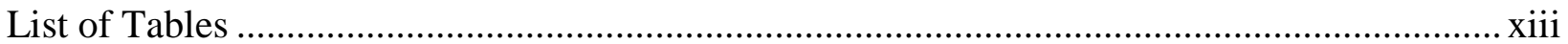

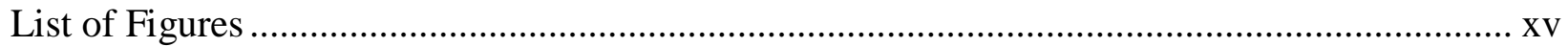

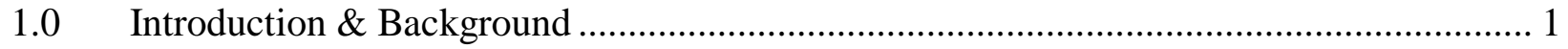

1.1 Research Purpose, Objectives, and Work Scope ……...................................................... 2

1.2 Research Approach ............................................................................................. 2

$2.0 \quad$ Literature Review......................................................................................... 3

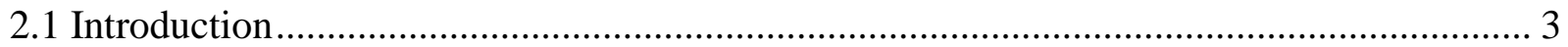

2.2 Blasting Effects on Slope Instability ....................................................................... 4

2.2.1 Subsurface Exploration and Material Testing .................................................... 5

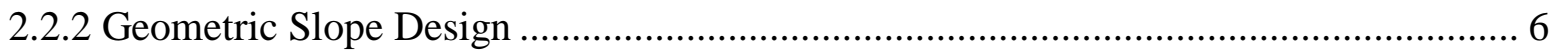

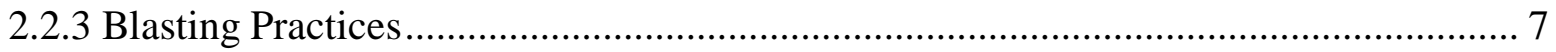

2.3 Cut Slope Practices and Design Requirements …………............................................. 7

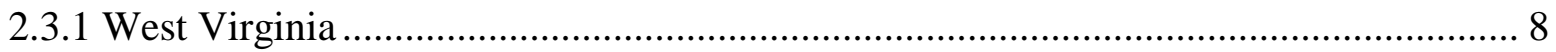

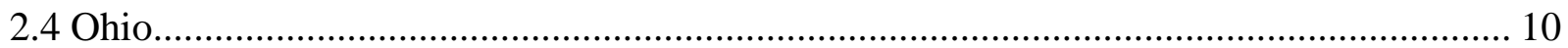

2.4.2 Rock Quality Designation (RQD) ........................................................................ 10

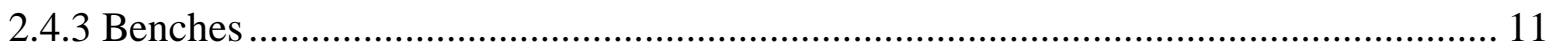

2.5 Cut Slope Design and Assessment........................................................................... 11

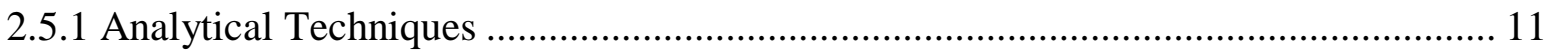

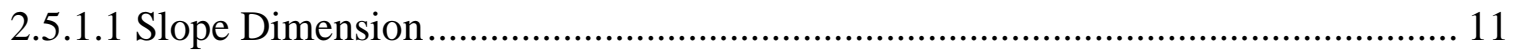

2.5.2 Factor of Safety General Limit Equilibrium Approach .............................................. 12

2.5.3 Colorado Rock Fall Simulation Program.............................................................. 12

2.6 Analysis Method and Approach.............................................................................. 12

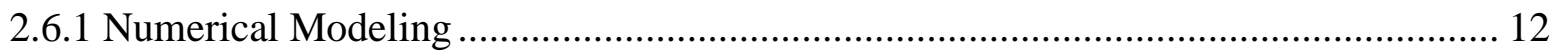

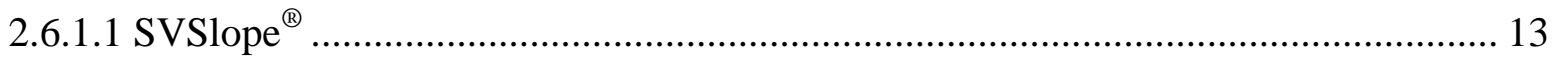

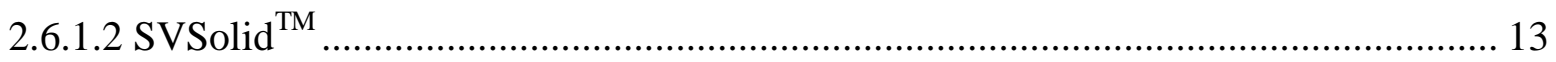

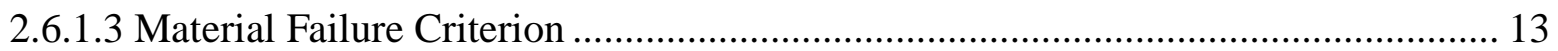

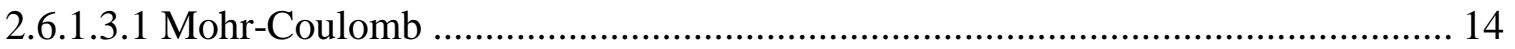

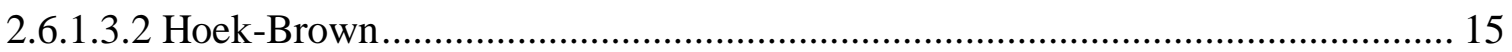

2.6.1.3.3 Comparison of Failure Criterion ................................................................. 16

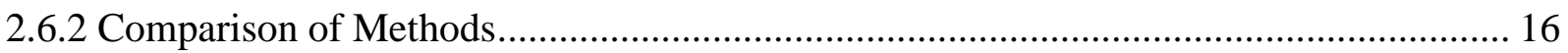




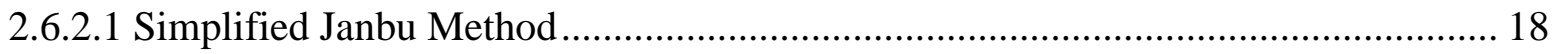

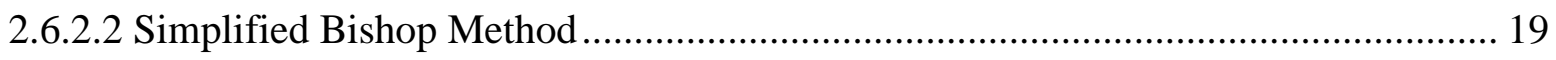

2.6.2.3 General Limit Equilibrium................................................................................. 20

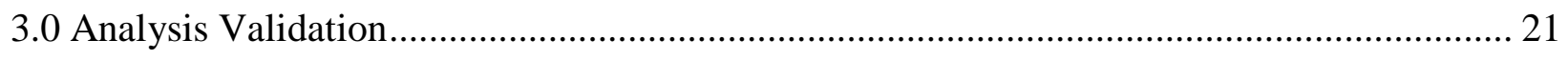

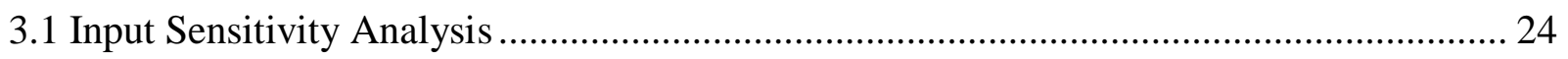

3.1.1 Salient Findings of Sensitivity Analysis ................................................................ 28

3.2 New Slope Construction Design Charts and Analysis................................................... 32

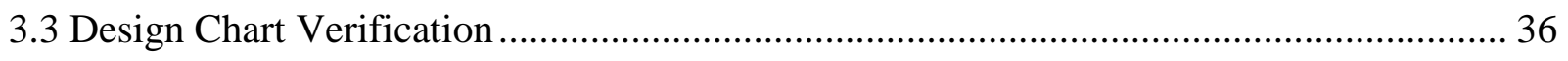

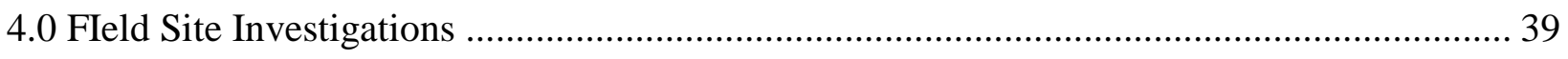

4.1 Site 1: Route 121 - Coalfields Expressway: Sophia, West Virginia .................................... 39

4.1.1 Site 1: Coalfield's Expressway: WVDOH Plan Geometry......................................... 44

4.1.2 Site 1: Coalfield's Expressway: WVDOH design Slope Stability Analysis and Results 46

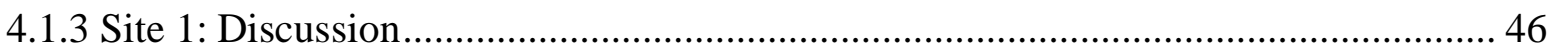

4.1.4 Site 1: Coalfield's Expressway: As-Built Geometry ............................................... 50

4.1.5 Site 1: Coalfield's Expressway: As-Built Slope Stability Analysis............................. 52

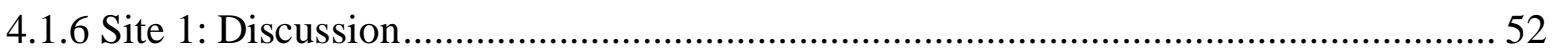

4.1.7 Site 1: Summary and Comparison: Coalfields Expressway ……………………...... 33

4.2 Site 1: Coalfields Expressway: Bench Reduction Slope Design ...................................... 34

4.2.1 Site 1: Coalfield's Expressway Field Measurements: Initial Slope Assessment......... 38

4.2.2 Site 1: Coalfield's Expressway Field Measurements: New Slope Design Trial 1....... 40

4.2.3 Site 1: Coalfield's Expressway Field Measurements: New Slope Design Trial 2....... 42

4.2.4 Site 1: Coalfield's Expressway Field Measurements: New Slope Design Trial 3 ....... 44

4.2.5 Site 1: Coalfield's Expressway Field Measurements: New Slope Design Trial 4....... 46

4.2.6 Site 1: Summary and Comparison: Coalfields Expressway: Bench Reduction............ 48

4.3 Site 2: Route 48 - Corridor H: Grant and Hardy County, WV ………........................... 51

4.3.1 Site 2: Corridor H: WVDOH Design - As-Built Measurement Geometry .................. 56

4.3.2 Site 2: Corridor H: WVDOH Design - As-Built Slope Stability Analysis ................. 57

4.3.3 Site 2: Corridor H: WVDOH Design - As-Built Slope Stability Analysis ................. 59

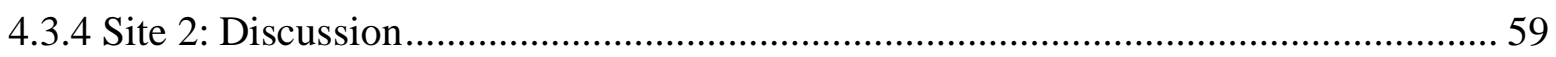

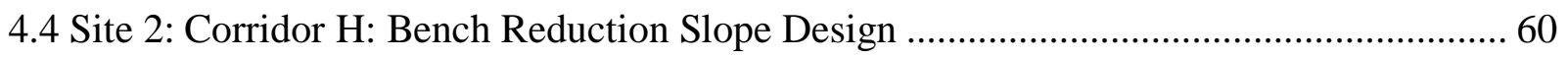

4.4.1 Site 2: Corridor H: WVDOH Design - As-Built: Initial Slope Assessment ............... 61

4.4.2 Site 2: Corridor H: WVDOH Design - As-Built: New Slope Design Trial 1 ............. 64

4.4.3 Site 2: Corridor H: WVDOH Design - As-Built: New Slope Design Trial 2 ............. 66

4.4.4 Site 2: Corridor H: WVDOH Design - As-Built: New Slope Design Trial 3 .............. 68 
4.4.5 Site 2: Corridor H: WVDOH Design - As-Built: New Slope Design Trial 4 ............ 70

4.4.6 Site 2: Summary and Comparison: Corridor H: Bench Reduction............................ 72

4.4.7 Site 2: Corridor H: Layer Sensitivity .............................................................. 74

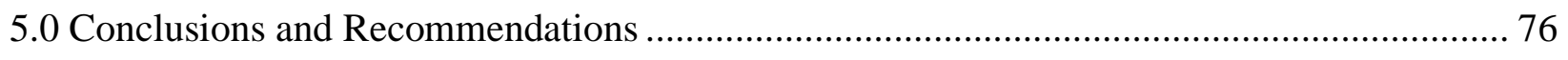

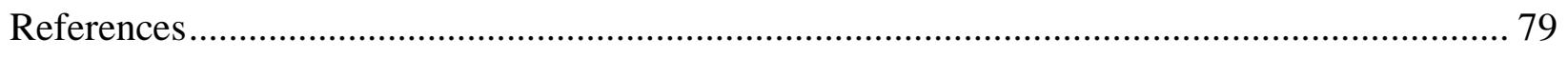

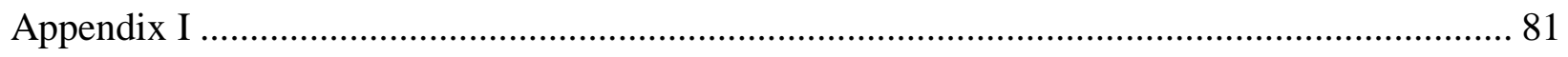

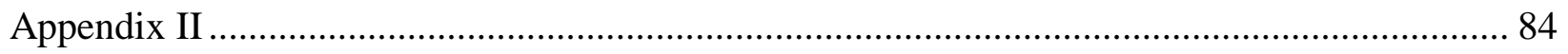




\section{LIST OF TABLES}

Table 2.3.1: WVDOH cut slope bench design (WVDOH, 2006) ........................................... 8

Table 2.4.1.1: Slake durability index and associated slope angles for Ohio (OHDOT 2011) .... 10 Table 2.4.2.1: Rock quality designation and associated slope design recommendations (OHDOT 2011)

Table 3.1: Mohr-Coulomb input parameters provided from the Coalfields Expressway geotechnical report. 21

Table 3.2: Validation model stability results .............................................................. 23

Table 3.1.1: Idealized Critical Number of Bench Analysis ............................................... 24

Table 3.1.2: Inputs for the sensitivity analysis.................................................................. 27

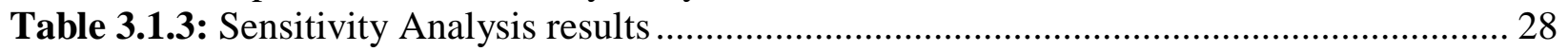

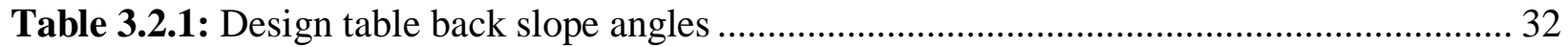

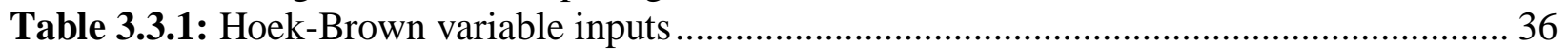

Table 3.3.2: Factor of Safety Response vs. Back Slope Angle ............................................... 36

Table 4.1.1: Models to be analyzed on the Coalfield's Expressway site................................ 42

Table 4.1.2: Approximate Master Borehole Log ................................................................ 43

Table 4.1.1.1: Mohr-Coulomb material input parameters (Lin, 2006) .................................. 45

Table 4.1.1.2: Hoek-Brown material input parameters (SjÖberg, 1997) (Zhao, 2010)............. 45

Table 4.1.2.1: Calculated factor of safety with Mohr-Coulomb failure criterion ...................... 46

Table 4.1.2.2: Calculated factor of safety with Hoek -Brown failure criterion ......................... 46

Table 4.1.5.1: Calculated factor of safety with Mohr-Coulomb failure criterion ....................... 52

Table 4.1.5.2: Calculated factor of safety with Hoek -Brown failure criterion ........................ 52

Table 4.1.7.1: Summary table of stability results given the Hoek-Brown failure criterion......... 33

Table 4.1.7.2: Summary table of stability results given the Mohr-Coulomb failure criterion..... 33

Table 4.2.1: Bench Alteration Criteria based upon research findings and observations ............ 35

Table 4.2.1.1: Hoek-Brown Input Parameters (SjÖberg, 1997) (Zhao, 2010) .......................... 38

Table 4.2.1.2: Coalfield's Expressway Field Measurements: Initial Slope Assessment stability analysis...

Table 4.2.2.1: Coalfield's Expressway Field Measurements: New Slope Design 1 .................. 40

Table 4.2.3.1: Coalfield's Expressway Field Measurements: New Slope Design Trial 2 .......... 42

Table 4.2.4.1: Coalfield's Expressway Field Measurements: New Slope Design Trial 3 .......... 44

Table 4.2.5.1: Coalfield's Expressway Field Measurements: New Slope Design Trial 4 .......... 46

Table 4.2.6.1: Summary table of factor of safety influence with new slope design .................. 48

Table 4.2.6.2: Bench Reduction Summary Table ............................................................... 50

Table 4.3.1: Models conducted in the Corridor H cut slope evaluation .................................. 56

Table 4.3.2.1: Master Borehole Log for Corridor $\mathrm{H}$ from the crest to toe of slope.................... 58

Table 4.3.2.2: Hoek-Brown material inputs (SjÖberg, 1997) (Zhao, 2010) ............................. 58

Table 4.3.3.1: Factor of Safety - Hoek-Brown Failure Criterion for Corridor H..................... 59

Table 4.4.1.1: Corridor H: Hoek-Brown Input Parameters (SjÖberg, 1997) (Zhao, 2010)......... 62

Table 4.4.1.2: Corridor H: WVDOH Design - As-Built: Initial Slope Assessment................. 62

Table 4.4.2.1: Corridor H: WVDOH Design - As-Built: New Slope Design Trial 1 ............... 64

Table 4.4.3.1: Corridor H: WVDOH Design - As-Built: New Slope Design Trial 2 ............... 66

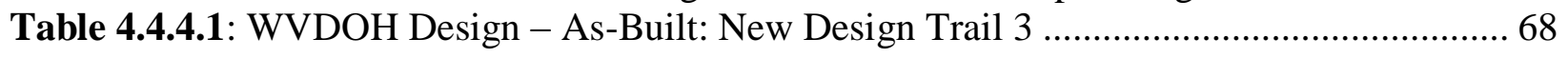

Table 4.4.5.1: Corridor H: WVDOH Design - As-Built: New Design Trail 4......................... 70

Table 4.4.6.1: Summary table of factor of safety influence with new slope design .................. 72 
Table 4.4.6.2: Bench Reduction Summary Table ...

Table 4.4.7.1: Corridor $H$ validation material values ........................................................... 74 


\section{LIST OF FIGURES}

Figure 1.1: Slope profile illustration....................................................................... 1

Figure 2.2.1: Definitions of "B" and "L" in a typical Bench Blasting design (FHWA, 1991) .... 5

Figure 2.6.2.1: Forces Acting for a Method of Slices (Non-Circular Failure) (Fredlund, 1981) 17

Figure 3.1: Coalfields W Helen to Allen Creek Station 5659+50 w/Fill Bench ...................... 22

Figure 3.1.1.1: Factor of Safety vs. Unconfined Compressive Strength ................................. 29

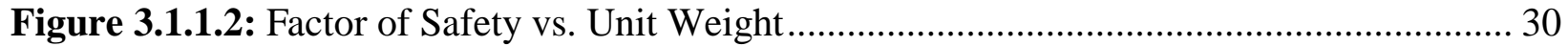

Figure 3.1.1.3: Factor of Safety vs. Disturbance Factor ................................................... 30

Figure 3.1.1.4: Factor of Safety vs. Geological Strength Index ........................................... 31

Figure 3.1.1.5: Factor of Safety vs. Rock Mass Constant ............................................... 31

Figure 3.2.1: New Slope Design Flow Chart................................................................. 33

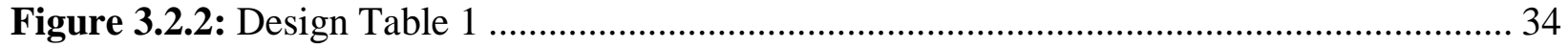

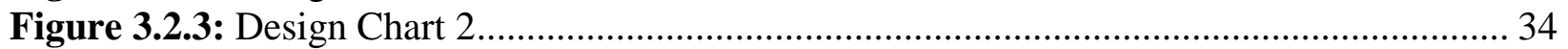

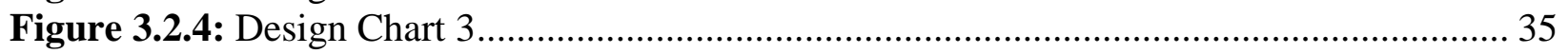

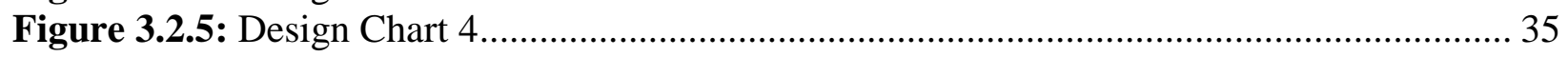

Figure 3.3.1: Factor of Safety vs. Back Slope Angle graphical response ................................ 37

Figure 3.1.2: Slice information from models $50^{\circ}, 60^{\circ}, 70^{\circ}$................................................ 38

Figure 4.1.1: Slope evaluated on U.S. Route 121 ........................................................... 40

Figure 4.1.2: Accumulation of fallen rock debris ........................................................... 41

Figure 4.1.1.1: Coalfield's Expressway: WVDOH Plan Geometry ........................................ 44

Figure 4.1.3.1: Mohr-Coulomb failure criterion for the WVDOH design model...................... 47

Figure 4.1.3.2: Hoek-Brown failure criterion for the WVDOH design model......................... 48

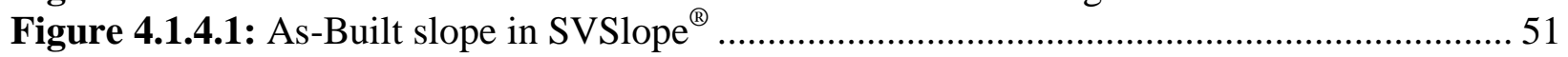

Figure 4.1.6.1: Mohr-Coulomb failure criterion for the As-Built Profile................................. 53

Figure 4.1.6.2: Hoek-Brown failure criterion for the As-Built Profile .................................... 54

Figure 4.2.1: Flow chart for bench reduction procedure .................................................. 36

Figure 4.2.2: Coalfield's Expressway As-Built screen shot with the proposed area for new slope

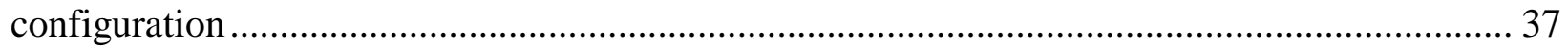

Figure 4.2.1.1: Initial Slope Assessment ........................................................................ 39

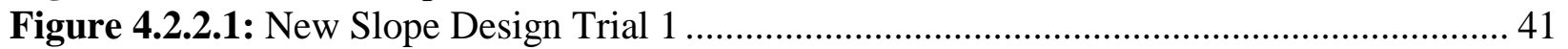

Figure 4.2.3.1: New Slope Design Trail 2 ...................................................................... 43

Figure 4.2.4.1: New Slope Design Trial 3 ................................................................... 45

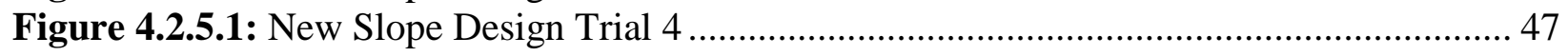

Figure 4.2.6.1: Coalfield's Expressway Design Trials .................................................... 50

Figure 4.3.1: Slope 1 evaluated during the field visitation .................................................5 52

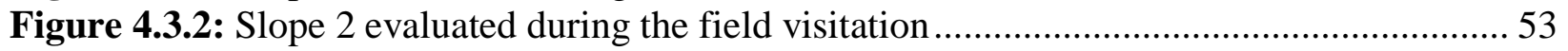

Figure 4.3.3: Fallen debris on Corridor $\mathrm{H}$......................................................................... 54

Figure 4.3.4: Clay seem leading to rock fall................................................................... 55

Figure 4.3.2.1: Slope constructed via WVDOH design.................................................. 57

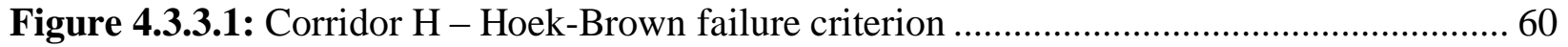

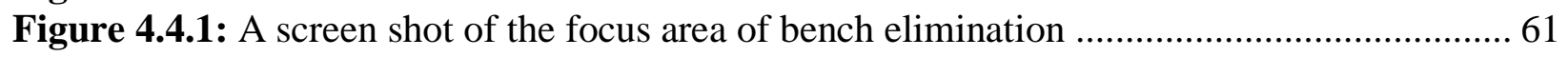

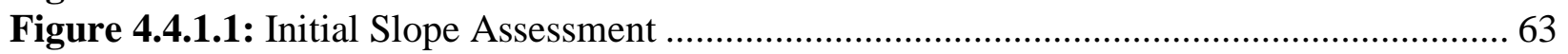

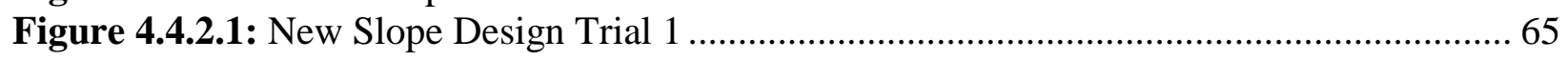

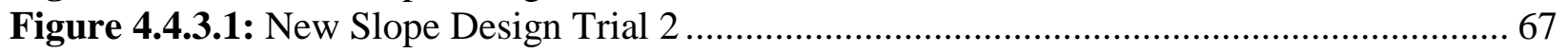

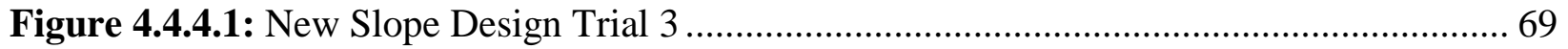


Figure 4.4.5.1: New Slope Construction Trial 4......................................................... 71

Figure 4.4.6.1: Corridor H Design Trials......................................................................... 73

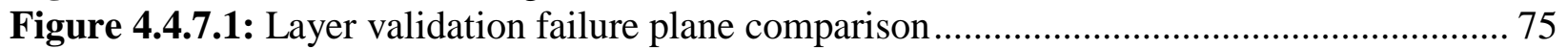

Figure A1-1: Geologic Map of West Virginia ............................................................. 81

Figure A1-2: Filling of bench on Coalfield's Expressway majority of debris was siltstone....... 82

Figure A1-3: Photograph from Final As-Built Plan Corridor-H ....................................... 83 


\subsection{INTRODUCTION \& BACKGROUND}

Population growth and sprawl throughout the United States has initiated the necessity for new highway and road construction. Roadway construction often requires removal or addition of earthen material, such as large volumes of sedimentary rock. The removal and excavation of overburden material demands the use of explosives to blast rock. The fracturing caused by blasting allows for fissure propagation into the newly exposed material which has led to rock fall and slope instability issues. With some cut slopes extending to $300 \mathrm{ft}$. or more, cut slope design in regards to stability and rock fall attenuation are a primary concern.

West Virginia has an extensive history and range in geologic formations. The strata primarily found within the state are of sedimentary classification. Among the concern involved with sedimentary rock is that strength parameters can vary widely, which can lead to economic and user vulnerabilities. Along with high variability in strengths, these strata are often times highly erodible. High erosion rates can lead to instability issues such as undercutting and create toppling rock falls different than rotational failure planes produced in soil. Figure 1.1 illustrates the layout of the section of a slope profile to allow the reader to better understand the terms used throughout this literature.

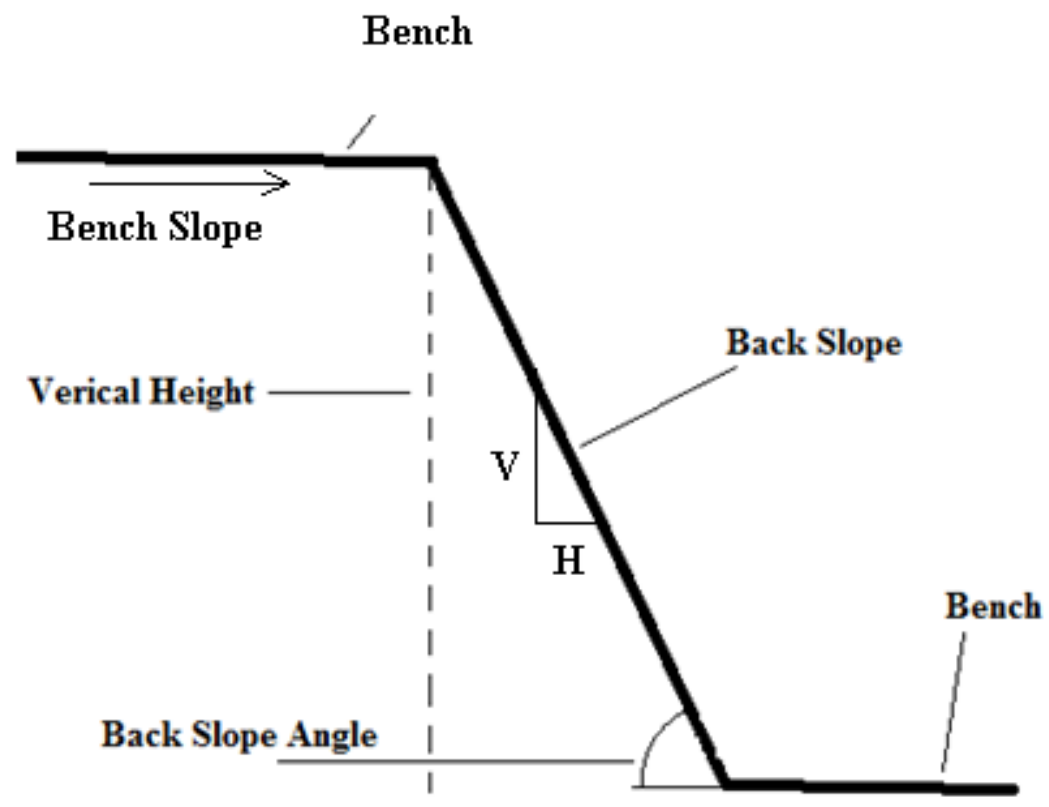

Figure 1.1: Slope profile illustration

Current rock cut slope regulations and practices are governed with the West Virginia Department of Highways Design Directives: Section 403. This section addresses issues and design restraints such as strata, benching, maximum and minimum geometry requirements and a minimum factor of safety requirement for all highway cut slopes. It is the intent of this research to optimize the 
design process through field exploration and computer aided modeling. Optimization of the design process will minimize the number of benches; decrease the possibility of the launching of falling debris in addition to lowering excavation volumes and construction costs.

\subsection{Research Purpose, Objectives, and Work Scope}

The objective of this research was to identify and investigate the feasibility of implementing rock cut slope design alternatives in West Virginia (WV). Cut slope design alternatives were assessed for feasibility in WV and were carried out by computer aided modeling for slope stability and rock fall mitigation. Slope stability modeling includes physical material properties as input parameters to uniquely define failure criterion and specify an analysis method. Slope geometry proved to be of utmost importance in creating slope alternatives. West Virginia currently has a design manual for rock cut slope excavation. One goal of this research was to establish a range of input parameters to implement a greater design standard through the use of the modeling. This aspect was addressed by the removal or addition of geotechnical bench structures throughout the slope allowing for larger planar sections. Slope alternatives also have the potential to decrease long term maintenance cost by reducing the rate of slope degradation.

The intent of the modeling was to establish a factor of safety for current cut slopes and assess the change due to geometric alterations while keeping material inputs constant. The objectives and work scope for this research was to:

- Identify problematic design flaws

- Optimize slope design to ensure stability

- Draw conclusions based on the implementation of design recommendations into the computer modeling of new design alternatives

- Develop design charts based upon findings

- Develop a written tutorial on the use of the developed design guides and flow charts listed in the Appendix

\subsection{Research Approach}

The approach for this study involved the investigation of rock properties pertaining to slope design throughout the state of West Virginia. Individual site specific tested parameters would provide a more accurate representation of the data set and allow for a high level of confidence in the slope design. This data was not readily available so the strengths of the rock were gathered through literature on similar rock types which exist in WV. These researched physical properties were applied to all the modeled cases throughout this study. During the course of this research it was necessary to consider maximum and minimum strength parameters to illustrate the importance of material testing so that more specific data can be gathered to provide an increased 
assurance in slope design. The approach of the research is shown below; these steps were taken at each geographic region that was evaluated.

- Visit cut slopes to obtain geometric dimensions and note signs of erosion and slope degradation.

- Acquire geotechnical reports and WVDOH designs to retrieve pertinent information.

- Interpret the borehole logs to establish a master material classification chart. It was sometimes necessary to combine two similar borehole logs and closely related borehole logs to acquire the entire depth of excavated material.

- Input the required geometric, material parameters, and failure mode criterion into SVSlope ${ }^{\circledR}$ to model the behavior and differences between WVDOH designs and the field measured slope.

- Begin an iterative process of bench reduction in the attempt to increase the factor of safety. This was also coupled with a rock fall simulation program to ensure driver safety.

- Conclude on redesign findings and report in a final design guide outline

- Develop example analysis and design information for bench cut removal in rock slope

\subsection{LITERATURE REVIEW}

Cut slope design is independently governed by self-regulating state departments. Difference in cut slope design procedures between states allowed for various comparisons and conclusions to be drawn regarding design practices. The common goal of this research was to optimize rock cut slope design. The attempts at rock fall mitigation were controlled by slope geometry, ditch design, and catchment devices. The focus of this study dealt with the geometric design of cut slopes, primarily the vertical height between benches, bench width, and variation in back slope angle. Along with the design parameters the assessment of the design was of concern. Various finite element slope stability analyses are available. In addition, methods of slope construction were researched in regards to blasting and erosive occurrences to ensure the most accurate analysis method was conducted.

\subsection{Introduction}

The intent of an optimized rock slope design is to minimize the need for maintenance while maximizing the structural integrity. Cut slopes have the potential to fail in a variety of ways with many contributing factors to each independent rock fall event. Root causes of slope failure can be found by observing in-field evidence of contributing factors. Root causes can also be concluded by deductive reasoning based on known facts about the event. Assessing failure events by a root cause analysis approach has significant importance for accurately creating fault trees. Fault trees are a set of propagating data points that illustrate the failure path through a series of events. Understanding the implications of root causes of slope failure can also carry 
significance to create more durable and erosion resistant future slope designs. Some known root causes of slope failure are described in this chapter.

The ability to predetermine a failure and the series of events associated with failure is known as Potential Failure Mode Analysis. This process is extremely important because one is able to understand the structure's weaknesses as well as causes and event outcomes. Events that are common causes to slope failure may include: seismic action, weathering events, and severe weathering. It is vital to establish a list of causal events so that all possibilities are assessed and the initiators that lead to failures are identified and removed or minimized.

\subsection{Blasting Effects on Slope Instability}

Issues with instability of rock cut slopes initiate from multiple areas, however careful consideration must be taken into the initial blasting of the overburden material. Over blasting is a common occurrence which directly leads to instability issues throughout the life of the structure. The term "back break" is used to define the excessive fracturing of rock stratum extending from the final boreholes into the final slope face. Back break is known to cause instability in the final rock face contour. If the rock strata discontinuities are oriented between $30^{\circ}$ to $80^{\circ}$, they are fairly resistant to back break from blasting. When the orientation of the discontinuities are between $20^{\circ}$ to $25^{\circ}$ leaving the slope face vulnerable to back break due to stress component vectors of the blasting having substantial magnitude upon the discontinuities. When the orientation of the discontinuities are less than $15^{\circ}$ to the slope face, blasting stress vectors travelling into the discontinuities allow for a clean, natural looking final face (FHWA, 2011).

In general, there are many factors that cause back break of massive rock slopes. One factor

causing back break occurs when excessive rock burden on the drill holes causes the explosion to direct its energy in an altered direction (FHWA, 1991). The redirected energy causes radial fractures and cracks. This scenario typically occurs on benches that are excessively stiff for blasting, or the bench height is less than twice the size of the burden width ( L/B < 2) (see Fig. 2.2.1). The notation of " $L$ " represents the length of the charge, while " $B$ " illustrates the horizontal distance of the burden material. Attempting to blast excessively stiff benches causes a large amount of uplift and back break near the collar of the hole. Additionally, the use of large stemming depths on stiff benches will typically lead to back break. Another factor causing back break is improper delay timing from row to row of blast holes. When the timing from row to row is too short, excessive confinement will occur for the last row of blast holes in the production blast. If the blast holes are too short in depth creating low $\mathrm{L} / \mathrm{B}$ ratios due to excessive burden, then the blast holes size should be decreased to reduce the burden and increase the stiffness ratio. This technique cannot be always used and other techniques must be used in order to give desirable shear at borehole collars (FHWA, 1991). 


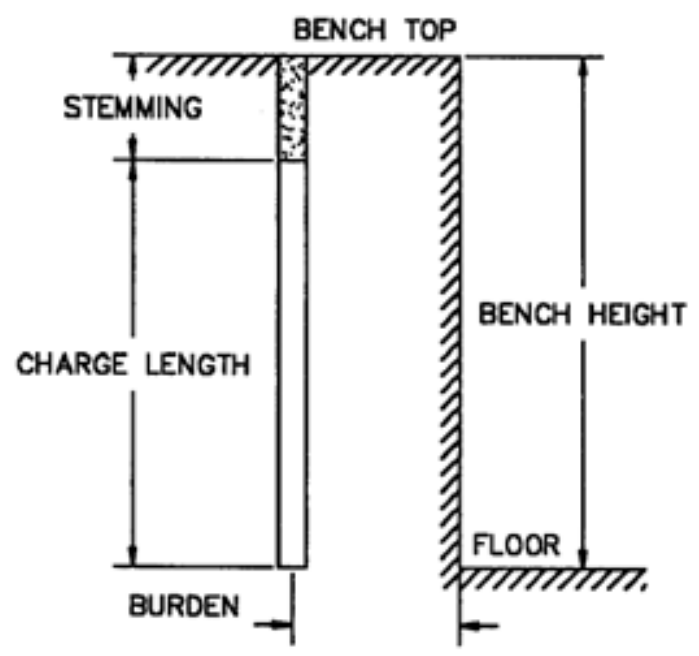

Figure 2.2.1: Definitions of " $B$ " and " $L$ " in a typical Bench Blasting design (FHWA, 1991)

The exact blasting design plan used on a specific rock cut-slope involves several parameters such as: borehole timing, quantity and type of explosives, and borehole size and spacing that are best left to the expertise of a blasting specialist. Other parameters such as those listed in the following sections are to be considered in the design of a rock cut-slope.

Each of these parameters individually do not directly affect the short and long term performance of a highway rock cut slope, but together as a collective design practice can attribute to increased short and long term performance of a rock cut slope.

The following sections provide an ordered design philosophy of the previously listed blasting design parameters with respect to a cut slope design.

\subsubsection{Subsurface Exploration and Material Testing}

Borehole site investigation must be comprehensive to provide information on all of the strata layers that will be exposed as the final face material. This information should include:

i. Determination of modulus of elasticity

ii. Determination of Poissons ratio

iii. Slake Durability Index ranges

iv. Respective layer thicknesses

v. Any attainable information regarding the lithography of the strata such as its strike, dip, and discontinuities.

vi. Unconfined Compressive Strength

vii. Presence of infilling of clay or any other material. 
In the determination of the modulus of elasticity and Poissons ratio the rock strata under investigation are typically considered homogeneous and isotropic; this is an idealized assumption that typically does not exist in field rock slopes. The slake durability index determined for each layer should be considered for the placement of benches, over break control methods used for that stratum and for the erosion control measures needed to reduce the rate of erosion of low slake durability indices. Layer thickness of both strong and weak layers should be considered for slope stability along with specific blasting techniques needed in order to minimize over break of the final face.

Lithology plays one of the largest roles in blasting design of cut slope. In many circumstances the strike, dip, and discontinuities control the design of the blasting. In other cases where the strata is approaching or lies in a horizontal bedding arrangement, the overall blasting design and slope geometry is at greater discretion of the designer. Infilling between larger layers must be thoroughly investigated and considered in a blasting design. The infilling material is much weaker in shear than the capping strata and slip planes from both during blasting itself and more importantly, will exist in the final constructed slope. Therefore, these areas require consideration in a slope's geometry and rock fall attenuation devices.

\subsubsection{Geometric Slope Design}

The following principals should be used for all geometric considerations such as the placement of benches, back slope angle, and back slope height of the proposed rock cut slope in order to ensure that conventional beam bending fracture failure mode occurs.

\section{i. Appropriate stiffness ratio}

ii. Capping of a strong layer by a weak layer or a strong layer material bound by a layer of weak material above and below

iii. Minimization of back break and end break

The stiffness ratio of a proposed burden layer should be calculated in order to ensure that the layer has a low enough stiffness ratio that excessive back break does not occur. Additionally with consultation of the blasting specialist, satellite holes may be necessary to reduce back break even when stiffness ratios are within acceptable limits. Oftentimes, stronger strata will be capping a weaker material such as shale. In this case the displacement of the weaker strata will be less. Therefore the blasting design should be adjusted as to ensure the desired fracture mode occurs. Additionally if a strong layer is bound by a weaker material the displacement of the stronger layer is lower than if the material was bound by material of similar strength. Again the blasting design should reflect this situation in order to ensure that the desired failure mode occurs and over blasting is minimized. 


\subsubsection{Blasting Practices}

Over break control measures help to increase the propensity of long term slope stability and erosion control such as the amount of sloughing, undercutting, and block/wedge failure rock fall. The inherent variability or lack thereof of strata type should be considered in order to minimize final face erosion. Using the borehole information and a blasting specialist's expertise one of the following over break control measures should be considered.

i. Presplitting the final rock faces

ii. Trim blasting the final faces

iii. Smooth blasting the final face

In cases where over break and excessive rock fall is expected after final face blasting has occurred presplitting of the final face can be performed in order to reduce these effects. Moderate to strong strata without excessive fracturing should be considered as candidate material for presplitting blasting techniques. Trim blasting offers an effective means preventing over break and excessive rock fall in material that exhibits low strength lithology along with those with medium to highly fractured strata. Smooth blasting can be used on a wide spectrum of rock strata and geometric configurations as an alternative to presplitting and trim blasting. Smooth blasting is most effective in competent rock and in slopes with benches where the blasting height or back slope height is relatively small.

Erosion is a leading factor in geometric alterations from original design. Erosive forces can stem from a multitude of events; however, hydrological effects are the leading contributor to earthen material deterioration and sediment transport. Hydrological effects such as water runoff, raindrop impact, and freeze-thaw conditions cause breakdown of friable materials which tend to be intermittent throughout rock strata. The geology of West Virginia is primarily sandstone and limestone with interlayered areas of shale, coal, clay and silt materials. These materials are highly erosive on cut slopes where they are exposed to weathering. Clay and silt materials are more prone to erode due to sheet erosion and raindrop impact. Rock materials such as shale and coal are more susceptible to an erosion type known as slaking. Slaking, quantified as the Slake Durability Index (SDI), reflects the ability for material to resist deterioration when subjected to water. With these highly erodible materials throughout the state of West Virginia, strata configuration is a major subject to consider while selecting a slope profile design. A geologic map of the state is illustrated in Appendix I: Figure A1-1.

\subsection{Cut Slope Practices and Design Requirements}

This section provided the evaluation of current cut slope practices from Ohio because of comparable geological features to West Virginia to identify similarities and differences. 


\subsubsection{West Virginia}

According to West Virginia Department of Highways Design Directive-403 (DD-403): Guide for Design in Cut Sections through Bedrock (WVDOH, 2006), slopes cut at ratio noted as Horizontal distance: Vertical Height (H:V) 2H:1V or flatter will normally not require benches. If benches are constructed, the main purpose is to catch boulders that would otherwise roll down the slope. A slope constructed at $1.5 \mathrm{H}: 1 \mathrm{~V}$ is recommended to be constructed with a bench near roadway grade termed a "sighting bench", and would serve as a catchment device if erosion is suspected from the slope material. If little to no material is expected to erode from the slope, this bench may be omitted. Intermediate structural benches are recommended for providing catchment for possible rock fall producing strata layers.

The DD-403 recommends that slopes greater than 1H:1V should have a bench 5 feet above the roadway ditch grade and at intermediate intervals along the cut face. The only exception is when a cut slope contains hard to medium-hard rock. Regardless of material present in the proposed cut slope, the Engineering Division may elect to place benches at their discretion.

Benches should be cut parallel to the roadway, or may be cut parallel to the lithological orientation of the strata layer. Benches should be angled away from the face at a rate of $15 \mathrm{H}: 1 \mathrm{~V}$. The WVDOH states that benches are needed to provide impact areas to reduce rock rolling, to retain sloughing material on the slope, and sloped to mitigate water ponding on benches. On arterial routes (highways), the first bench and intermediate benches should be constructed to a minimum width of 15 feet. On local service routes (speed limit of $40 \mathrm{mph}$ or less), the minimum width should be 10 feet. All overburden benches should be constructed to a 10 foot minimum width. All back slope heights are held to a 50 foot maximum unless extenuating circumstances are present, making this depth extend to an absolute maximum of 70 feet. All back slopes greater than 50 feet should only be constructed in competent material with a back slope ratio 1.5h:1V or flatter (WVDOH, 2006). In general, the WVDOH uses Table 2.3.1 for the calculation of bench width to the back slope ratios of the corresponding rock types in cut rock slope design:

Table 2.3.1: WVDOH cut slope bench design (WVDOH, 2006)

\begin{tabular}{|c|c|c|}
\hline Rock Type & Bench Width & Back slope Vertical Height \\
\hline 1 & 1 & 2.5 \\
\hline 2 & 1 & 2.5 \\
\hline 3 & 1 & 2.5 \\
\hline 4 & 1 & 2 \\
\hline
\end{tabular}

The third section of DD-403 is titled "Design of Cuts in Bedrock." This section breaks down rock cut slope design into four distinct bedrock types other than those listed above. The four types are listed in Table 2.3.1 are discussed below in detail along with WVDOH recommendations. 


\section{Type 1}

Medium-Hard to Hard Limestone, Sandstone and Hard Shale: Type 1 bedrock has a compressive strength minimum of 8000 psi. This type of bedrock exists in massive formations with varying degrees of dip. Softer material such as coal or shale may be present in Type 1 bedrock in smaller seams. For Type 1 bedrock with shale, a slake durability index of at least 95 percent is required for the shale layer. (WVDOH, 2006)

\section{Type 2}

Soft Limestone or Sandstone, Medium-Hard Shale, Siltstone and Interbedded Combinations of any of these listed types: Type 2 bedrock has a Compressive Strength ranging from 4000-8000 psi, and covers the vast majority of all strata present in West Virginia. Many areas of the state have soft shale and coal seams present in this classification. Slake durability should be between 51 to 94 percent (WVDOH, 2006).

\section{Type 3}

Soft Shale Interbedded with Siltstone, Sandstone, or Limestone: Type 3 bedrock has a Compressive Strength ranging from 1000-4000 psi. These Soft Shale bedding planes are typically not very thick, and the interbedded, harder bedrock varies in thickness. Type 3 only varies from Type 4 bedrock due to the bedding of stronger, more competent materials interbedded with the shale (WVDOH, 2006).

\section{Type 4}

Soft and Very Soft Shale: The compressive strength of Type 4 bedrock is approximately 1000 psi. Weak shale may be considered indurated clays when fissility is lacking. When exposed to water, these materials completely degrade into tiny particles. Slake Durability values for these materials range between 0 and 50 percent (WVDOH, 2006). 


\subsection{Ohio}

This section contains pertinent information for comparison and correlation to West Virginia through the current rock cut practices in the state of Ohio.

\subsubsection{Slake Durability Index (SDI)}

The durability of a rock is measured by its resistance against erosion, degradation, and weathering as well as climatic changes. To test for rock durability, the proper procedure should be taken and followed in ASTM D 4644 Slake Durability Test. The durability of rocks or a difference in durability of rock layers in slopes that promotes undercutting within slopes are the main failure mechanisms causing block and rock fall in Ohio (OHDOT, 2011). Table 2.4.1.1 presents slake durability index ranges and their associated suggested slope angles for OHDOT.

Table 2.4.1.1: Slake durability index and associated slope angles for Ohio (OHDOT 2011)

\begin{tabular}{|c|l|}
\hline SDI $\left(\mathbf{I d}_{\mathbf{2}}\right) \mathbf{( \% )}$ & \multicolumn{1}{c|}{ Slope Angle } \\
\hline$<20$ & $2 \mathrm{H}: 1 \mathrm{~V}$ or flatter - Special design; contact District Geotechnical Engineer \\
\hline $20-60$ & $2 \mathrm{H}: 1 \mathrm{~V}$ \\
\hline $61-85$ & $1.5 \mathrm{H}: 1 \mathrm{~V}$ \\
\hline $86-95$ & $1 \mathrm{H}: 1 \mathrm{~V}$ \\
\hline $96-100$ & $1 \mathrm{H}: 1 \mathrm{~V}$ or steeper - contact DGE \\
\hline
\end{tabular}

\subsubsection{Rock Quality Designation (RQD)}

Section 207.4 of the Design Guide discusses rock quality designation, or RQD. The RQD is a measurement of a specimen quality related to the susceptibility to fracture. A value is determined from a summation of fragments equal to four inches with a boring divided by the total length of the core cut. The RQD can also be extrapolated with the use of a directional outcrops if available. Table 2.4.2.1 presents rock quality designation ranges and their associated slope design recommendations for OHDOT.

Table 2.4.2.1: Rock quality designation and associated slope design recommendations (OHDOT 2011)

\begin{tabular}{|c|l|}
\hline RQD (\%) & \multicolumn{1}{c|}{ Recommendations } \\
\hline $0-50$ & Cut slope to 1H:1 V or consult with District Geotechnical Engineer \\
\hline $51-75$ & $\begin{array}{l}\text { Review global stability and design based on engineering judgment or consult } \\
\text { with DGE }\end{array}$ \\
\hline $76-100$ & Slope grade of 0.5H:1V, or 0.25H:1V for thickly bedded sandstones \\
\hline
\end{tabular}




\subsubsection{Benches}

Section 400 of the Design Guide discusses benches. The objective of a bench is to provide protection to a slope that is highly susceptible to erosion and undercutting of a weak rock layer. There are multiple ways to minimize erosion: re-routing surface water from the crest, mid-slope and not allowing the water to erode the weak material. Benches can also serve as a design component that allows for a steeper slope angle in weak material as compared with a planar slope. Benches constructed with the specific intent of catchment should be avoided (OHDOT, 2011). Mid-slope benches can result in launching features for falling rock due to the inability for the bench to attenuate the falling mass.

\subsection{Cut Slope Design and Assessment}

Cut slopes are common in highway designs throughout the United States. Many slope design alternatives are currently used with varying dimensions. It is important for a slope design to be durable in the geology present for each slope to ensure public safety, and minimize the necessity for maintenance funding. This section discusses techniques that are commonly used to assess slope designs to ensure slope design durability and slope stability.

\subsubsection{Analytical Techniques}

This section discusses the criterion and analyses addressed throughout this research for geometric consideration, stability performance modeling, and rock fall simulation.

\subsubsection{Slope Dimension}

Slope dimensions are based upon multiple parameters including and but limited to; stratigraphy, competence of material, slope height and length. A driving factor of slope stability is the competence of material. The slopes can either be planar or benched. Determination of benching a slope in lieu of a planar design is a decision based upon the District Geotechnical Engineer's discretion, with respect to OHDOT practices. A contributing factor that will assist Engineers to improve the stability of a highway cut slope design is the available right-of-way. Right-of-way can be extremely high cost acquisition depending upon the location of the cut slope. Planar slopes can require more right-of-way than a benched slope; however, the initial investment may offset maintenance costs throughout the life cycle. The competence of the material will control the ability to design a slope as a planar slope within a given right-of-way area. At times, the action that must be taken upon material strength and right-of-way evaluation is the implementation of benches throughout the slope. Benches are horizontal or very low graded areas that are found throughout the slope. These structures provide an area that will slow down water runoff velocities while helping control erosion rates. Erosion is a problematic issue that can lead to catastrophic slope failures. 


\subsubsection{Factor of Safety General Limit Equilibrium Approach}

One design method commonly employed to ensure slope stability is the Factor of Safety Equilibrium Approach. This approach is based upon designing a slope profile using the unit weight of the materials, material properties, slope geometry, and hydrological conditions. Factor of safety is defined as the ratio of average strength of a member or property divided by the developed stress of a member or property along a potential failure surface (Das, 2006). A factor of safety of 1.0 illustrates the structure is on the verge of failure. Any factor of safety less than 1.0 signifies that a failure has already occurred.

\subsubsection{Colorado Rock Fall Simulation Program}

One of the more popular simulation programs available is the Colorado Rock fall Simulation Program (CRSP). Developed by Colorado DOT with the assistance FHWA, CRSP has recently been updated from a 2D modeling software to 3D software using the Discrete Elements Method. CRSP-3D is able to model impact, rolling, launching, and sliding on various paths with various shaped rock fall. The output of CRSP-3D shows all possible rock trajectories and energies for a given slope, thus allowing the user to easily determine fallout/catchment area dimensions (FHWA, 2012). State transportation agencies that currently use CRSP include Colorado, Oregon, Ohio, and California. CRSP modeling can be used concurrently with stability modeling to ensure safe designs were met with respect to stability and rock fall attenuation.

\subsection{Analysis Method and Approach}

Numerical modeling was the primary tool used in this research. The modeling allowed for a conceptual slope to be constructed within the program; which alterations were made possible to geometry, composition, and analytical procedures throughout the evaluation process. Computer software programs have become an extremely powerful tool that allows for immense amount of iterative analyses while providing realistic results.

\subsubsection{Numerical Modeling}

Finite element base software can perform multiple analytical procedures within a program suite. The use of a finite element software makes computational procedures not feasible by hand calculations or capable from an economic stand point, easily accessible to a user. For this research, the modeling suite used was SoilVision Systems ${ }^{\mathrm{TM}}$. There were two modules within the program that aided in the numerical modeling; SVSlope ${ }^{\circledR}$ and SVSolid ${ }^{\mathrm{TM}}$, used respectively for slope stability and stress deformation analyses. SVSlope ${ }^{\circledR}$ is an analysis tool with various earthwork design functions. SVSolid ${ }^{\mathrm{TM}}$ utilizes stress deformation and stress concentrations on earthen designs from external as well as internal loading conditions. 


\subsubsection{SVSlope ${ }^{\circledR}$}

SVSlope $^{\circledR}$ is a finite element method analysis software that possesses the capability to analyze slope stability; cut or fill slopes, earthen structures, and other various earthwork designs. The results can be evaluated in multiple ways such as sensitivity analysis, stochastic, or deterministic based upon input data parameters. Material input failure criterion play an important role in the final outcome of the analysis. The two input failure criterions evaluated throughout the process were the Mohr-Coulomb and Hoek-Brown theories. Analysis methods within SVSlope ${ }^{\circledR}$ vary based upon user needs, in regards to this project the following analytical methods were used to evaluate the slope stability; Simplified Bishops, Simplified Janbu, and General Limit Equilibrium. The end result output of the software is an overall factor of safety. The factor of safety is determined by the material, geometric, and analysis method. In addition to the computed factor of safety, a visual output of the projected weakest failure plane is present. The slopes were analyzed under a non-circular slip surface condition which will for adequate representation with regards to rock fall failure..

\subsubsection{SVSolid ${ }^{\mathrm{TM}}$}

SVSolid $^{\mathrm{TM}}$ is a finite element method of analysis that has the capacity to analyze strain consolidations and stress deformations within large earthen masses. The program simulates the behavior of soil or rock which may undergo elastic or plastic deformations due to various loading conditions. Similar to SVSlope ${ }^{\circledR}$ material input data plays a direct role in the final results. This module can be coupled with other SoilVision Systems ${ }^{\mathrm{TM}}$ modules to allow for multiple analysis methods to be conducted concurrently. In the case of this project SVSolid ${ }^{\mathrm{TM}}$ was able to be coupled with SVSlope ${ }^{\circledR}$ using the Mohr-Coulomb failure criterion to assess the stability behavior once a stress state had been analyzed.

\subsubsection{Material Failure Criterion}

In the analytical process of selecting a material input failure criterion it was deemed necessary to evaluate multiple standards. The two criterion reviewed were Mohr-Coulomb and Hoek-Brown. 


\subsection{Mohr-Coulomb}

Mohr-Coulomb is the most common failure criterion encountered in geotechnical engineering (Hoek, 2005). The Mohr-Coulomb criterion is used widely in rock engineering modeling and design, which at times can inaccurately represent a material set. The basic concept of MohrCoulomb is based upon two parts, cohesion and friction with a direct relation between normal stress and shear stress. The failure envelope defined in Equation 3.1 is a linear function and is sufficient to approximate the shear stress on the failure plane (Das, 2006).

Where:

$$
\tau=c+\sigma \tan \emptyset
$$

Equation 2.1

$\tau=$ shear strength

$c=$ cohesion

$\sigma=$ normal stress on the failure plane

$\emptyset=$ angle of internal friction

The cohesion and angle of internal friction are direct material properties and vary between materials. Testing was not conducted on materials to achieve this data within the geotechnical reports provided from the West Virginia Department of Highways. Published data and technical reports were researched and evaluated; resulting pertinent data was used in the analysis method. 


\subsection{Hoek-Brown}

Hoek and Brown introduced their failure criterion to provide an analysis method for the evaluation required for the civil engineering rock removal and design of underground excavation in hard rock (Hoek, 2002). The failure criterion can also be based on small scale blasting for engineered slopes. The Hoek-Brown criterion is not widely used in slope stability issues, due to convenient use of the Mohr-Coulomb failure criterion based on shear and normal stress rather. The importance of a Hoek-Brown evaluation stems from the origin of the theory, which is intended solely for rock analysis with parameters focused on discontinuities, disturbances, and competency of the rock masses. The generalized equations on the basis Hoek-Brown failure criterion (Hoek, 2002) are Equation 3.2 - Equation 3.5.

Where:

$$
\sigma_{1}^{\prime}=\sigma_{3}^{\prime}+\sigma_{c i}\left(m_{b} \frac{\sigma_{3}^{\prime}}{\sigma_{c i}}+s\right)^{a}
$$

$\sigma_{1}^{\prime}$ and $\sigma_{3}^{\prime}=$ major and minor effective principal stresses at failure

$\sigma_{c i}=$ the uniaxial compressive strength of the intact rock material

$m_{b}=$ is a reduced value of the material constant $m_{i}$ which evaluates intact rock

$$
m_{b}=m_{i} \exp \left(\frac{G S I-100}{27-14 D}\right)
$$

Equation 2.3

$s=$ constant of the rock material based by the given relationship

$$
S=\exp \left(\frac{G S I-100}{9-3 D}\right)
$$

Equation 2.4

Note:

- $\quad D$ is a factor which depends upon the degree of disturbance to which the rock mass has been subjected by blast damage and stress relaxation. It varies from 0 for undisturbed in situ rock masses to 1 for very disturbed rock masses.

- $\quad$ factors used in this analysis ranged from 0.7 for good blasting to 1.0 for poor blasting (Hoek, 2005).

- GSI or Geological Strength Index is a constant of the rock material and will be further discussed in section 3.3. The geological character of rock material, together with the visual assessment of the mass it forms, is used as a direct input to the selection of parameters relevant for the prediction of rock-mass strength (Hoek, 2005).

$a=$ constant of the rock material based by the given relationship

$$
a=\frac{1}{2}+\frac{1}{6}\left(e^{-\frac{G S I}{15}}-e^{-\frac{20}{3}}\right)
$$

Equation 2.5 
For this research, laboratory testing was not conducted to achieve Hoek-Brown data parameters. Subsequently the input data for the Hoek-Brown was researched and gathered to establish a wide data base that would deal with the rock types found within the state of West Virginia.

\subsection{Comparison of Failure Criterion}

Through literature finding the Hoek-Brown failure criterion was found to more accurately represent the rock stability behavior in this research as compared to the Mohr-Coulomb. The Mohr-Coulomb theory, on the other hand, is simple and practical, and although far from perfect, it is probably the most commonly used failure theory in rock mechanics. Because intact rock usually has an appreciable unconfined compressive strength and zero confining stress, the Mohr failure has a significant intercept, because unconfined compressive strength (Holtz, 2011). This statement states the criterion is ideal for "intact" rock meaning minimal to no fracturing. The Hoek-Brown failure criterion is an innovative failure criterion for rock mechanics. The Hoekbrown criterion is used for fractured rock. Fracture propagation into the rock is leaving instability with leads to rock fall toppling events as seen in field observations. The Hoek-Brown criterion is a very practical empirical criterion based on years of experience observing the behavior of rock masses in tunnel and slope construction, supplemented by laboratory test on fractured rock and model studies of jointed rock (Holtz, 2011).

\subsubsection{Comparison of Methods}

The finite numerical modeling conducted with SoilVision Systems ${ }^{\mathrm{TM}}$ particularly the SVSlope ${ }^{\circledR}$ module allowed for multiple analysis slope stability methods. The analysis preformed during a slope stability process is based upon the Method of Slices. Method of Slices breaks down a failure area of a slope into predetermined segments or slices that allows for the assessment of the shear and normal forces present on each individual slice.

The method of slices becomes more accurate with the increased number of slices used during the analysis. This is a substantial benefit to using a finite element software, it makes computational work of slice assessment that would otherwise be impossible via hand computation and become readily available for analysis. Upon review of the West Virginia Department of Highways: Geotechnical Report it was found that the current slope stability analysis method preformed is

the Simplified Janbu and Simplified Bishop method run with the PCSTABLE $6^{\text {TM }}$ slope stability software.

In order to proceed with the slope stability modeling a validation model was necessary to ensure that SVSlope ${ }^{\circledR}$ would in fact compute a similar result file. The validation model was run identically to establish the accuracy of the software. In addition one other analysis method was considered during the process, General Limit Equilibrium to compare the resulting data. The 
General Limit Equilibrium method was considered due to the nature if takes the produced moments and forces into the stability analysis. Further information will be disclosed in the Validation Modeling write up Section 3.3. Figure 2.6.2.1 is a graphic representation and breakdown of a general method of slices evaluation.

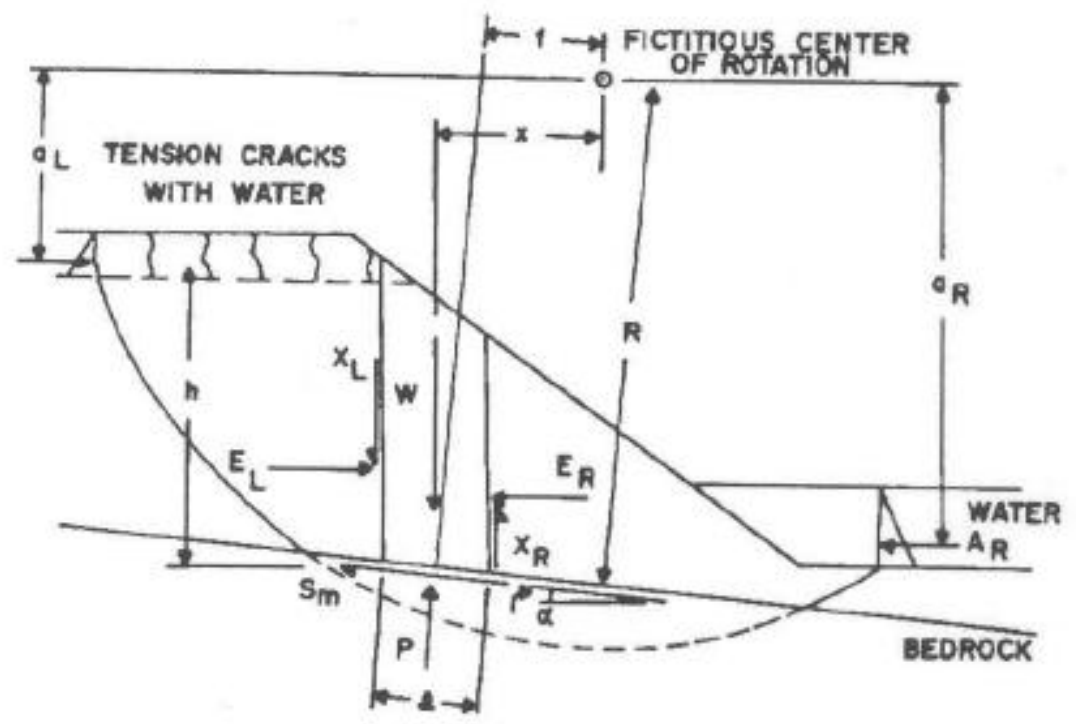

Figure 2.6.2.1: Forces Acting for a Method of Slices (Non-Circular Failure) (Fredlund, 1981) 


\subsubsection{Simplified Janbu Method}

The simplified Janbu method is a slope stability analysis method based upon the method of slices. The series of slices found during the analysis may appear to be similar, however vary vastly in forces present on each individual slice. In the derivation of the Simplified Janbu method the interslice shear forces are assumed to be zero (Fredlund, 1981). The elimination of the interslice shear force caused the analysis method to be based up normal force calculations, thus producing a factor of safety based upon forces. The factor of safety determined in this analysis method is found by Equation 2.6. The method of factor of safety calculation is determined by a summation of the forces of the individual slices. The results are similar to other analytical methods, providing a finalized factor of safety.

Where:

$$
F_{f}=\frac{\Sigma\left[c^{\prime} l+(P-u l) \tan \emptyset^{\prime}\right] \cos \alpha}{\Sigma P \sin \alpha \pm A}
$$

Equation 2.6

$F_{f}=$ computed factor of safety

$c^{\prime}=$ effective cohesion

$u=$ pore water pressure (if present)

$l=$ length of the failure surface at the bottom of each slice

$\emptyset^{\prime}=$ effective angle of internal friction

$\mathrm{P}=$ the total normal force on the base of a slice

Once a factor of safety has been established an empirical correction factor is applied in an attempt to account for the effect of the interslice shear forces (Fredlund, 1981). 


\subsubsection{Simplified Bishop Method}

The basis of the simplified Bishop Method is a hybrid of multiple analytical procedures. Similar to the Simplified Janbu, the interslice shear force is negated and taken to be zero (Fredlund, 1981). The factor of safety computation is based around a point of rotation which projects the failure plane throughout the slope. This analysis methods works concurrently with circular and non-circular failure cases (Fredlund, 1981). The method of calculation is by the summation of the moments, derived by individual slices. The basis of analysis can be seen in the following equations, variables found within can be traced back to Figure 2.7.

$$
F_{m}=\frac{\Sigma\left[c^{\prime} l+(P-u l) \tan \emptyset \prime\right] \mathrm{R}}{\Sigma W_{x} \pm A a}
$$

Equation 2.7

Where:

$F_{m}=$ computed factor of safety

$c^{\prime}=$ effective cohesion

$u=$ pore water pressure (if present)

$l=$ length of the failure surface at the base of each slice

$\emptyset^{\prime}=$ effective angle of internal friction

$\mathrm{P}=$ the total normal force on the base of a slice

$\mathrm{R}=$ radius of curvature

$W_{x}=$ the total vertical forces due to the mass of a slice of width ' $b$ ' and height ' $h$ '

$A=$ the resultant external water forces

$a=$ the perpendicular distance from the resultant external water forces to the center of rotation 


\subsubsection{General Limit Equilibrium}

The General Limit Equilibrium method is based upon static analysis that can be used to derive the factor of safety are the summation of forces in two direction and the summation of moments about a chosen point of rotation (Fredlund, 1981). The presence of a non-circular slip is often assumed to be due to geological discontinuity within the media (Fredlund, 1981). During the calculation of a non-circular failure the radius of curvature is varying, which results in complex computation which reiterates the benefit of a finite element modeling software.

The main difference between this method and the previously discussed methods is that the General Limit Equilibrium method takes interslice shear force into consideration. The calculations performed to obtain the factor of safety with the General Limit Equilibrium method, takes into account driving moments and forces; deeming it the preferred method for slope stability analysis. An over view of the calculation method can be seen in the Equation 2.8.

$$
F_{m}=\frac{\Sigma\left[c^{\prime} l+(P-u l) \tan \emptyset \prime\right] \mathrm{R}}{\Sigma W_{x}-\Sigma \operatorname{Pf} \pm \mathrm{Aa}}
$$

Equation 2.8

Where:

$F_{m}=$ computed factor of safety

$c^{\prime}=$ effective cohesion

$u=$ pore water pressure (if present)

$l=$ length of the failure surface at the base of each slice

$\emptyset^{\prime}=$ effective angle of internal friction

$\mathrm{P}=$ the total normal force on the base of a slice

$\mathrm{R}=$ radius of curvature

$W_{x}=$ the total vertical forces due to the mass of a slice of width ' $b$ ' and height ' $h$ '

$A=$ the resultant external water forces

$a=$ the perpendicular distance from the resultant external water forces to the center of rotation

$\mathrm{Pf}=$ resulting moment of failing mass, independent from slice to slice 


\subsection{ANALYSIS VALIDATION}

The West Virginia Department of Highways provided a geotechnical report on Route 121, Coalfields Expressway located in Sophia, WV. A slope stability analysis was found on a fill construction design within the report at station $5659+50$. The slope stability analysis performed within the geotechnical report was performed with a software program PCSTABL6 ${ }^{\mathrm{TM}}$. Two analysis methods considered; Simplified Janbu and Simplified Bishop. A third analysis method was conducted to further ensure the validity of the software; the General Limit Equilibrium method. The report noted the geometric data points as well as Mohr-Coulomb material parameters that allowed for complete reconstruction of the model. Table 3.1 presents the material input parameters provided and analyzed in the geotechnical report.

Table 3.1: Mohr-Coulomb input parameters provided from the Coalfields Expressway geotechnical report

\begin{tabular}{|c|c|c|c|c|}
\hline Material & $\begin{array}{l}\text { Dry Unit Weight } \\
\left(\mathbf{l b} . / \mathbf{f t}^{3}\right)\end{array}$ & $\begin{array}{l}\text { Sat. Unit Weight } \\
\left(\mathbf{l b} / \mathrm{ft}^{3}\right)\end{array}$ & Cohesion (psf) & $\begin{array}{c}\begin{array}{c}\text { Friction Angle } \\
\text { (degrees) }\end{array} \\
\text { (dent }\end{array}$ \\
\hline Soil 1 & 120 & 125 & 100 & 30 \\
\hline Soil 2 & 130 & 135 & 0 & 40 \\
\hline Soil 3 & 120 & 125 & 50 & 28 \\
\hline Soil 4 & 140 & 145 & 2000 & 45 \\
\hline
\end{tabular}

The geometry was provided in the report in the form of $\mathrm{X}$ and $\mathrm{Y}$ coordinates. In Figure 3.3.1, visual representation of the slope stability analysis screen shot from PCSTABL $6{ }^{\mathrm{TM}}$ provided in the geotechnical report. 


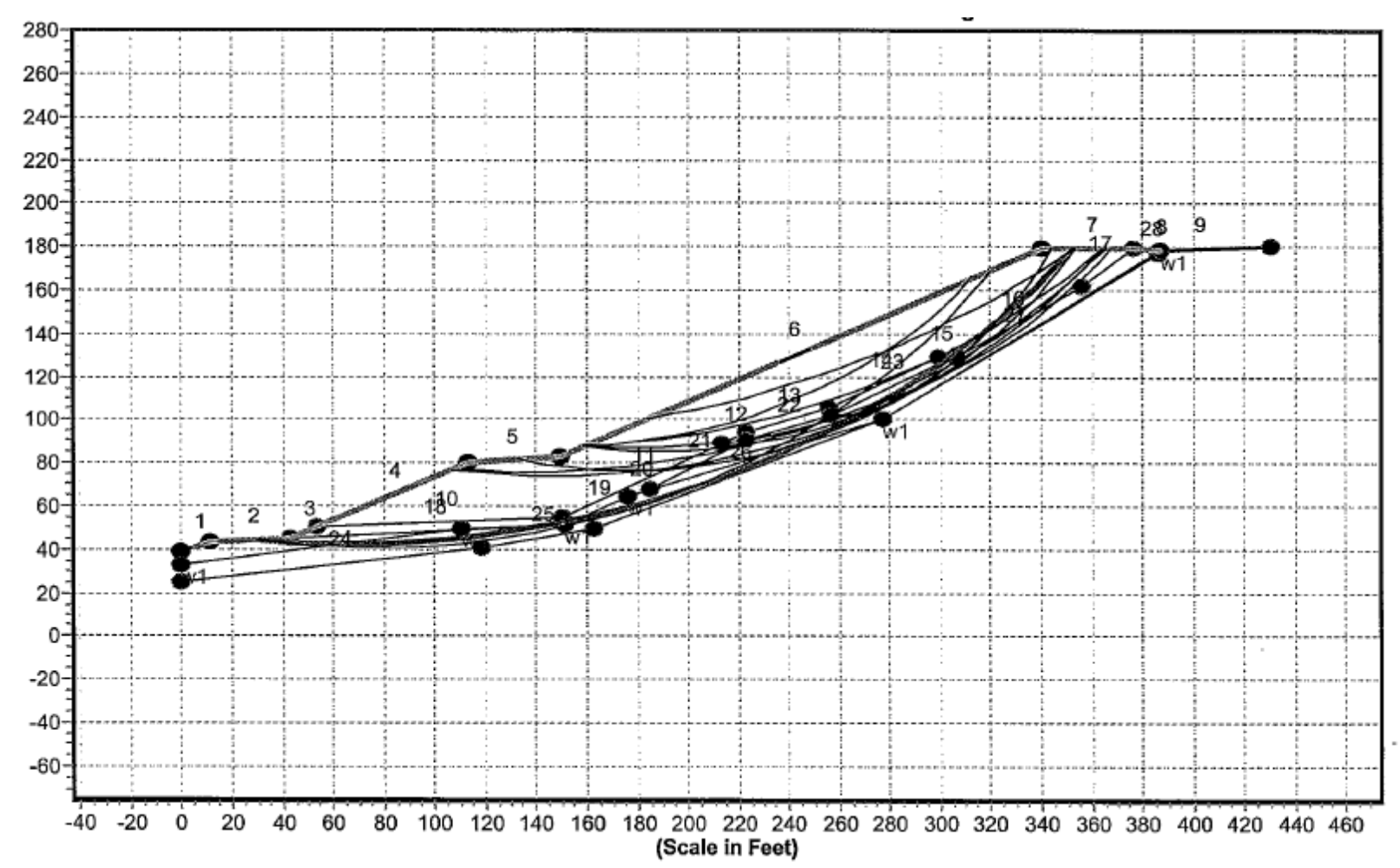

Figure 3.1: Coalfields W Helen to Allen Creek Station 5659+50 w/Fill Bench

Final review of the analysis in the geotechnical report, a global factor of safety was found to be 1.381 for this slope. A factor of safety of 1.381 or higher was the targeted outcome upon completion of the SVSlope ${ }^{\circledR}$ analysis.

The interface in SVSlope ${ }^{\circledR}$ initially loads to a blank screen with an X-Y coordinate system with the magnitudes preselected by the user. The initial step to run the model was to establish a slope profile by inputting geometric data points obtained through the provided geotechnical report. Input data into the program must be in such a way to construct a complete closed geometric shape; this is to ensure the search area of the program when predicting failure planes. For the data set provided within the geotechnical report four shapes were constructed in accordance to encompass the four soil types previously listed in table 3.1. Figure 3.3.2 illustrates the complete constructed slope within SVSlope ${ }^{\circledR}$. Also, a color-coded legend has been included to depict the variance in the four geological layers. 


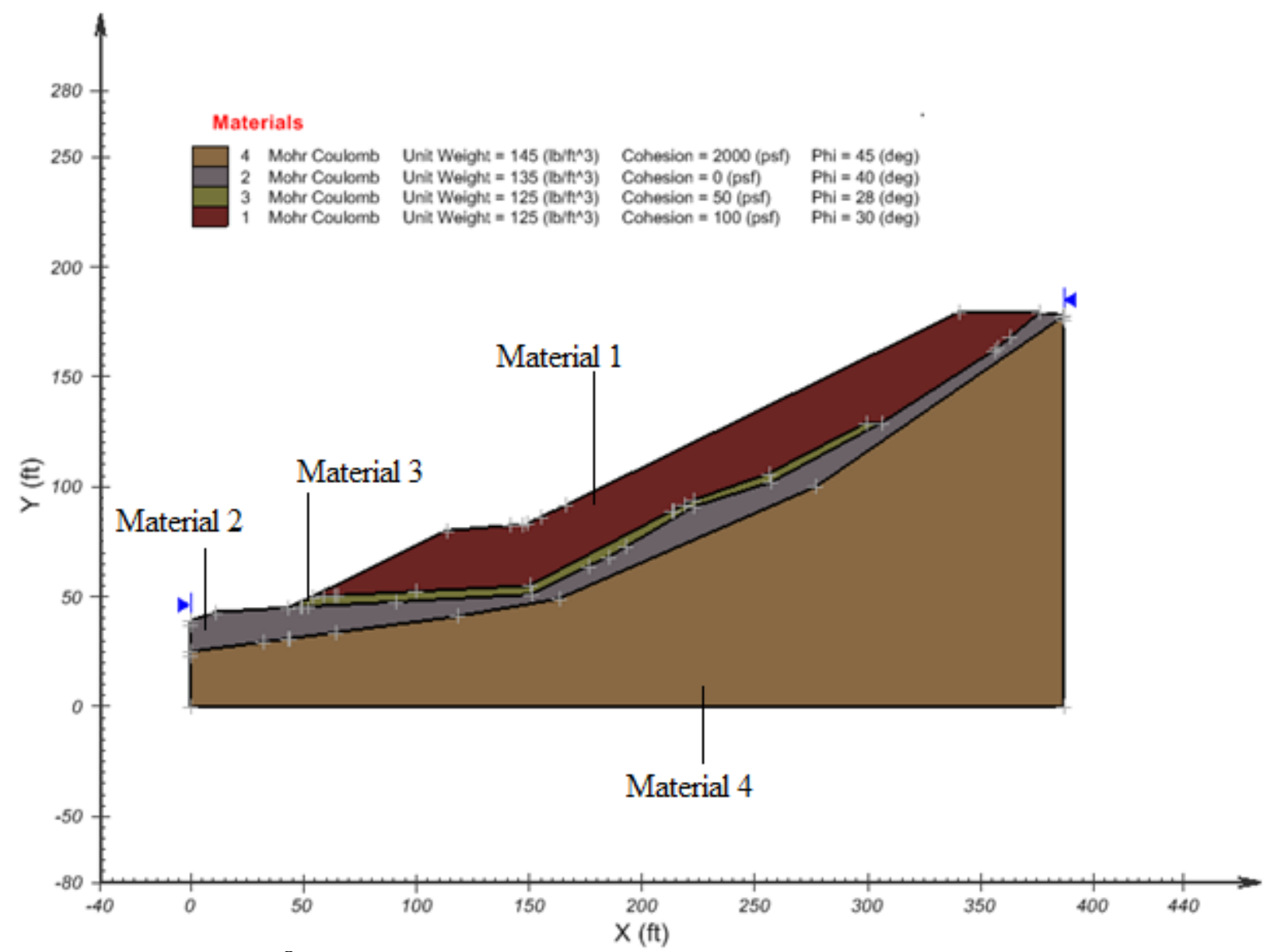

Figure 3.2: SVSlope ${ }^{(1)}$ validation model of fill slope constructed at station $5659+00$

The material inputs were taken from the geotechnical report. All the soil inputs were MohrCoulomb criterion in this analysis. Three slope stability analysis procedures were conducted and the global results can be seen for each of the analysis methods in Table 3.2. The results that derived from the completion of the SVSlope ${ }^{\circledR}$ illustrated a higher factor of safety than provided within the geotechnical report.

Table 3.2: Validation model stability results

\begin{tabular}{|l|c|}
\hline \multicolumn{1}{|c|}{ Analysis Method } & Factor of Safety \\
\hline SVSlope $^{\circledR}:$ Simplified Janbu / Simplified Bishop & 1.394 \\
\hline SVSlope $^{\oplus}:$ General Limit Equilibrium & 1.397 \\
\hline $\begin{array}{l}\text { PCSTABL6 } \\
\text { Bishop } \text { : Simplified Janbu / Simplified }\end{array}$ & 1.381 \\
\hline
\end{tabular}

In conclusion of this validation analysis, it is confirmed that the suite SoilVision Systems ${ }^{\mathrm{TM}}$ is a suitable software program to perform slope stability analysis on the fill and cut slopes present within the state of West Virginia. The General Limit Equilibrium method takes into consideration the driving moments and forces in the factor of safety calculation; with this, it 
eliminated the need for the use of the other calculation methods and the Simplified Bishops and Simplified Janbu methods will subsequently be dropped from further slope analyses. Modeling proceeded on to the proposed sites with the confidence the results will provide correct results.

Material input parameters are physical properties which are independent of one another; however, a range of strength parameters were evaluated during this process to simulate the effects of fracture propagation subjected onto the remaining exposed rock face as well as competency of the material. Strength values were obtained through literature findings and were used in the analysis. The slope stability assessment was utilized to assist in the cut slope redesign process. The final objective was to establish a range of slope designs pertaining to stability which were intended to assist in producing a rock cut slope design guide, rock fall mitigation strategies, and ensure safety to roadway users.

\subsection{Input Sensitivity Analysis}

A sensitivity analysis was conducted on a generalized slope to illustrate the behavior an individual input variable has on the factor of safety. This process of modeling resulted in two outcomes, the intended sensitivity analysis in addition to design charts based upon material strength for the four most prevalent slope back slope angles that were seen in the field and proposed in DD-403. Completion of the sensitivity analysis required the assessment of 99 individual models.

The sensitivity analysis began with the development of an idealized slope with a slope designed to a $\mathrm{H}: \mathrm{V}$ ratio of $1: 1$. Modeling construction of the slope was done in accordance with DD-403, using a minimum bench width of $20 \mathrm{ft}$. to a maximum vertical height of $50 \mathrm{ft}$. Three trial runs were completed on this idealized slope to find the critical number of benches. The models consisted of three slopes which had varied bench amounts, three, six and nine.

Through these model runs evidence tends to indicate that the slope constructed with six benches resulted in the lowest factor of safety. Once the number of benches was determined the sensitivity analysis was conducted on the Hoek-Brown failure criterion assessed with the General Limit Equilibrium analysis method. Table 3.4.1 illustrates the resulting factors of safety from the analysis procedure.

Table 3.1.1: Idealized Critical Number of Bench Analysis

\begin{tabular}{|c|c|}
\hline Critical Bench Analysis & Factor of Safety \\
\hline Three Benches & 2.577 \\
\hline Six Benches & 2.564 \\
\hline Nine Benches & 2.626 \\
\hline
\end{tabular}

The Hoek-Brown failure criterion had five individual parameters that were evaluated during this process, in addition the four most prevalent material types found within the state of West 
Virginia were evaluated which allowed the construction of the final design charts. The sensitivity analysis of the individual parameters was performed using; minimum values, 25, 50, 75 , and 100 percent of maximum value. A five point data analysis allowed for a range in values to be analyzed while illustrating the factors of safety possible throughout a given range in the parameter. The Hoek-Brown material parameters are listed below:

- Unconfined Compressive Strength (UCS) - Maximum axial load without lateral confining pressures a material can withstand prior to failure

- Unit Weight - The density of the material which will be noted as $1 \mathrm{~b} . / \mathrm{ft}^{3}$

- Disturbance Factor (D) - Disturbance factor is a direct relation to blasting performed during slope construction

- Geological Strength Index (GSI) - Is the relation of lithology, structure and surface conditions of the discontinuities. It should be noted that this is an estimation, discrete values should be negated and a generalized values should be evaluated for a given slope.

- Rock Mass $\left(\mathrm{m}_{i}\right)$ - Constant for intact rock pieces

The sensitivity analysis consisted of varying each of the listed parameters while keeping the others constant. Some of the determined factors of safety were calculated below 1.0, [it is important to realize that this process does not pertain to any stability issues more so the fact of the response and behavior an individual parameter affects the performance of a rock cut slope]. The method of approach for the analysis is listed in Table 3.1.2 for each of the input parameters:

Example Percentage Calculation: Mass Index: Sand Stone 25 percent of ranged data

Range: $31: 25 \%:(31 * 0.25)+5($ initial $/$ minimum value $)=\underline{12}$

- Unconfined Compressive Strength:

- Strength values from Table 3.1.2 were altered for each run and the resulting factor of safety is tabulated in Table 3.1.3

- All other parameters were held the respected minimum values, the Geological Strength Index was held at 25 percent in perspective with what has been seen in field evaluations

- Unit Weight:

- Unit weight values were initially obtained and varied by intervals of $5 \mathrm{lb}$. $/ \mathrm{ft}^{3}$

- All other parameters were held constant to the respected minimum values, the Geological Strength Index was held at 25 percent of maximum value in perspective with what has been seen in field evaluations 
- Disturbance Factor:

- Through literature the disturbance factor was found to vary from 0.6 for good blasting to 1.0 for poor blasting the range was subsequently broken into five equally spaced intervals

- All other parameters were held constant to the respected minimum values, the Geological Strength Index was held at 25 percent of maximum value in perspective with what has been seen in field evaluations

- Geological Strength Index:

- The Geological Strength Index was varied into five intervals in relation to literature attained values

- All other parameters were held constant to the respected minimum values, the Geological Strength Index was held at 25 percent of maximum value in perspective with what has been seen in field evaluations

- Rock Mass:

- Rock Mass was assessed similar to the GSI parameter. The shale was unable to be varied in the evaluation due to the lack of published research on rock mass constants.

- All other parameters were held constant to the respected minimum values, the Geological Strength Index was held at 25 percent of maximum value in perspective with what has been seen in field evaluations

Table 3.1.2 illustrates the input variation of the parameters with respect to material type. These values were obtained and broken into the respective ranges as previously discussed in the method of approach for the sensitivity analysis. 
Table 3.1.2: Inputs for the sensitivity analysis

\begin{tabular}{|c|c|c|c|c|c|c|}
\hline \multicolumn{7}{|c|}{ Sensitivity Analysis } \\
\hline & \multicolumn{6}{|c|}{ Trial } \\
\hline \multirow[t]{2}{*}{ Parameter } & Initial & 1 & 2 & 3 & 4 & 5 \\
\hline & & $\mathbf{0 \%}$ & $25 \%$ & $\mathbf{5 0 \%}$ & $75 \%$ & $100 \%$ \\
\hline \multicolumn{7}{|l|}{ UC Strength (KSF) } \\
\hline Sandstone & & 417.7 & 1200.9 & 1984.1 & 2767.3 & 3550.5 \\
\hline Shale & & 104.4 & 600.5 & 1096.5 & 1592.5 & 2088.5 \\
\hline Siltstone-Mudstone & & 208.9 & 678.8 & 1148.7 & 1618.6 & 2088.5 \\
\hline Limestone & & 626.6 & 1775.3 & 2924.0 & 4072.7 & 5221.4 \\
\hline Unit Weight (lb/ft^3) & & 1 & 2 & 3 & 4 & 5 \\
\hline Sandstone & 151.08 & 141.08 & 146.08 & 151.08 & 156.08 & 161.08 \\
\hline Shale & 137.34 & 127.34 & 132.34 & 137.34 & 142.34 & 147.34 \\
\hline Siltstone-Mudstone & 137.34 & 127.34 & 132.34 & 137.34 & 142.34 & 147.34 \\
\hline Limestone & 156.07 & 146.07 & 151.07 & 156.07 & 161.07 & 166.07 \\
\hline \multirow[t]{3}{*}{ Disturbance Factor - D (Blasting) } & & 1 & 2 & 3 & 4 & 5 \\
\hline & & \multicolumn{5}{|c|}{ 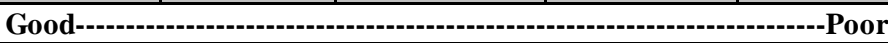 } \\
\hline & & 0.6 & 0.7 & 0.8 & 0.9 & 1.0 \\
\hline \multirow[t]{3}{*}{ Geologic Strength Index - GSI } & & 1 & 2 & 3 & 4 & 5 \\
\hline & & \multicolumn{5}{|c|}{ Poor-1- } \\
\hline & & 5 & 25 & 45 & 65 & 85 \\
\hline \multirow[t]{2}{*}{ Mass Index - mi } & & 1 & 2 & 3 & 4 & 5 \\
\hline & & 0\% & $25 \%$ & $\mathbf{5 0 \%}$ & $75 \%$ & $100 \%$ \\
\hline Sandstone & & 5 & 12 & 20 & 28 & 36 \\
\hline Shale & & 8 & 8 & 8 & 8 & 8 \\
\hline Siltstone - Mudstone & & 9 & 18 & 28 & 37 & 47 \\
\hline Limestone & & 4 & 15 & 27 & 38 & 50 \\
\hline
\end{tabular}

The assessment of the sensitivity required the analysis of 99 individual models and the resulting data was populated into a results table. The resulting factors of safety were graphed against the varied parameter to illustrate the significance on the performance of the slope. Table 3.1.3 illustrates the resulting outcome in regards to a factor of safety obtained from each of the model runs. 
Table 3.1.3: Sensitivity Analysis results

\begin{tabular}{|c|c|c|c|c|c|}
\hline \multicolumn{6}{|c|}{ Sensitivity Analysis Results } \\
\hline Parameter & 1 & 2 & 3 & 4 & 5 \\
\hline UC Strength & \multicolumn{5}{|c|}{ Factor of Safety } \\
\hline Sandstone & 1.241 & 1.881 & 2.345 & 2.699 & 2.999 \\
\hline Shale & 0.909 & 1.674 & 1.839 & 2.398 & 2.680 \\
\hline Siltstone-Mudstone & 1.196 & 1.797 & 2.024 & 2.466 & 2.729 \\
\hline Limestone & 1.173 & 2.114 & 2.616 & 3.052 & 2.958 \\
\hline Unit Weight & 1 & 2 & 3 & 4 & 5 \\
\hline Sandstone & 1.273 & 1.257 & 1.241 & 1.226 & 1.212 \\
\hline Shale & 0.934 & 0.921 & 0.909 & 0.904 & 0.892 \\
\hline Siltstone-Mudstone & 1.228 & 1.212 & 1.196 & 1.182 & 1.168 \\
\hline Limestone & 1.399 & 1.380 & 1.173 & 1.158 & 1.144 \\
\hline \multirow[t]{2}{*}{ Disturbance Factor - D } & 1 & 2 & 3 & 4 & 5 \\
\hline & \multicolumn{5}{|c|}{ 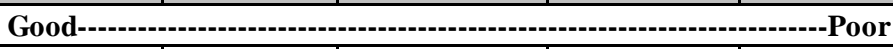 } \\
\hline Sandstone & 1.860 & 1.854 & 1.691 & 1.475 & 1.241 \\
\hline Shale & 1.530 & 1.393 & 1.245 & 1.073 & 0.909 \\
\hline Siltstone & 1.975 & 1.798 & 1.616 & 1.417 & 1.196 \\
\hline Limestone & 2.334 & 2.096 & 1.854 & 1.601 & 1.173 \\
\hline \multirow[t]{2}{*}{ Geologic Strength Index - GSI } & 1 & 2 & 3 & 4 & 5 \\
\hline & \multicolumn{5}{|c|}{ 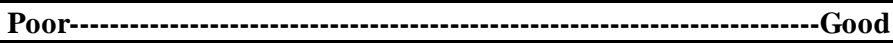 } \\
\hline Sandstone & 0.767 & 1.321 & 2.507 & 6.336 & 35.05 \\
\hline Shale & 0.552 & 0.957 & 1.614 & 3.085 & 10.08 \\
\hline Siltstone - Mudstone & 0.760 & 1.269 & 2.163 & 4.21 & 16.58 \\
\hline Limestone & 0.817 & 1.448 & 2.900 & 10.70 & 170.9 \\
\hline Mass Index - mi & 1 & 2 & 3 & 4 & 5 \\
\hline Sandstone & 1.241 & 1.601 & 1.844 & 2.021 & 2.175 \\
\hline Shale & 0.909 & - & - & - & - \\
\hline Siltstone - Mudstone & 1.196 & 1.486 & 1.691 & 1.842 & 1.961 \\
\hline Limestone & 1.173 & 1.952 & 2.26100 & 2.478 & 2.640 \\
\hline
\end{tabular}

\subsubsection{Salient Findings of Sensitivity Analysis}

1. The sensitivity analysis identified that unconfined compressive strength, disturbance factor, and geological strength index had the largest impact on the slope performance. These variables provided the largest range in calculated factor of safety for their cases.

2. The unconfined compressive strength parameter will be the driving restriction in rock cut slope design because it is the only testable and obtainable parameter prior to slope construction. Figure 3.1.1 illustrates the behavior in which the material unconfined compressive strength directly affects the slope stability performance. The largest percent difference in the calculated factor of safety for the maximum and minimum case is approximately $194 \%$ for the shale material type. 
3. The disturbance factor is only obtainable prior to the completion of the slope; however careful consideration and planning should go into the blasting process due to the large effect it can have on the slope performance if poor blasting is completed during slope construction.

4. Similar to the disturbance factor the geological strength index is not obtainable prior to the construction of the slope. The joints and discontinuities of the rock may be evaluated to an extent through borehole extraction however should not be a driving factor if slope design due to the vast range in probable outcomes.

Through the completion of the sensitivity analysis it was evident that the unconfined compressive strength is the leading factor in the design guide graphs. All the graphical results with respect to factor of safety are shown in Figure 3.1.1.1- Figure 3.1.1.5.

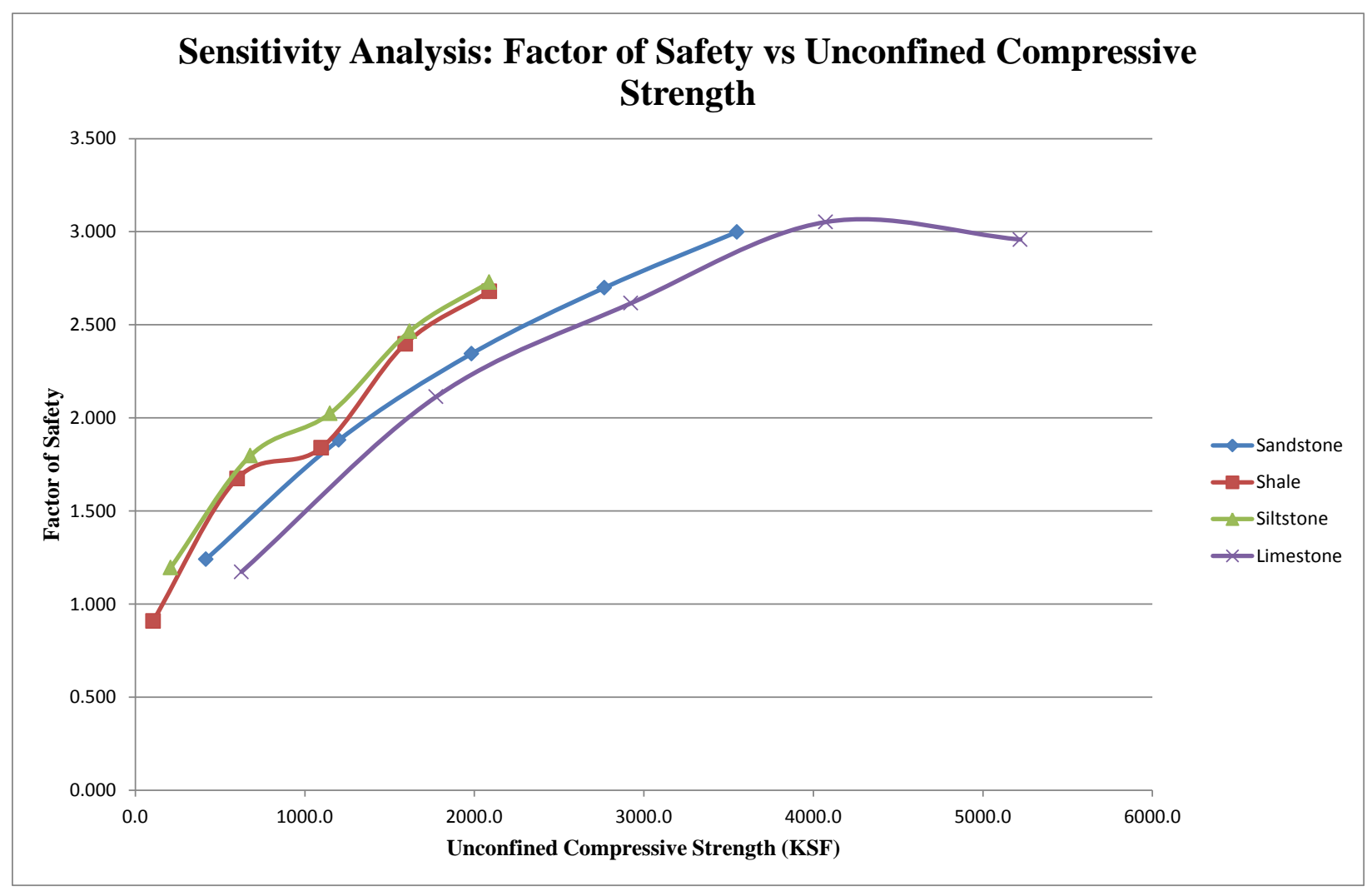

Figure 3.1.1.1: Factor of Safety vs. Unconfined Compressive Strength 


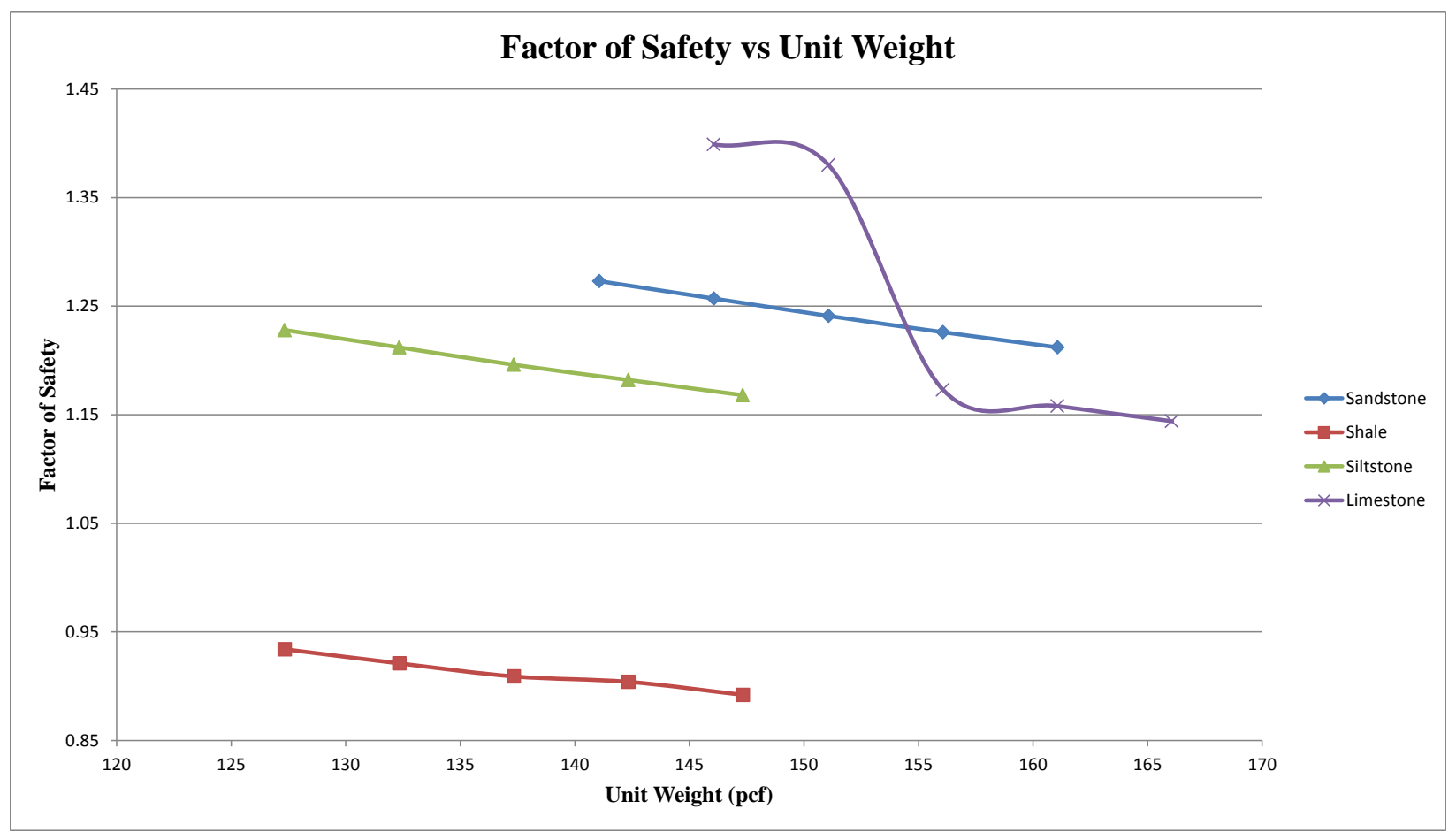

Figure 3.1.1.2: Factor of Safety vs. Unit Weight

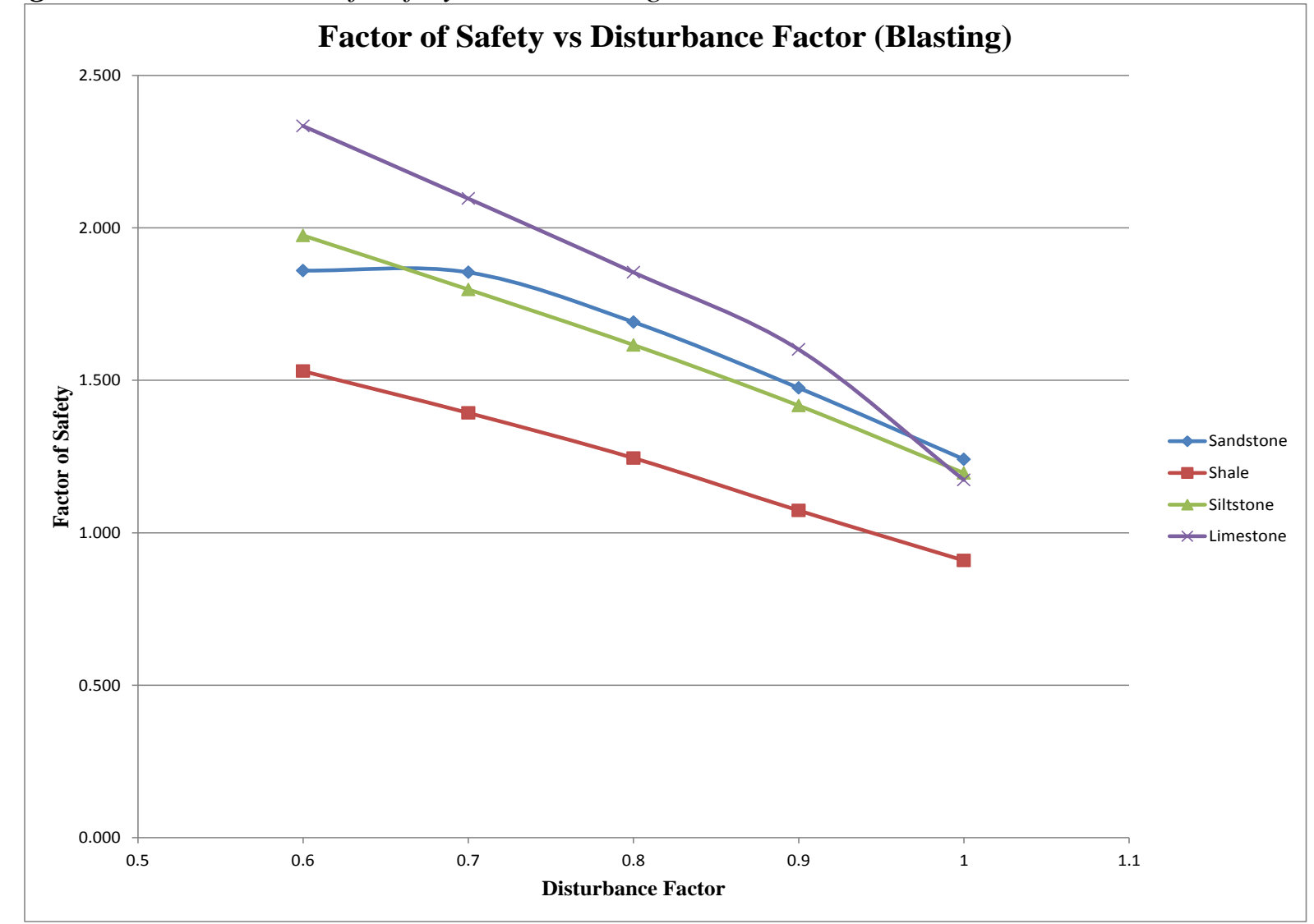

Figure 3.1.1.3: Factor of Safety vs. Disturbance Factor 


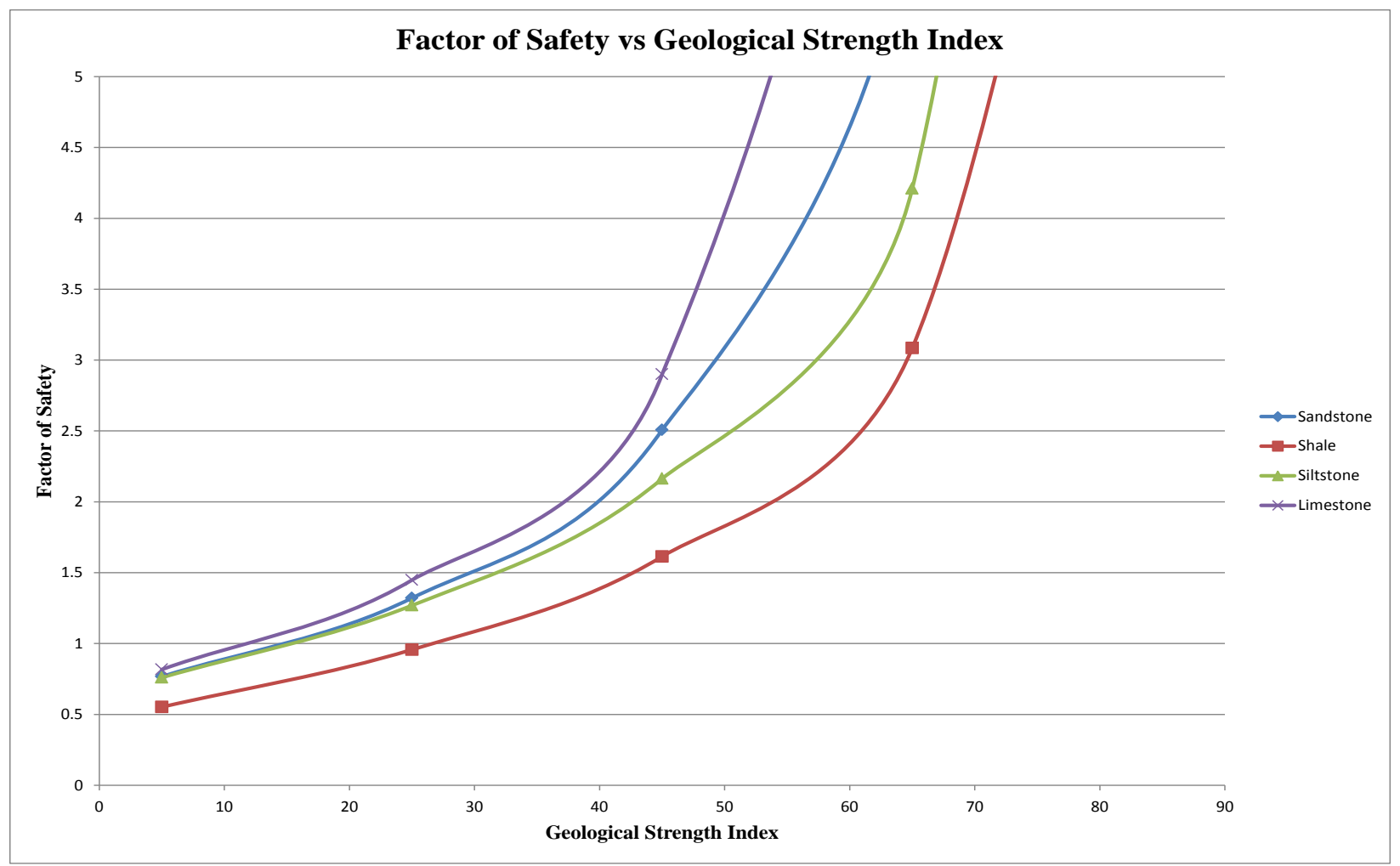

Figure 3.1.1.4: Factor of Safety vs. Geological Strength Index

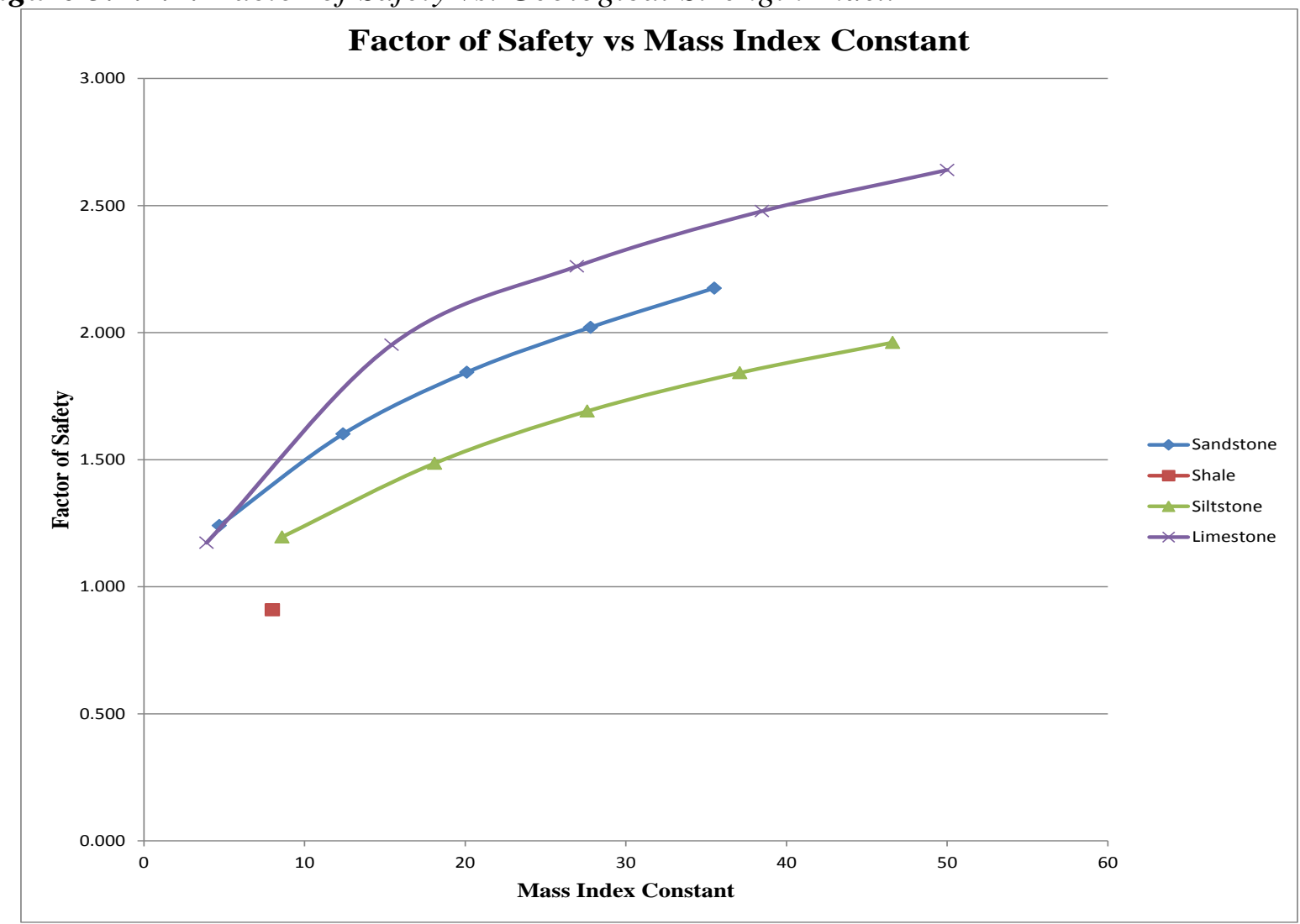

Figure 3.1.1.5: Factor of Safety vs. Rock Mass Constant 


\subsection{New Slope Construction Design Charts and Analysis}

The design guides provide assistance in the design of a rock cut slope given the unconfined compressive strength values are obtained, the design should be limited to the strength of the most prevalent material found by subsurface exploration. In accordance with DD-403, as well as field assessments, the four design charts constructed are applied to the back slope angles listed in Table 3.2.1. Figure 3.2.1 is the flow chart of how the initial design profile angle should be derived upon, with the use of the design charts.

The completion of the design charts were completed by altering the unconfined compressive strength for each of the materials at the respective value listed in Table 3.2.1 against the profile design back slope angle. In order to complete the other design charts and additional 60 models were required. Upon running all of the inputs design charts were constructed and can been seen in Figures 3.2.2 - Figure 3.2.5.

Table 3.2.1: Design table back slope angles

\begin{tabular}{|c|c|}
\hline \multicolumn{2}{|c|}{ Profile Design Back Slope Angle } \\
\hline H:V & Corresponding Angle \\
\hline $1: 1$ & $45^{\circ}$ \\
\hline $0.75: 1$ & $53.1^{\circ}$ \\
\hline $0.5: 1$ & $63.4^{\circ}$ \\
\hline $0.25: 1$ & $76.0^{\circ}$ \\
\hline
\end{tabular}




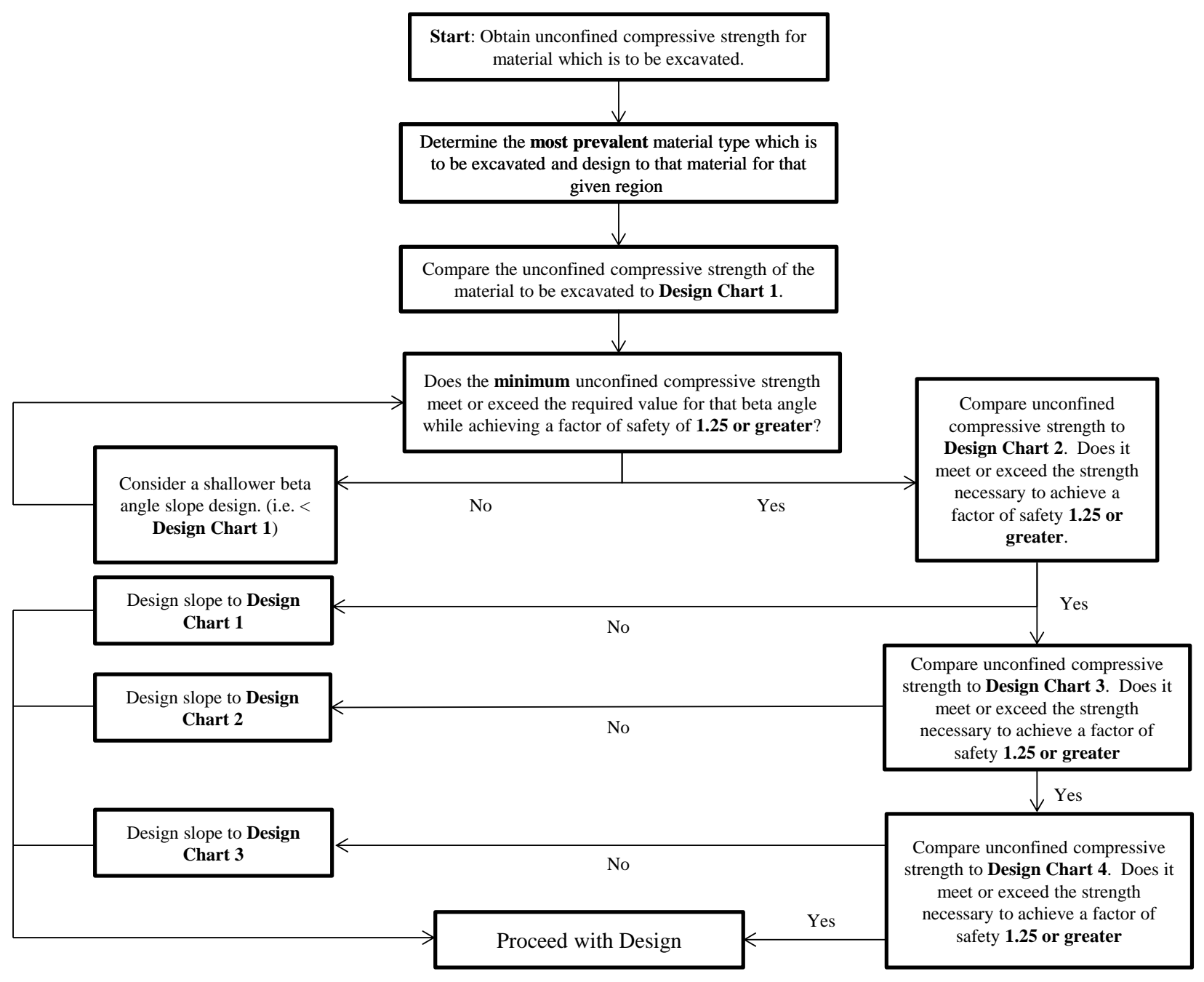

Figure 3.2.1: New Slope Design Flow Chart 


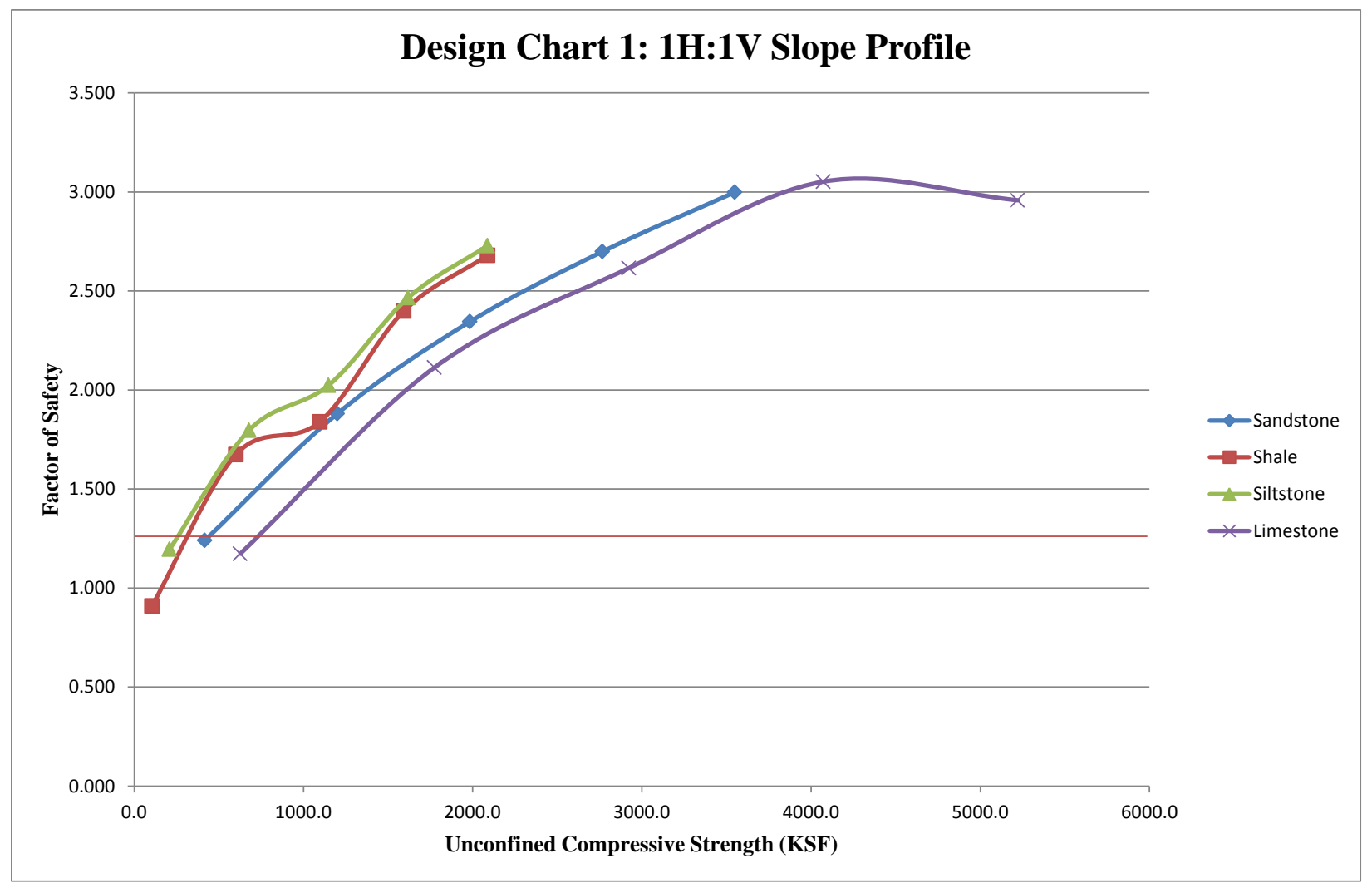

Figure 3.2.2: Design Table 1

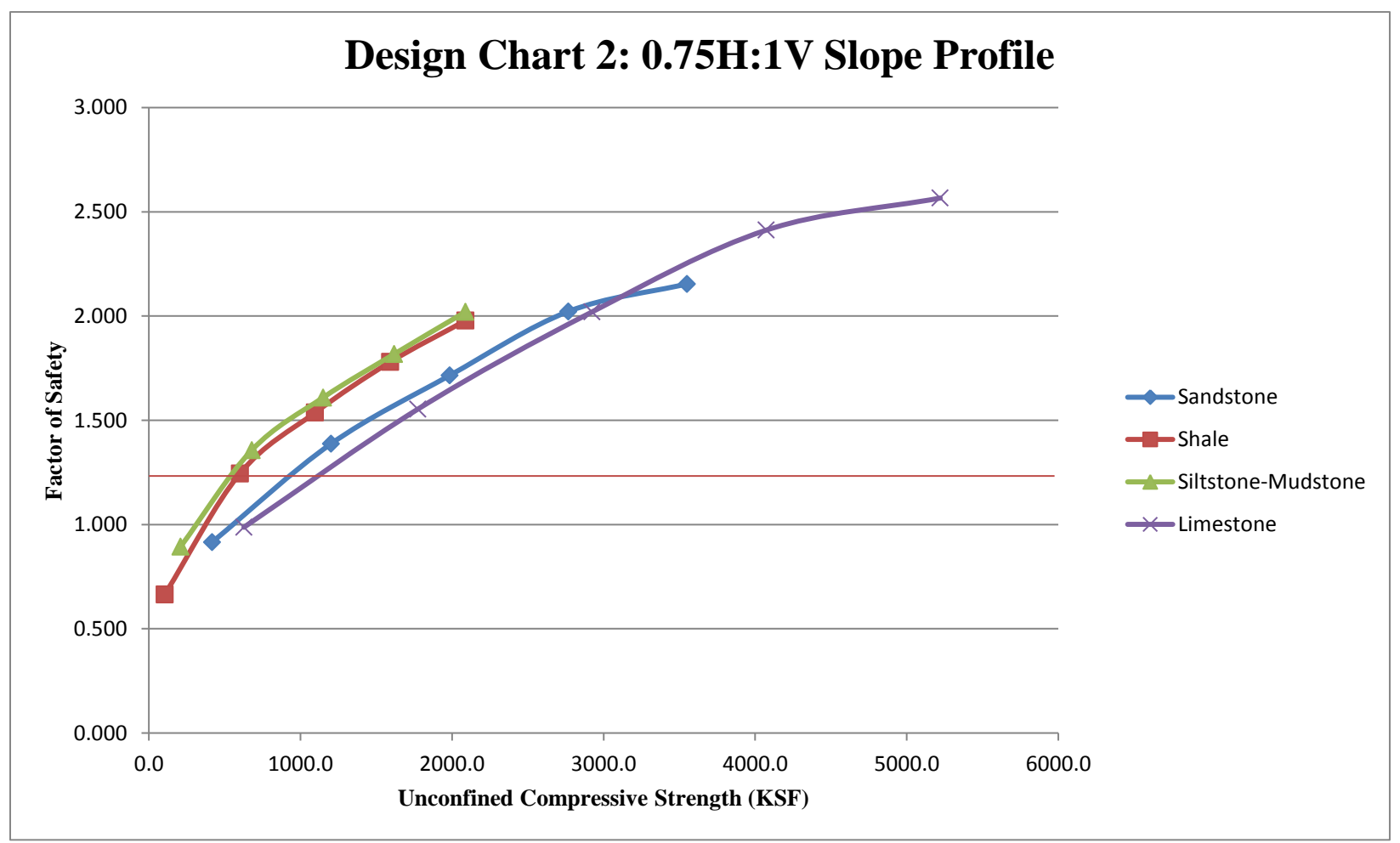

Figure 3.2.3: Design Chart 2 


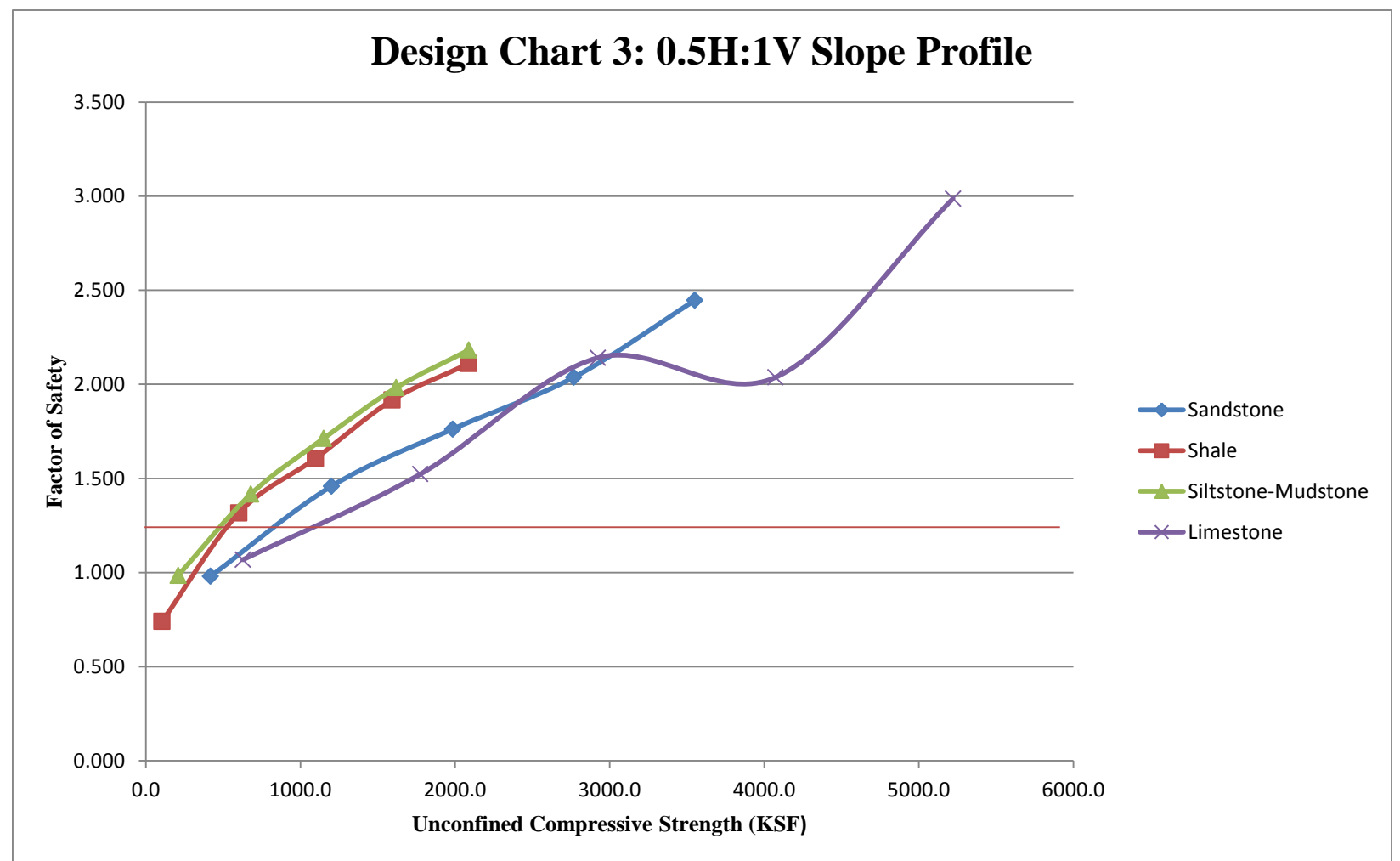

Figure 3.2.4: Design Chart 3

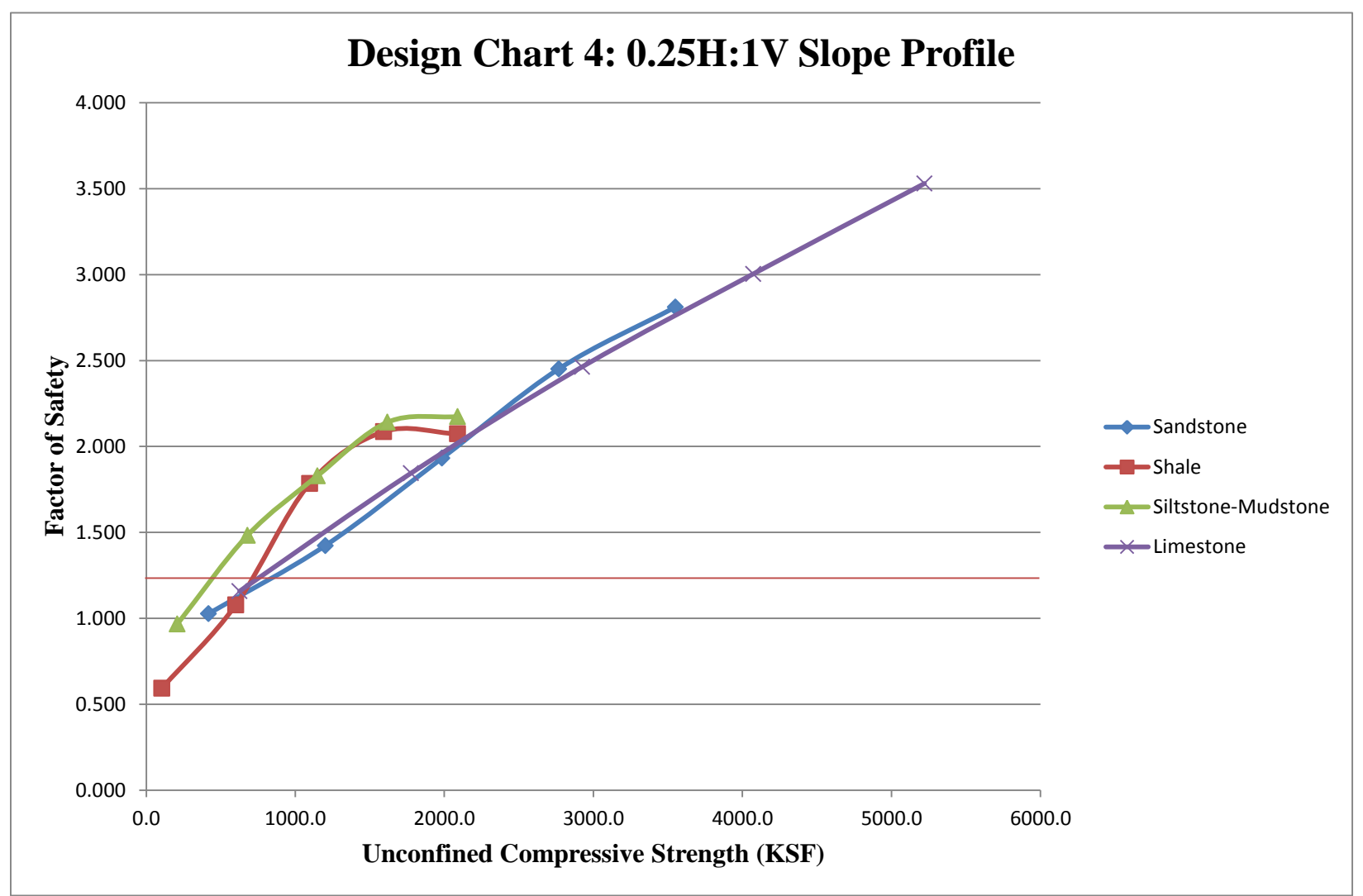

Figure 3.2.5: Design Chart 4 


\subsection{Design Chart Verification}

The data reduction procedure within the design charts showed an increasing relation in factor of safety with a respected increase in back slope angle. This behavior is the opposite in which one would expect. Assessing the back slope angle with regards to factor of safety for an idealized slope was conducted to illustrate the area in which the stability of a slope beings to increase again. This response assessment was conducted with an idealized homogeneous three bench profile cut slope. The slopes were constructed within the current guidelines in DD-403; maximum cut of 50 vertical feet and a required minimum bench width of 20 feet, sloped at a $15 \mathrm{H}: 1 \mathrm{~V}$ away from the slope. The assessment of each model was held constant to material input values, the only alteration within the models was the geometric design. There were nine models evaluated throughout this process. Factor of safety calculation was determined with the General Limit Equilibrium analysis method given the Hoek-Brown failure criterion. Table 3.3.1 notes the failure criterion variable with respected input value.

Table 3.3.1: Hoek-Brown variable inputs

\begin{tabular}{|c|c|}
\hline \multicolumn{2}{|c|}{ Hoek-Brown Failure Criterion } \\
\hline Variable & Input Value \\
\hline Unit Weight (lb./ft ${ }^{3}$ ) & 140 \\
\hline Unconfined Compressive Strength (KSF) & 1500.0 \\
\hline Geological Strength Index & 40 \\
\hline Rock Mass Index & 5 \\
\hline Disturbance Factor & 1 \\
\hline
\end{tabular}

Table 3.3.2 contains the back slope angle with the resulting factor of safety obtained through the analysis. Figure 3.3.1 illustrates a graphical representation of the data so the inflection point of the analysis can be seen.

Table 3.3.2: Factor of Safety Response vs. Back Slope Angle

\begin{tabular}{|c|c|}
\hline \multicolumn{2}{|c|}{ SVSlope $^{\circledR}$ : Factor of Safety vs. Back Slope Angle Results } \\
\hline Back Slope Angle $^{\circ}$ & Factor of Safety \\
\hline $10^{\circ}$ & 18.050 \\
\hline $20^{\circ}$ & 11.719 \\
\hline $30^{\circ}$ & 9.166 \\
\hline $40^{\circ}$ & 3.577 \\
\hline $50^{\circ}$ & 3.718 \\
\hline $60^{\circ}$ & 1.627 \\
\hline $70^{\circ}$ & 4.105 \\
\hline $80^{\circ}$ & 4.585 \\
\hline $90^{\circ}$ & 132.356 \\
\hline
\end{tabular}




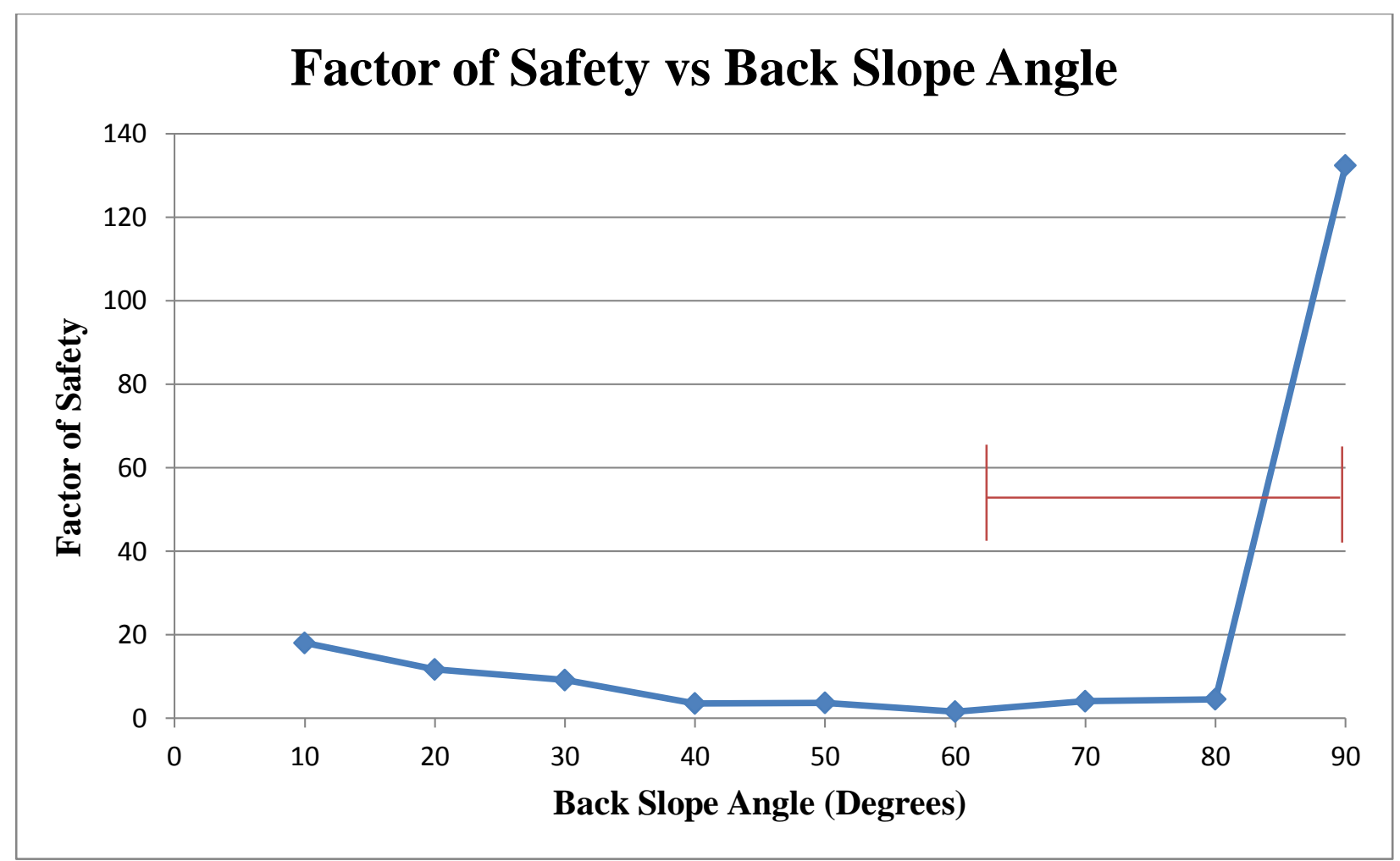

Figure 3.3.1: Factor of Safety vs. Back Slope Angle graphical response

Completion of the back slope assessment the results followed the same response of the design table outputs. Through the analysis the main inflection point or initiating factor of safety increase seems to occur around $60^{\circ}$. This increase in factor of safety is believed to be attributed to multiple aspects; internal modeling calculations and the theoretical basis of the General Limit Equilibrium method. The bracket on the graph encompasses the points in which a constant increase in factor of safety was seen.

Through the stability analysis a fully developed failure plane was seen in each of the cases, deeming the run acceptable and negating the horizontal material quantities and issue. The interpretation of the factor of safety causation based on the General Limit Equilibrium is believed to stem from the basis of the criterion and the calculability of a factor of safety based about a point of rotation. The General Limit Equilibrium method calculates a factor of safety that encompasses the driving force vectors in addition to a summation of moments about a rotation. As the beta angle increases it decreases the horizontal forces which aid in the calculation of the moments, and is driven more so by the vertical forces. The diminishing moments thus allows for a factor of safety to be force driven, which is direct response of material strength and forces it can withstand. This resulting data tends to indicate that the convergence of the factor of safety calculation stems from within the programs computational power. Excavation would expose rock strata that exhibit highly variable rates of weathering both vertically and horizontally due to discontinuous strata. This condition made it impractical to consider employing different cut slope angles as a function of rock type (Kutschke, 2013). 
Figure 3.1.2 shows a screen shot obtained from the modeling outcome illustrating the force and stress distribution on slices of two different analyses.
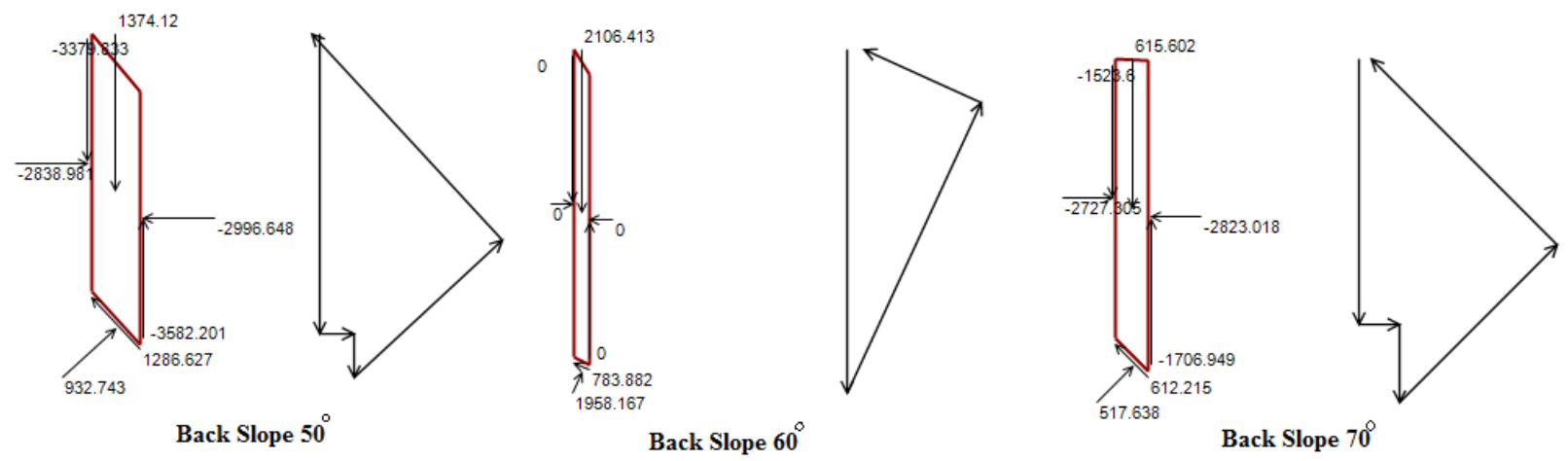

Figure 3.1.2: Slice information from models $50^{\circ}, 60^{\circ}, 70^{\circ}$

In conclusion the modeling outputs are accurate in regards to analysis methods and failure criterion with respect to a mathematical based approach; geological anomalies may in fact result with a different response given material composition and competency. 


\subsection{FIELD SITE INVESTIGATIONS}

During this research two different geological formations were assessed to evaluate competent rock strata and also a weaker, less desirable material. Throughout meetings and discussion with the WVDOH, two sites were selected; U.S. Route 121: Coalfield's Expressway located in the southern WV and U.S. Route 48: Corridor H located in the eastern panhandle. Figure 4.1 illustrates the location of the two sites investigated throughout this research.

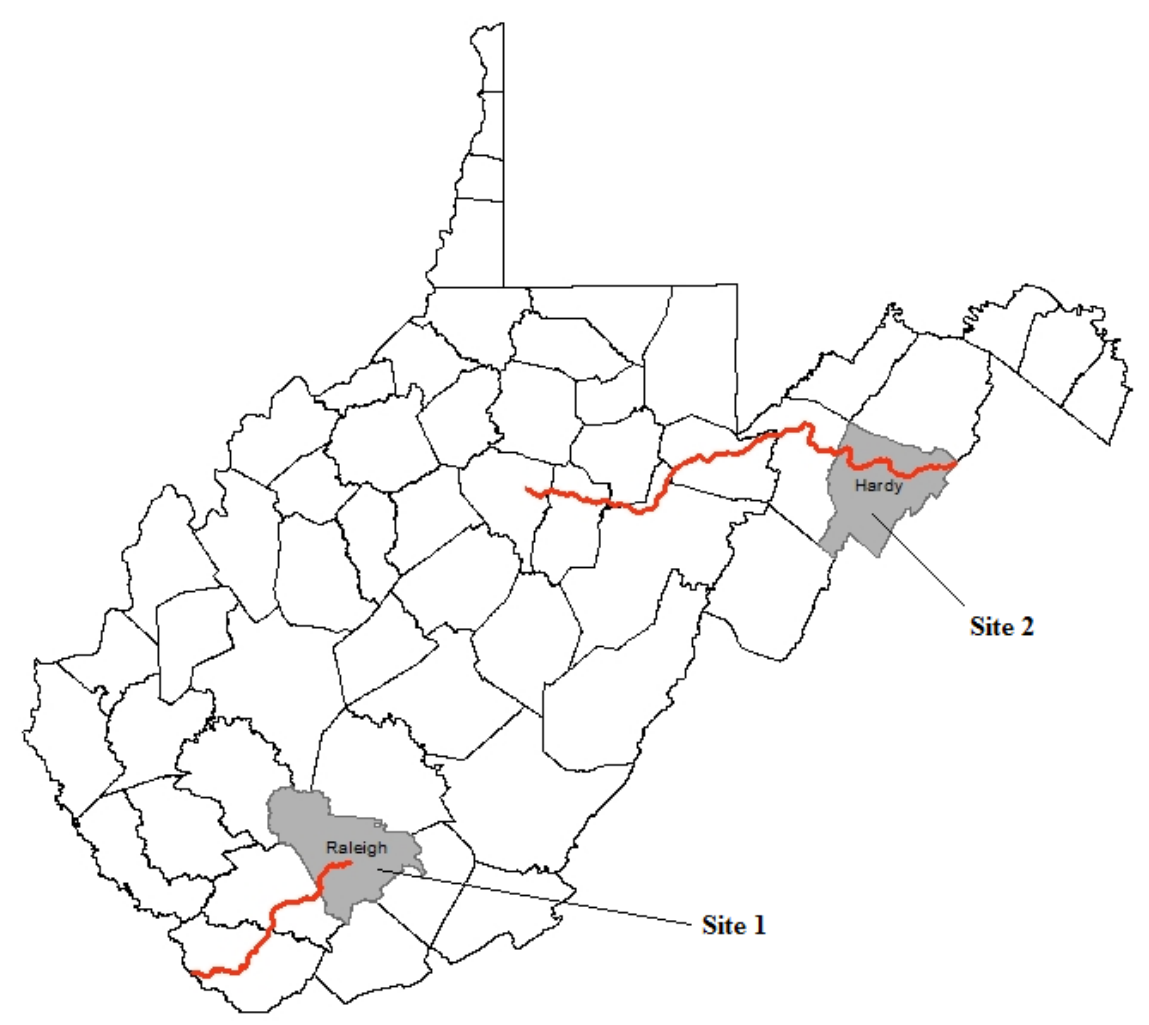

Figure 4.1: Field Site Location (Idleman, 2014)

\subsection{Site 1: Route 121 - Coalfields Expressway: Sophia, West Virginia}

The site evaluation on Route 121 in Raleigh County was conducted on 21 August 2013. The purpose of the visit was to evaluate the current performance of the bench cut profiles along Route 121, post construction prior to being open to the public. Route 121 will be a connector route from near Beckley, WV to Pound, VA. The construction on this route is fairly new, with the oldest portion (not open to the public) being completed within the last 8 years. This portion of the state is very mountainous and required various land cut and fills for the construction of the roadway. 
The field research team from West Virginia University measured slopes to ensure accuracy of slope geometry in comparison with the design plans. The study slope that was selected was found at station $5652+00$ and was one of the larger slopes on the site, with a total height approximately $370 \mathrm{ft}$. Due to the magnitude of the profile selected, only one slope was able to be assessed during this site visit. The team was able to access the entire slope and take geometric measurements and record geological zones. The geological observation gathered regarding the slope showed the lack of competent material. The material present was highly fractured and eroding at an aggressive rate. There were two main geological formations one of sandstone and the other siltstone. The layers of sandstone and siltstone were sporadic throughout, with an occasional intermittent layer of coal. Sandstone is usually a very competent material, however this formation was extremely fractured which was leading to large blocky rock fall events. Most of the fallen sandstone was cobble sized, with the largest recorded piece around three feet in diameter. Figure 4.1.1 and 4.1.2 are photographs obtained during the field exploration.

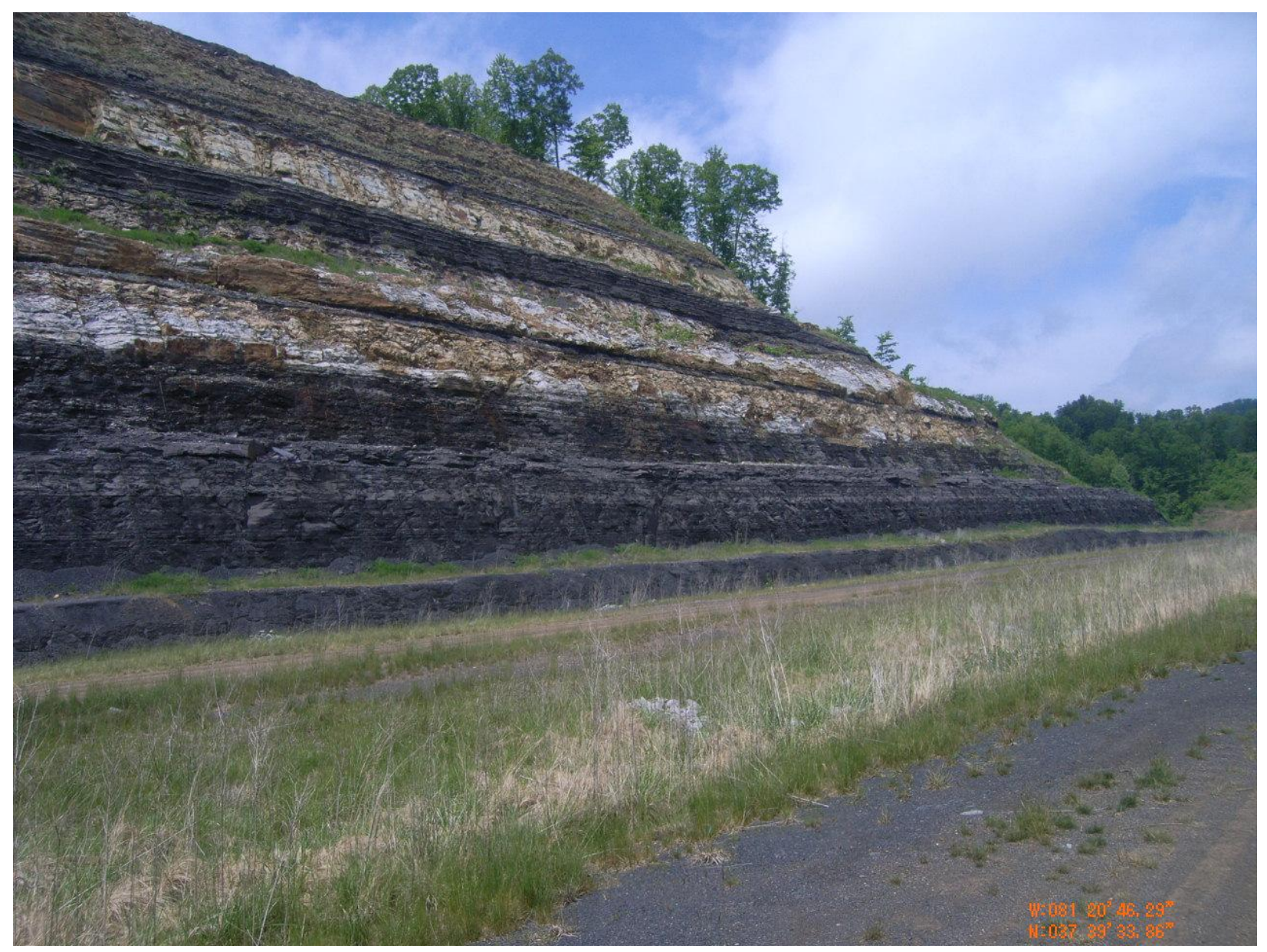

Figure 4.1.1: Slope evaluated on U.S. Route 121 


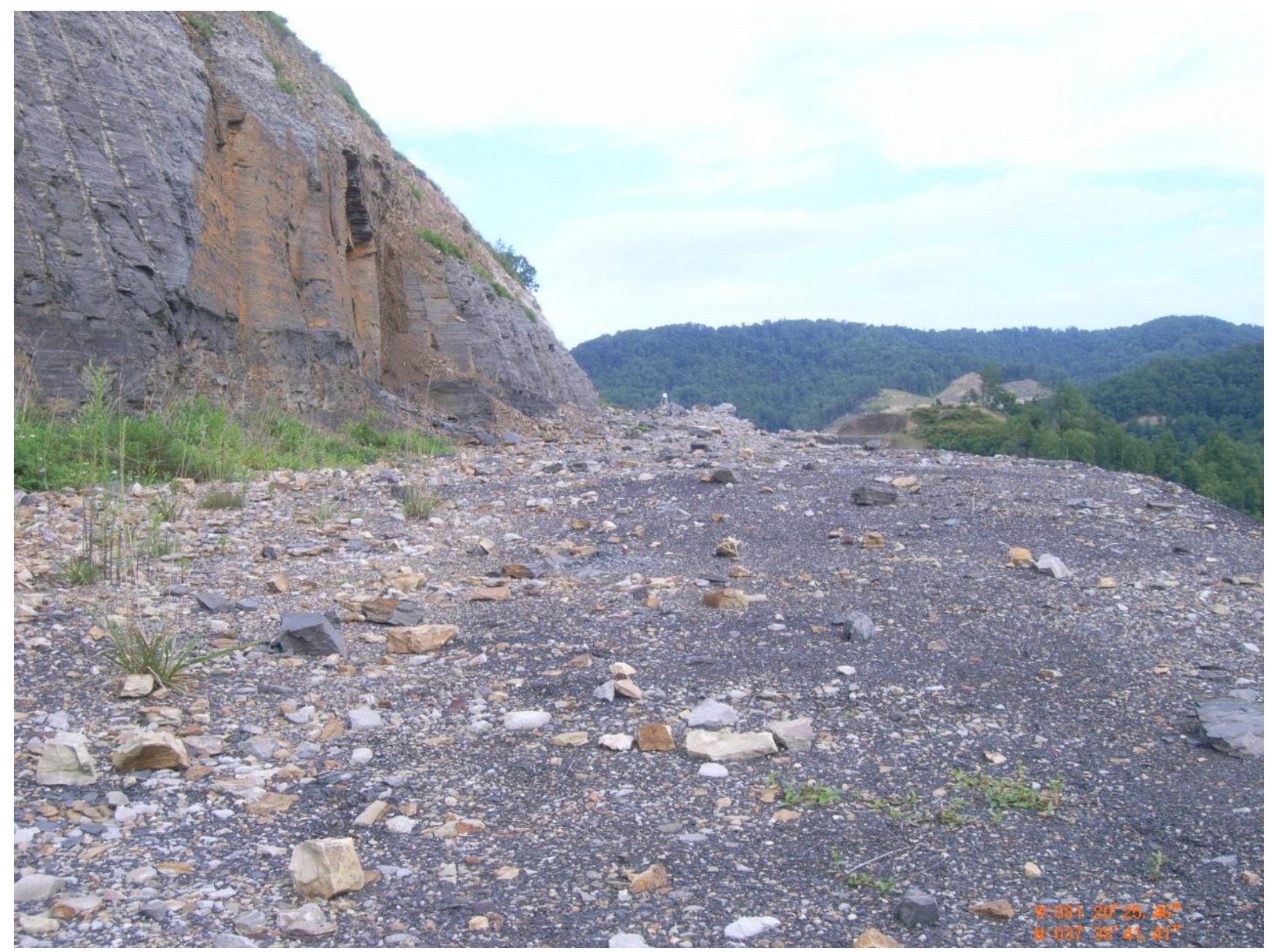

Figure 4.1.2: Accumulation of fallen rock debris

The siltstone showed more severe signs of weathering than the sandstone. The siltstone was very friable and highly erodible. The frequency of falling siltstone was so high that it happened as the team was on site evaluating the slope and continued throughout the duration of the visit. Large piles of accumulated siltstone material could be found on all the benches, at the interface of the back slope and bench. The average recorded material was found to be gravel to sand sized particle ( 0.01 to $2.5 \mathrm{inch})$. There were some instances of fallen siltstone debris reaching two feet in diameter. With the majority of the material throughout the slope being highly fractured, it has left the slope very susceptible to aggressive raveling of material and further detrimental rock fall events. There was an elevated catchment bench present at the toe of the slope (referred to as a sighting bench by West Virginia Department of Highways), close to the proposed roadway surface that could pose a threat to roadway users with the current slope behavior.

The slope stability modeling conducted on the Coalfields expressway would result in ten individual models to establish factor of safety ranges. Ranges in the factor of safety are calculated using the material input parameters, a maximum and minimum strength values were input into the program to allow for best and worst case design scenarios. Table 4.1.1 presents a breakdown of the individual models required in the analysis of Coalfield's Expressway. 
Table 4.1.1: Models to be analyzed on the Coalfield's Expressway site

\begin{tabular}{|c|l|l|}
\hline Model & \multicolumn{2}{|c|}{ Material Strength / Failure Criterion } \\
\hline WVDOH design & Minimum - Hoek-Brown & Maximum - Hoek-Brown \\
\hline As-Built & Minimum - Hoek-Brown & Maximum - Hoek-Brown \\
\hline WVDOH design & Mohr-Coulomb \\
\hline As-Built & Mohr-Coulomb \\
\hline Re-designed Profile & 50 percent of maximum value Strength Value - Trial 1 \\
\hline Re-designed Profile & 50 percent of maximum value Strength Value - Trial 2 \\
\hline Re-designed Profile & 50 percent of maximum value Strength Value - Trial 3 \\
\hline Re-designed Profile & 50 percent of maximum value Strength Value - Trial 4 \\
\hline
\end{tabular}

The WVDOH design model was constructed using the design plan, containing the geometry and borehole log locations. This allowed for model construction and assessment for the designed factors of safety with the given ranges in material strength. The importance of modeling the design profile is to illustrate any alteration that may be present from the field condition. Field condition models were constructed entirely with the geometric data collected on the field visit. The difference between the WVDOH design geometry and the field collected data was quite substantial, and was seen in final data output results. Depicted in Table 4.1.1.1 and Table 4.1.1.2 two material failure criterions that were assessed throughout the slope stability modeling on Coalfield's Expressway. The Mohr-Coulomb failure criterion is the most commonly used throughout geotechnical analyses. It was important to evaluate this procedure and compare the results to the Hoek-Brown criterion. The Hoek-Brown failure criterion is designed for rock and considers blasting and fracture propagation into the stability analysis. The project focused on rock cut slope using the Hoek-Brown method for consideration.

Documents from West Virginia Department of Highways: Geotechnical Report included borehole logs. The borehole logs included a detailed list of material type, thickness and location on site via construction stationing. Review of the borehole logs concluded the absence of a continuous borehole for the entire depth of the cut slope. It was necessary to match up two borehole logs, by evaluating the geologic formations recorded. The two borehole logs that were recorded and matched were drilled at stations $5652+00$ and 5649+75 a spacing of $225 \mathrm{ft}$. Subsequently some layers had to be removed to establish an approximate master materials log used further in the modeling process. The approximate master borehole log is presented in Table 4.1.2; and included is material type, seem depth, and seem thickness. During the modeling process to meet the scope of this project targeting rock cut slope redesigns the soil layer at the crest of the slope will be treated as a "bedrock" layer. Within SoilVision Systems ${ }^{\mathrm{TM}}$ layers denoted as bedrock are treated and assessed as an impervious zone, meaning no failure planes will exist in this area. The treatment of the soil layer as bed rock allowed for the failure plane to occur in the rock zone. 
Table 4.1.2: Approximate Master Borehole Log

\begin{tabular}{|c|c|c|}
\hline \multicolumn{3}{|c|}{ Approximate Master Borehole Log } \\
\hline Material Type & Depth (ft.) & Layer Thickness (ft.) \\
\hline Soil - Silty Sand with Gravel & $0-5$ & 5.0 \\
\hline Soil - Silty Sand & $5-15$ & 10 \\
\hline Sandstone & $15-22.8$ & 7.8 \\
\hline Siltstone & $22.8-49.0$ & 26.2 \\
\hline Sandstone & $49.0-64.2$ & 15.2 \\
\hline Sandstone & $64.2-91.0$ & 26.8 \\
\hline Siltstone & $91.0-96.0$ & 5.0 \\
\hline Sandstone & $96.0-103.3$ & 7.3 \\
\hline Siltstone & $103.3-104.5$ & 1.2 \\
\hline Sandstone & $104.5-118.0$ & 13.5 \\
\hline Sandstone & $118.0-120.1$ & 2.1 \\
\hline Siltstone & $120.1-121.2$ & 1.1 \\
\hline Siltstone & $121.2-124.0$ & 2.8 \\
\hline Sandstone & $124.0-137.5$ & 13.5 \\
\hline Siltstone & $137.5-170$ & 32.5 \\
\hline *Siltstone & $239.5-262.5$ & 23.0 \\
\hline Sandstone & $262.5-271.5$ & 9.0 \\
\hline Sandstone & $271.5-306.0$ & 34.5 \\
\hline Siltstone & $306.0-334.7$ & 28.7 \\
\hline Sandstone & $334.7-337.7$ & 3.0 \\
\hline Sandstone & $337.7-343.9$ & 6.2 \\
\hline Siltstone & $343.9-348.1$ & 4.2 \\
\hline Siltstone & $349.1-351.2$ & 3.1 \\
\hline Siltstone & $351.2-371.0$ & 19.8 \\
\hline
\end{tabular}

* Layer 16 illustrates a $69.5 \mathrm{ft}$. increase from the previous layer, this was due to the matching of two borehole logs which caused an increase in order maintain the actual slope height 


\subsubsection{Site 1: Coalfield's Expressway: WVDOH Plan Geometry}

The analyzed slope was constructed with a back slope angle of an $\mathrm{H}$ : $\mathrm{V}$ ratio of $3 / 4: 1$ or $53.1^{\circ}$. In accordance with DD-403 the cut slope length between benches should not exceed $50 \mathrm{ft}$.

vertically. The DD-403 guidelines require benches be constructed at a $\mathrm{H}: \mathrm{V}$ ratio of $15: 1$ or $3.8^{\circ}$ away from the slope to mitigate water infiltration. Figure 4.1.1.1 illustrates a screen shot of the constructed slope within the SVSlope ${ }^{\circledR}$ model interface. Materials used to construct the geologic variance illustrated in the Figure 4.1.1.1 are listed in Table 4.1.2.

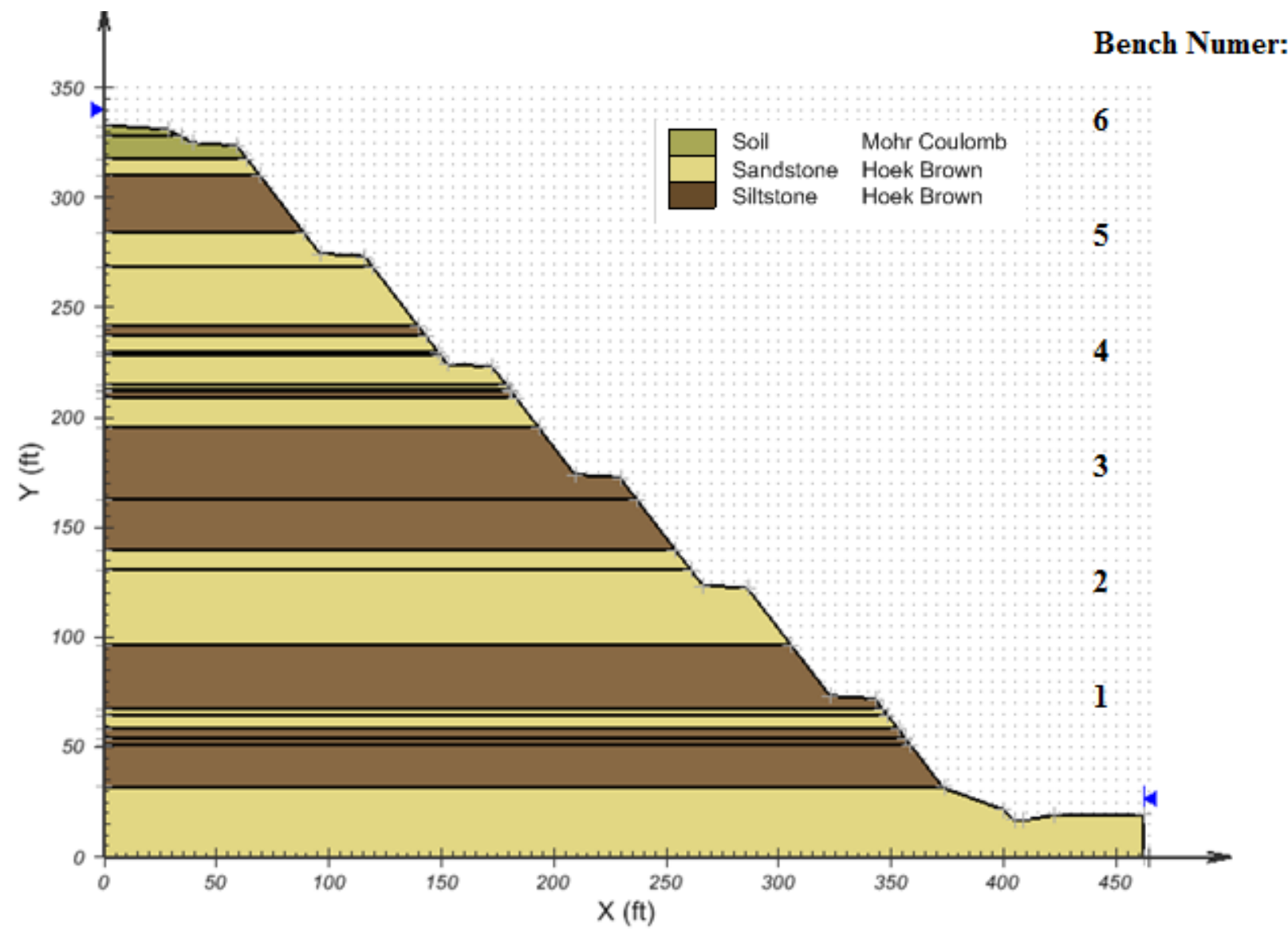

Figure 4.1.1.1: Coalfield's Expressway: WVDOH Plan Geometry

Review of the geotechnical reports identified a lack of information regarding strength parameters which needed to be obtained. The material strength parameters gathered were obtained from published articles and other university studies. Tables 4.1.1.1 and 4.1.1.2 list the material types, parameters (maximum and minimum), GSI, and D factor used in the slope stability analysis. The final data results show the factor of safety determined through the General Limit Equilibrium analysis given the Hoek-Brown and Mohr-Coulomb failure criterion. 
Table 4.1.1.1: Mohr-Coulomb material input parameters (Lin, 2006)

\begin{tabular}{|c|c|c|c|}
\hline Material Type & $\begin{array}{c}\text { Density, } \\
\mathbf{\gamma}\left(\mathbf{l b .} / \mathbf{f t}^{\mathbf{3}}\right)\end{array}$ & Cohesion, c (KSF) & Angle of Friction, $\mathbf{F}^{\circ}$ \\
\hline Siltstone & 137.34 & 1044.272 & 28 \\
\hline Sandstone & 151.08 & 939.845 & 22.50 \\
\hline Soil & \multicolumn{3}{|c|}{ Bedrock } \\
\hline
\end{tabular}

Table 4.1.1.2: Hoek-Brown material input parameters (Sjöberg, 1997) (Zhao, 2010)

\begin{tabular}{|c|c|c|c|}
\hline UC Strength (KSF) & \multicolumn{2}{|c|}{ Minimum } & Maximum \\
\hline Sandstone & \multicolumn{2}{|c|}{417.708} & 3550.523 \\
\hline Siltstone-Mudstone & \multicolumn{2}{|c|}{208.854} & 2088.543 \\
\hline \multirow{2}{*}{ GSI } & Minimum & Maximum & \\
\hline & 23 & 75 & \\
\hline \multirow{2}{*}{$\begin{array}{c}\text { D-Factor } \\
\text { *(values decrease as blasting } \\
\text { improves) }\end{array}$} & $\begin{array}{l}\text { Minimum - } \\
\text { Poor }\end{array}$ & $\begin{array}{l}\text { Maximum - } \\
\text { Good }\end{array}$ & \\
\hline & 1.0 & 0.7 & \\
\hline Mi & Minimum & Maximum & \\
\hline Sandstone & 4.7 & 35.5 & \\
\hline Siltstone & 8.6 & 46.6 & \\
\hline
\end{tabular}

The minimum and maximum values found within the Hoek-Brown allow a range in factor of safety to illustrate the necessity for material testing to determine the most precise data possible, leading to confident rock cut slope design. 


\subsubsection{Site 1: Coalfield's Expressway: WVDOH design Slope Stability Analysis and Results}

The results from the slope stability analysis yielded a range of factors of safety due primarily to material differences. Table 4.1.2.1 and Table 4.1.2.2 present the results from the MohrCoulomb failure criterion and Hoek-Brown failure criterion respectively.

Table 4.1.2.1: Calculated factor of safety with Mohr-Coulomb failure criterion Factor of Safety: Coalfield's Expressway: WVDOH design - Mohr-Coulomb Analysis Method Factor of Safety General Limit Equilibrium 1227.8

Table 4.1.2.2: Calculated factor of safety with Hoek -Brown failure criterion Factor of Safety: Coalfield's Expressway: WVDOH design - Hoek-Brown

\begin{tabular}{|c|c|c|}
\hline \multicolumn{2}{|c|}{ Factor of Safety: Coalfield's Expressway: WVDOH design - Hoek-Brown } \\
\hline Analysis Method & Minimum & Maximum \\
\hline General Limit Equilibrium & 0.962 & 49.76 \\
\hline
\end{tabular}

\subsubsection{Site 1: Discussion}

The Mohr-Coulomb failure criterion yielded a factor of safety 1227.8 and occurs on benches three and four. This value is the lowest factor of safety found during the run of the model, which conducted 1000 trials to assess the slope. The program reports the lowest factor of safety from the analysis in order to allow for a conservative assessment and show worst case scenario. Figure 4.1.3.1 illustrates the proposed failure plane location determined with the Mohr-Coulomb failure criterion. 


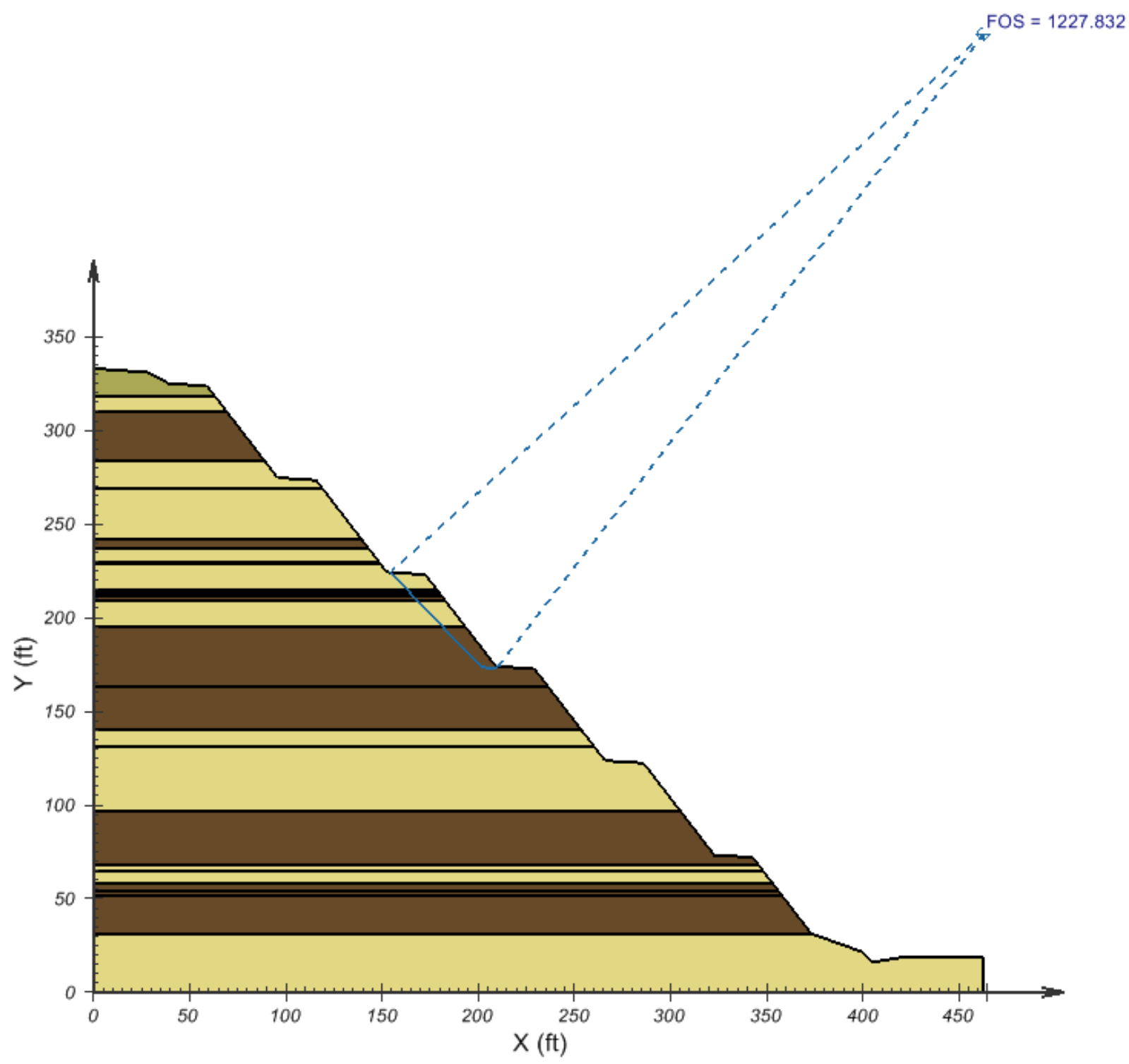

Figure 4.1.3.1: Mohr-Coulomb failure criterion for the WVDOH design model 
Results in factor of safety greatly varied in the slope stability analysis while using the HoekBrown failure criterion. The low material strength inputs yielded a factor of safety less than 1.0, thus deeming the slope unstable against its own weight. The range in the factor of safety calculation illustrates the best and worst case scenarios possible for this slope profile. Figure 4.1.3.2 illustrates an over laid screen shot of the proposed failure plane location given the HoekBrown failure criterion. The failure plane location was in the lower portion of the slope, through various layers of alternating sandstone and siltstone found on benches two and three. The HoekBrown analysis yielded two failure planes partially overlapping one another; this area will be an area of concern on the bench elimination process.

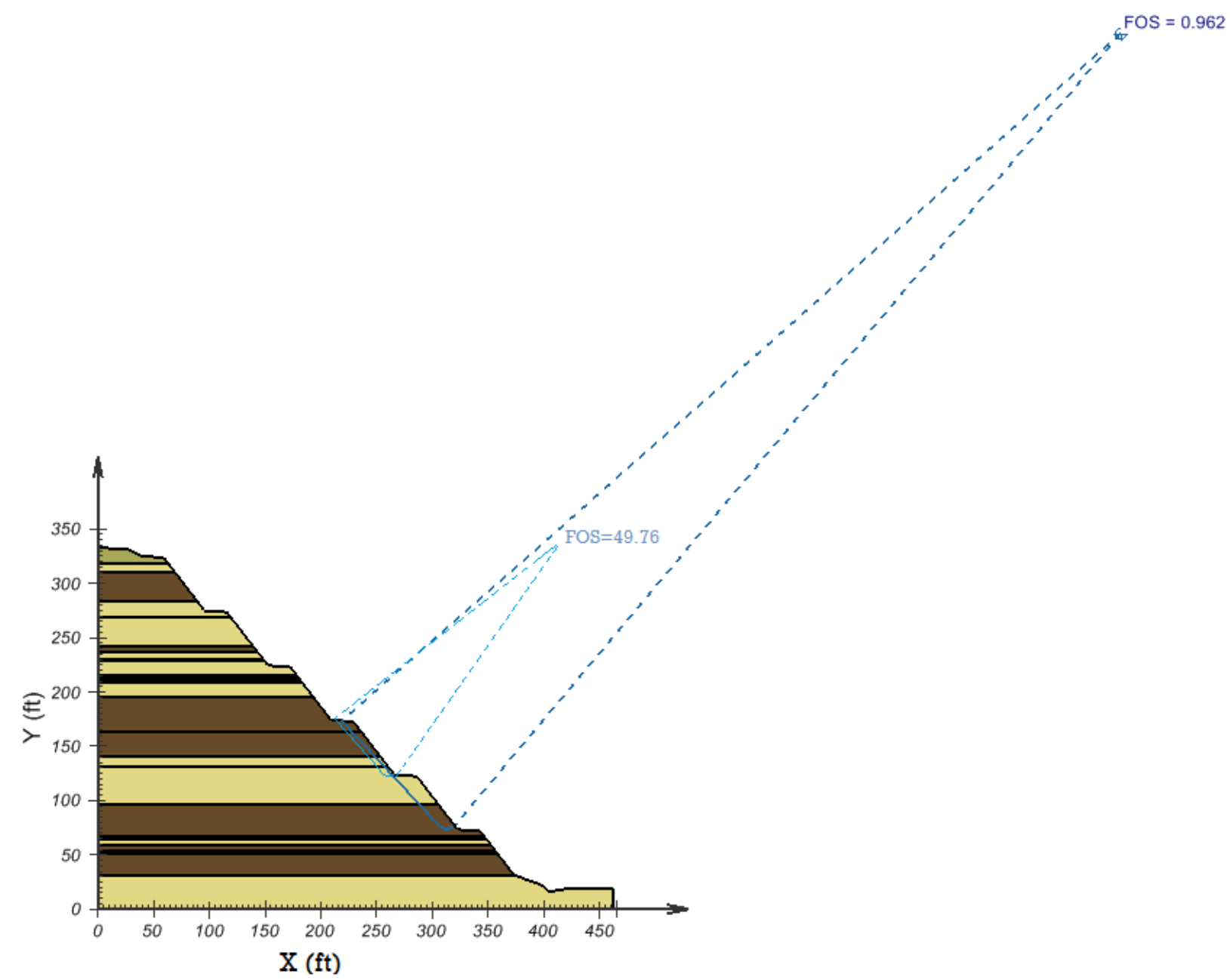

Figure 4.1.3.2: Hoek-Brown failure criterion for the WVDOH design model

It can be concluded on that the factor of safety is this low due solely to the fact in the range of material strength found in published literature. This value seems to be unrealistic due to the stable slope seen in the field it may be assumed that the data range does not adequately represent the material present. A more accurate analysis would have been possible provided site specific material testing would have been conducted. The higher end of the material input strength shows 
a factor of safety greatly exceeding the required factor of safety of 1.25 as stated in DD-403. It is important to note on the range in determined factor of safety. The range presents the importance of material testing on individual site acquired rock from borehole extraction. This range in data illustrates best and worst case scenarios possible.

The great variation in the calculated factor of safety given the material failure criterion can be attributed to the basis of each method. Mohr Coulomb only uses the unit weight of a material, cohesive strength, and the internal angle of friction. Without taking other factors into consideration as the Hoek-Brown analysis does, Mohr-Coulomb analyzes the material an extremely strong soil. The Hoek-Brown criterion takes into consideration the unconfined compressive strength and unit weight, the part that separates it from Mohr-Coulomb is the ability to assess the geological strength index, blasting and fracture propagation as well as rock mass constant of the material. As seen in the sensitivity analysis these parameters have a great effect on the stability of a slope profile. It was decided that the Hoek-Brown failure criterion would be the preferred method to be used throughout further modeling due to the nature and design being focused toward rock. 


\subsubsection{Site 1: Coalfield's Expressway: As-Built Geometry}

This section is a discussion on the as-built slope and includes an assessment to the WVDOH designed slope. Data collection on the as-built site included geometric measurements (i.e. back slope lengths, bench widths, and back slope angles). Back slope angles were attained with the use of a clinometer, geometric heights and lengths were attained with a $200 \mathrm{ft}$. tape measure. In addition a check sheet was filled out to note signs of erosion, fallen debris, as well as any other pertinent information.

The importance of the data collection was to recreate the model as precise as possible to current field conditions. Once the model was created there were obvious differences between the field measurement and WVDOH design. The difference in the two models included back slope angles and bench widths. The back slope angle showed signs of the largest difference between the two. As previously discussed the back slope angles were designed at a $\mathrm{H}: \mathrm{V}$ ratio of $3 / 4: 1$ or $53.1^{\circ}$, the average angle measured in the field was $65^{\circ}$.

The approximate master borehole log used in the WVDOH design analysis was also used to populate the geologic variance throughout this analysis. Figure 4.1.4.1 provides a visual representation of the field measurement profile, in addition a color-code legend has been include to denote material type. 


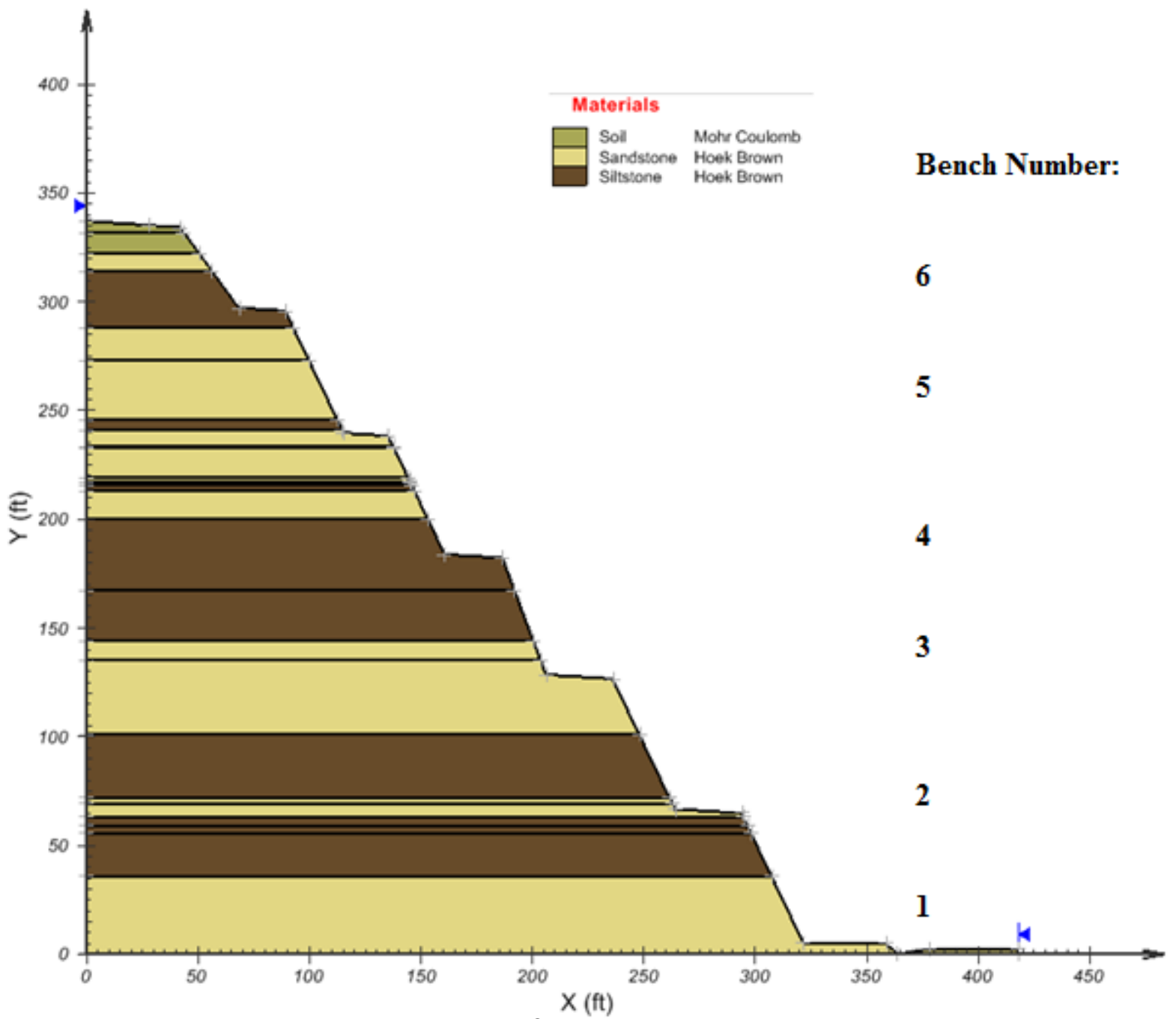

Figure 4.1.4.1: As-Built slope in SVSlope ${ }^{\circledR}$ 


\subsubsection{Site 1: Coalfield's Expressway: As-Built Slope Stability Analysis}

The results from the as-built slope stability analysis yielded varying factor of safety results primarily from the geometric differences between the models. The analytical procedure was identical to the WVDOH design with regards to material failure criterion as well as the analysis mode. Table 4.1.5.1 and Table 4.1.5.2 present the results from the Mohr-Coulomb failure criterion and Hoek-Brown failure criterion respectively.

Table 4.1.5.1: Calculated factor of safety with Mohr-Coulomb failure criterion Factor of Safety: Coalfield's Expressway: WVDOH design - Mohr-Coulomb \begin{tabular}{l|l} 
Analysis Method & Factor of Safety \\
\hline
\end{tabular}

\begin{tabular}{l|r} 
General Limit Equilibrium & 2207.2 \\
\hline
\end{tabular}

Table 4.1.5.2: Calculated factor of safety with Hoek -Brown failure criterion Factor of Safety: Coalfield's Expressway: WVDOH design - Hoek-Brown

\begin{tabular}{|c|c|c|}
\hline \multicolumn{3}{|c|}{ Factor of Safety: Coalfield's Expressway: WVDOH design - Hoek-BrowI } \\
\hline Analysis Method & Low & High \\
\hline General Limit Equilibrium & 0.802 & 36.83 \\
\hline
\end{tabular}

\subsubsection{Site 1: Discussion}

The Mohr-Coulomb analysis resulted in a factor of safety of 2207.2 located at bench 1. This factor of safety is substantially higher than the one previously calculated in the WVDOH design model. It is believed to be higher in the case of the Mohr-Coulomb due to the fact of the angles on the back slope. The steeper angle will create less driving force, increasing the overall factor of safety. Figure 4.1.6.1 depicts the proposed failure plane location given the Mohr-Coulomb failure criterion. 


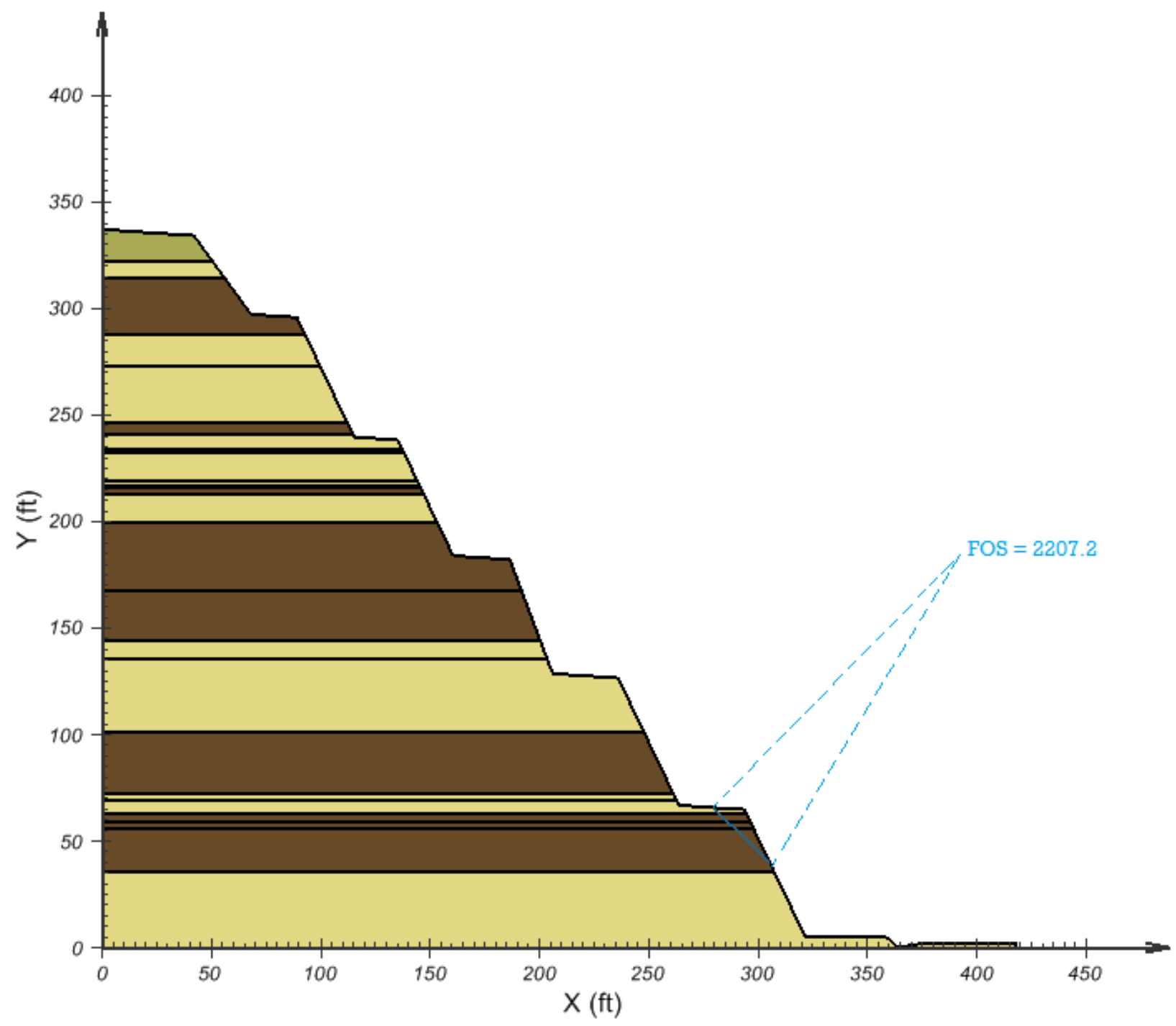

Figure 4.1.6.1: Mohr-Coulomb failure criterion for the As-Built Profile

Keeping all parameters constant other than the geometric design does not adequately depict the data as one would expect. The Hoek-Brown is a more idealistic representation to rock cut slope stability analysis and is the preferred method. The resulting data from the Hoek-Brown failure criterion analysis are more in line with expected values. The analysis was performed identically to the WVDOH design profile other than the geometric design. Factor of safety results showed lower values, this is to be expected with a steeper slope profile. Similar to the WVDOH design profile, the low material strength model yielded an unsatisfactory result; this is once again due to the wide range in material values. The calculated factor of safety range shows the best and worst case scenarios plausible for this slope profile. It can be stated that this value does not adequately represent the current status of the slope, rather just addresses the instability possibility. The purpose of these models was to illustrate the necessity for advanced material testing to safely design cut slopes which will aid in the design process leading to bench reduction alternatives. 
Figure 4.1.6.2 illustrates an overlaid screen shot of the proposed failure planes determined with the Hoek-Brown failure criterion.

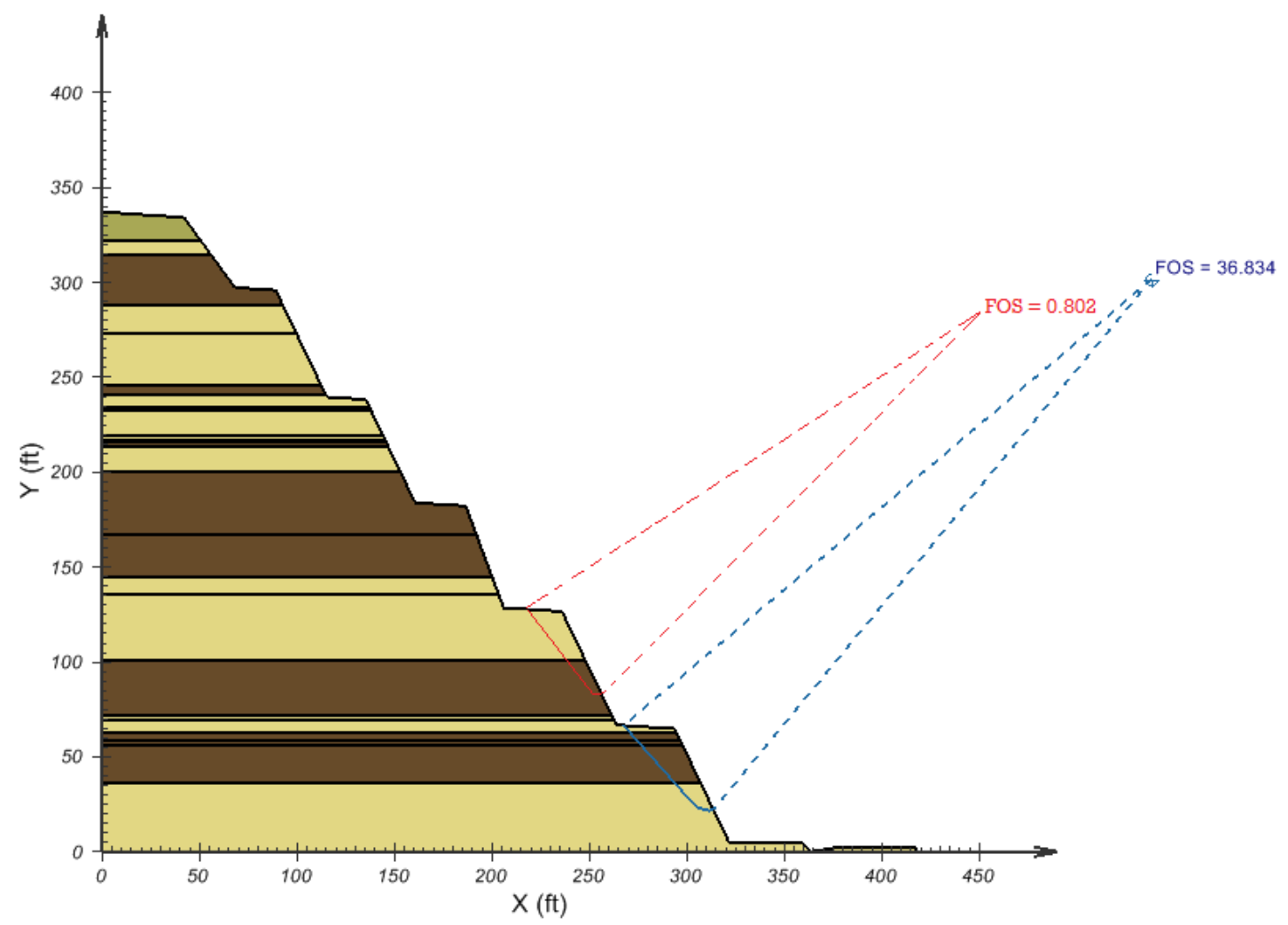

Figure 4.1.6.2: Hoek-Brown failure criterion for the As-Built Profile 


\subsubsection{Site 1: Summary and Comparison: Coalfields Expressway}

The slope stability assessment showed conclusive evidence was found relating the WVDOH design profile to the as-built profile which yielded different stability results. Through the modeling the importance of material testing to achieve site specific data can be seen through the wide range in possible stability outcome. The stability of the slope in field is over 1.0; this can be stated since the slope is standing in the field. A discrete factor of safety cannot be given to this slope until further information is obtained. Site specific data for unconfined compressive strength was needed to give the slope a distinct rating. Table 4.1.7.1 and Table 4.1.7.2 will list the calculated factors of safety through the modeling and the difference in outcomes as a percentage.

Table 4.1.7.1: Summary table of stability results given the Hoek-Brown failure criterion

\begin{tabular}{|c|c|c|c|c|c|c|}
\hline \multicolumn{7}{|c|}{ Factor of Safety: Coalfield's Expressway } \\
\hline & \multicolumn{2}{|c|}{$\begin{array}{l}\text { WVDOH design } \\
\text { 0.75H:1V }\left(53.1^{\circ}\right)\end{array}$} & \multicolumn{2}{|c|}{$\begin{array}{c}\text { As-Built } \\
0.5 \mathrm{H}: 1 \mathrm{~V}\left(65^{\circ}\right)\end{array}$} & \multicolumn{2}{|c|}{ F.O.S Difference } \\
\hline Analysis Method & Minimum & Maximum & Minimum & Maximum & Min-Min & Max-Max \\
\hline $\begin{array}{c}\text { General Limit } \\
\text { Equilibrium }\end{array}$ & 0.962 & 49.76 & 0.802 & 36.83 & $16.6 \%$ & $25.9 \%$ \\
\hline
\end{tabular}

Table 4.1.7.2: Summary table of stability results given the Mohr-Coulomb failure criterion

\begin{tabular}{|c|c|c|c|}
\hline \multicolumn{4}{|c|}{ Factor of Safety: Coalfield's Expressway } \\
\hline Analysis Method & $\begin{array}{c}\text { WVDOH design } \\
0.75 \mathrm{H}: 1 \mathrm{~V}\left(53.1^{\circ}\right)\end{array}$ & $\begin{array}{c}\text { As-Built } \\
0.5 \mathrm{H}: 1 \mathrm{~V}\left(65^{\circ}\right)\end{array}$ & F.O.S Difference \\
\hline $\begin{array}{c}\text { General Limit } \\
\text { Equilibrium }\end{array}$ & 1227.8 & 2207.2 & $79.7 \%$ \\
\hline
\end{tabular}

- In conclusion, a direct result in the potential hazard for the slope that can be linked to the General Limit Equilibrium analysis method and the difference in the factor of safety calculated during the analyses based upon material input values. The failure criterion has a substantial effect on the factor of safety in regards to the magnitude and range. With a large magnitude in the factor of safety calculation found with the Hoek-Brown criterion, it illustrates the necessity for site specific testing to ensure the safest design possible.

- The factor of safety behavior with the decrease from the WVDOH design and As-built followed the analysis with respect to back slope and corresponding factor of safety as seen in Figure 3.3.1. 
- The large effect on the factor of safety is due to the influence on the geometry. The factor of safety calculated in the Mohr-Coulomb is substantially higher than that of the Hoek-Brown results; this is believed to be a direct result of the theory of the criterion.

- When rock is assessed with the Mohr-Coulomb failure criterion the rock is treated as extremely strong soil, which provides inaccurate results. The Hoek-Brown failure criterion is the preferred method due to the nature of the criterion and its intended use on rock slopes. The method will be used from this point on, and throughout all the slope stability evaluation processes.

\subsection{Site 1: Coalfields Expressway: Bench Reduction Slope Design}

The scope of this research is to assess the opportunity to alter the current cut slope design practice with the intent to meet or exceed the previously determined factor of safety with the removal of benches. The redesigned slope will be directly compared to the initial slope assessment using the field measured geometry and the new material input value for strength, the behavior of the factor of safety notes the behavior of bench removal. The bench reduction ideology was based upon findings from literature review as well as physical recordings taken from field observations. Engineering judgment on bench reduction should include but not limited to the consideration of the following key points and Table 4.2.1. Figure 4.2.1 provides a flow chart in which the analysis procedure followed.

- If a thick, massive, stable erosion resistant layer rests above a thin, weak, erodible layer, then a bench may not be required in that location unless the bedding plane of a massive layer will induce slope instability leading to failure.

- If the layer or layers above a significantly thick erodible layer are not massive and do not appear to have the capacity to withstand the cantilever stresses that may be included by erosion of the erodible layer below it, then a bench should be included at that location.

- Erosion will occur in highly erodible sedimentary rock layers when exposed to surface climate. It is impractical to vary slope angles to mitigate the problem. Benching should be used to attenuate the undercutting issues caused by the erosion of these layers.

- Benching to reduce undercutting of rocks should be included at any location where a significant thick erodible layer exists which will induce rock fall.

- Surface runoff should be routed away from the face of the slope as quickly as possible by including drainage above and on the sides of each cut slope.

- Surface runoff should be routed away from the face of the cut slope by sloping benches away from the face. The benches should be sloped to route surface runoff to the ditches on the sides of the slope.

- If the strata found in the boring $\log s$ are sloped to benefit the drainage of the slope, then the drainage structure for surface runoff should be designed to follow the slope of the strata. 
- A back slope at the crest of a slope is recommended at sites where it is practical to reduce surface runoff on the face of the slope.

- In some scenarios when significant property damage or human life is at risk, alternatives such as grouting, concreting, or netting may be considered to reduce the erosion rate on highly erodible layers

Table 4.2.1: Bench Alteration Criteria based upon research findings and observations

\begin{tabular}{|c|c|}
\hline \multicolumn{2}{|c|}{ Bench Assessment Criteria } \\
\hline Modeling Findings & Physical Observations \\
\hline Proposed failure plane location & Excessive rock fall accumulation \\
\hline SVSlope $^{\circledR}-$ Factor of Safety & Excessive erosion \\
\hline CRSP - Rating & Competency of geology \\
\hline
\end{tabular}




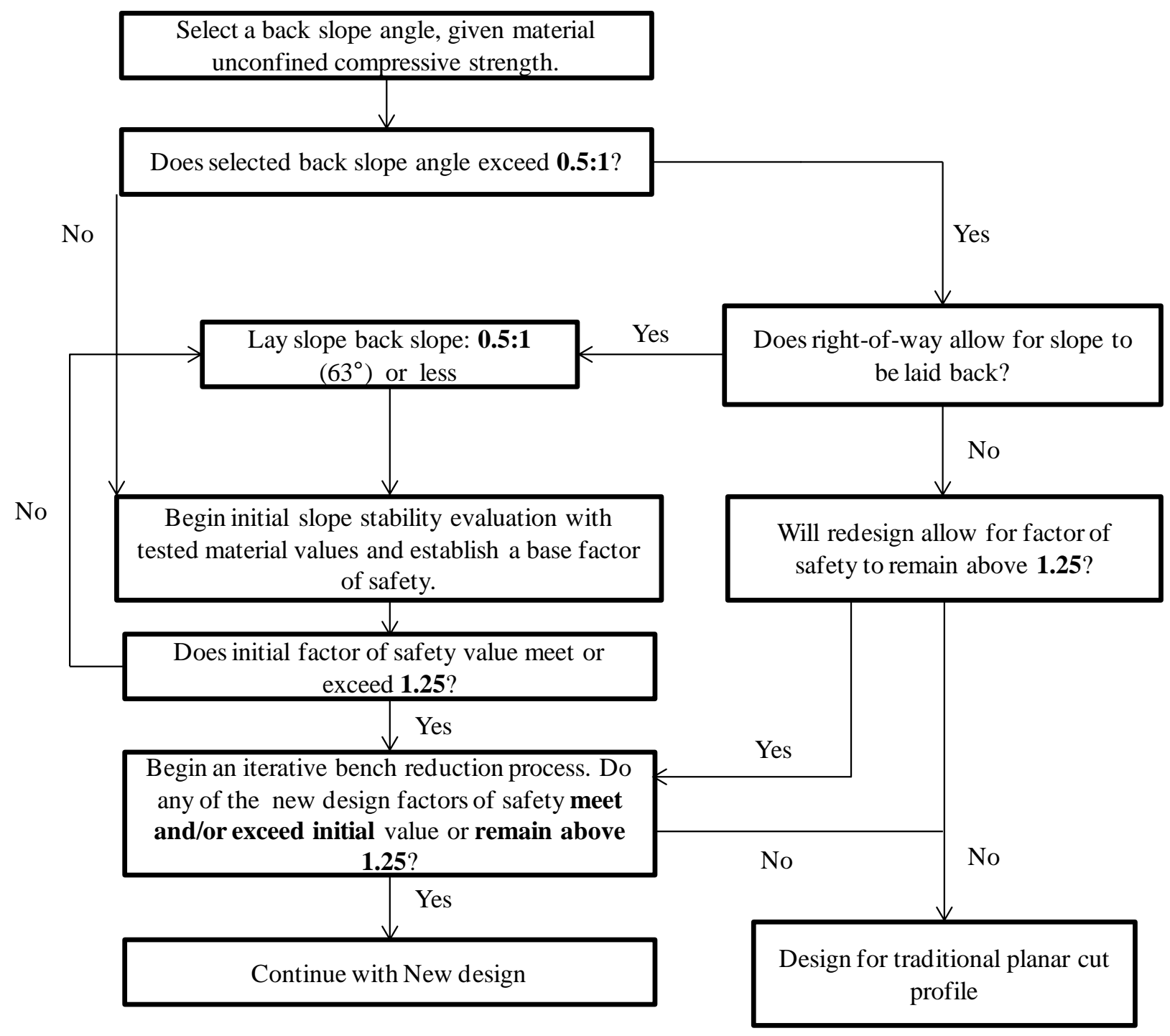

Figure 4.2.1: Flow chart for bench reduction procedure

In the process of the new slope design, the as-built slope profile was analyzed due to the fact it illustrated the lowest factors of safety during the modeling analysis with the Hoek-Brown failure criterion. It was determined that the location for redesign consideration would be the area between the first and sixth (bottom to top) bench illustrated within the box on the slope profile see Figure 4.2.2. The new slope design process will be a three step process:

- Initial slope stability models used conservative values for Hoek-Brown criteria, with the exception of the unconfined compressive strength. The input value was the mid-point of the data set or 50 percent of maximum value

- The suggested failure plane will be assessed and bench reduction will begin based upon the location and factor of safety calculation

- An iterative design process allowed models to be built and analyzed in accordance with the previously discussed bench alteration criteria [Figure 4.2.1] 
- Final comparison and conclusion were drawn with the factor of safety response in relation to the bench reduction in regards to bench reduction considerations

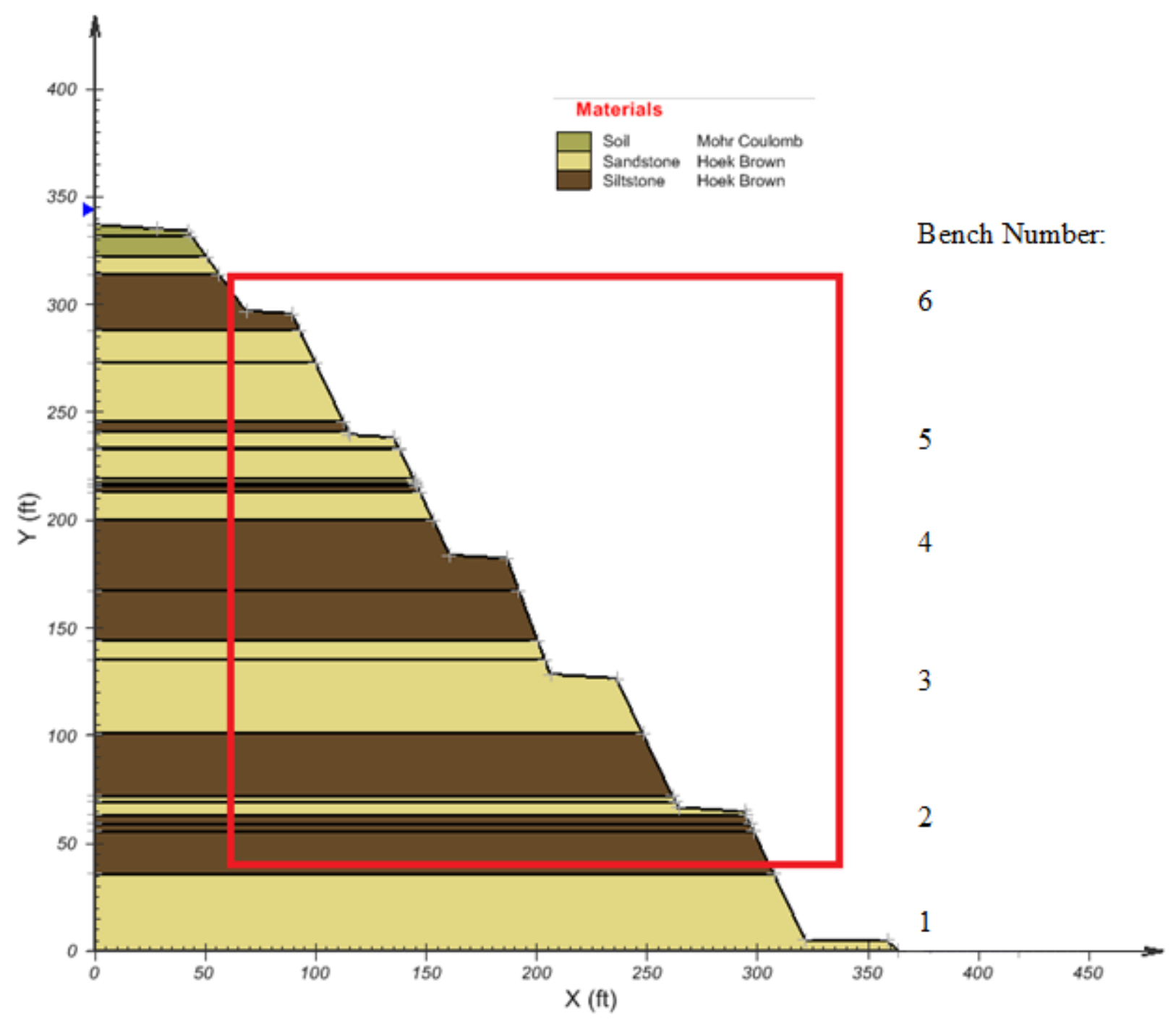

Figure 4.2.2: Coalfield's Expressway As-Built screen shot with the proposed area for new slope configuration

The goal for the slope design will be to meet or exceed the initial factor of safety for a stable slope design. The analysis of the slope redesign included the assessment of four slope profiles. The material failure criterion will be input as the Hoek-Brown method given the middle strength material input; all other values will be kept constant on the low end to ensure a more conservative design. The evaluation of the 50 percent of maximum value material strength value is the only one necessary for evaluation due to the fact it will allow for an acceptable initial factor of safety and show the response with bench removal throughout the designs. This method was selected in order to show percent increases or decreases in factor of safety which are 
determined via overall factor of safety results. Upon the completion of the design and evaluation the model was constructed in the modeling software Colorado Rockfall Simulation Program (CRSP) which assessed the rock fall propagation and traveling distance in the case of a computer-generated rock fall event.

\subsubsection{Site 1: Coalfield's Expressway Field Measurements: Initial Slope Assessment}

The redesign process started with the base evaluation of the various input parameters to assess the current slope stability as well to obtain a factor of safety to compare the new slope profiles against. As previously stated input parameters were input on the low end to ensure a conservative approach in the slope design. It should be noted that the geological strength index value was input from direct field observations obtained during a site exploration. The parameters that are listed in the following table were held constant throughout the duration of the Coalfield's Expressway modeling assessment. Table 4.2.1.1 includes the parameters and the values used in the modeling analysis.

Table 4.2.1.1: Hoek-Brown Input Parameters (Sjöberg, 1997) (Zhao, 2010)

\begin{tabular}{|c|c|c|}
\hline \multicolumn{2}{|c|}{ Coalfield's Expressway: Hoek-Brown Input Parameters } \\
\hline Parameter & Sandstone & Siltstone-Mudstone \\
\hline $\begin{array}{c}\text { Unconfined Compressive Strength } \\
\text { (KSF) @ 50\% of maximum UCS }\end{array}$ & 1984.116 & 1148.698 \\
\hline Disturbance Factor & 1.0 & 1.0 \\
\hline Geological Strength Index & 23 & 23 \\
\hline Rock Mass & 5 & 9 \\
\hline Unit Weight (lb./ft ${ }^{3}$ ) & 151.08 & 137.34 \\
\hline
\end{tabular}

The initial slope assessment geometry is identical to the as-built profile. The result for the initial slope assessment is listed in 4.2.1.2. A screenshot has been included in the Figure 4.2.1.1 to show the proposed failure plane location.

Table 4.2.1.2: Coalfield's Expressway Field Measurements: Initial Slope Assessment stability analysis

\begin{tabular}{|c|c|}
\hline \multicolumn{2}{|c|}{ Coalfield's Expressway Field Measurements: Initial Slope Assessment } \\
\hline Analysis Method & Factor of Safety \\
\hline General Limit Equilibrium & 1.254 \\
\hline
\end{tabular}




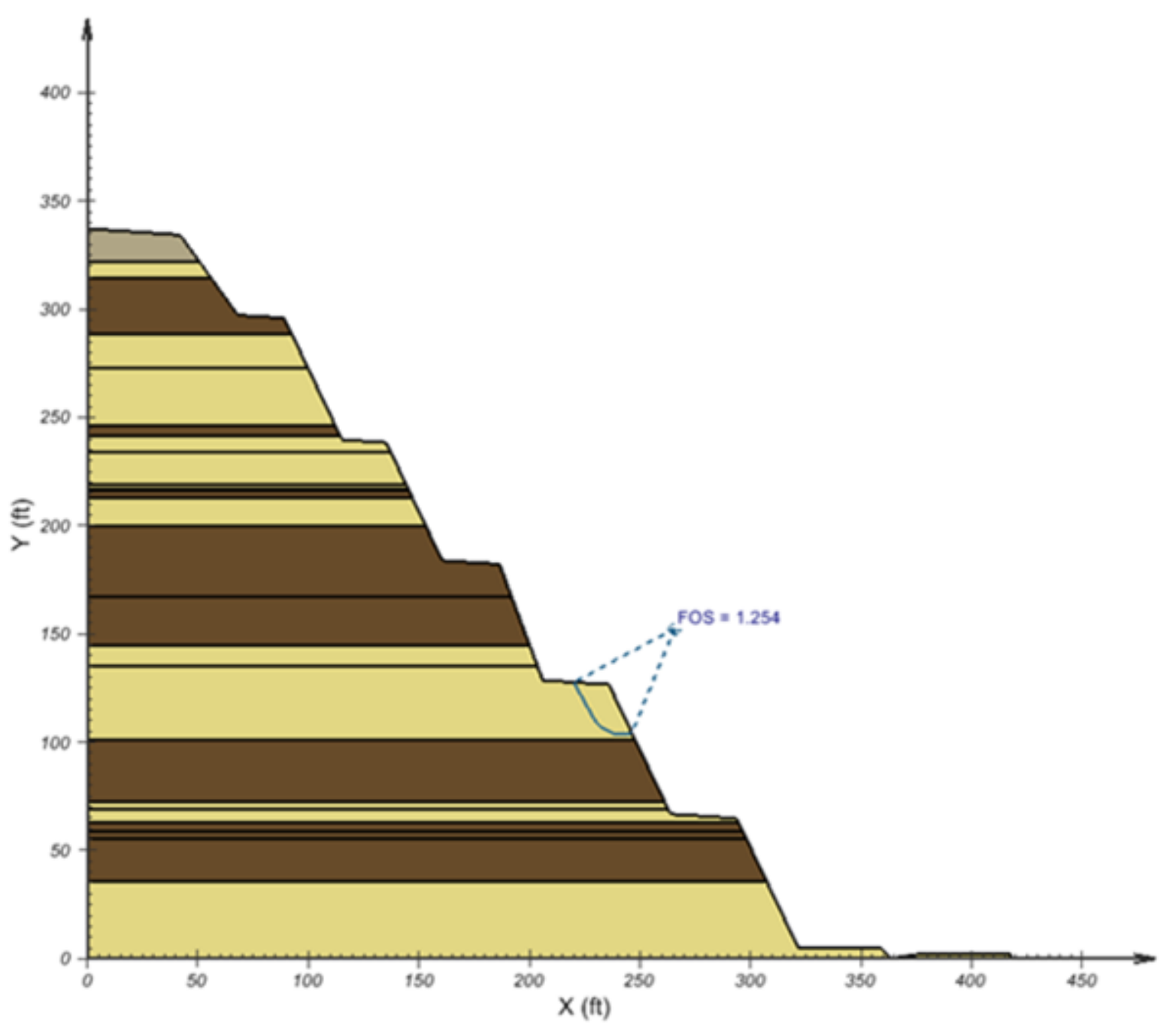

Figure 4.2.1.1: Initial Slope Assessment 


\subsubsection{Site 1: Coalfield's Expressway Field Measurements: New Slope Design Trial 1}

The analysis of this model was based upon the removal of the third bench see Figure 4.2.2.1 for visual representation, which was located directly in a large siltstone layer. This area was selected for various reasons which included empirical reasoning through modeling evaluation and physical data recordings and observations. The third back slope portion, located directly above the second bench was primarily comprised of siltstone material with a negligible sandstone area at the base of the slope.

During the field visit of this site extensive material accumulation was present on this bench and can be seen in the Figure A1-2 located in Appendix 1. Material that was found on bench two was predominately siltstone in various sizes ranging from less than one inch to three feet in diameter. The cause for the raveling material was due to erosive forces. The debris would disintegrate with minimal handling. Rock fall events were very frequent on site, multiple events happened while the slope evaluation was taking place.

Table 4.2.2.1: Coalfield's Expressway Field Measurements: New Slope Design 1

\begin{tabular}{|c|c|c|c|}
\hline \multicolumn{4}{|c|}{ Coalfield's Expressway Field Measurements: New Slope Design 1 } \\
\hline Analysis Method & Initial Factor of Safety & $\begin{array}{c}\text { Bench Reduction } \\
\text { Factor of Safety }\end{array}$ & F.O.S. Increase \\
\hline $\begin{array}{c}\text { General Limit } \\
\text { Equilibrium }\end{array}$ & 1.254 & 1.387 & $10.6 \%$ \\
\hline
\end{tabular}

The redesign of the slope included the removal of the bench placed directly in the siltstone layer. Removal of the bench would propagate through the two siltstone layers as well as the two sandstone layers located directly below. Subsequently upon removal of this bench it would create a new vertical back slope height of approximately 170 feet. The previously stated design restriction was a maximum vertical distance of 50 feet in accordance with DD-403. In addition to the removal of the third bench, the resulting bench was designed to a width of approximately $60 \mathrm{ft}$. A bench width of 60 feet exceeds the minimum bench width stated in DD-403 by almost 35 feet. The intent of removing the sandstone layer completely was to minimize the driving forces cause by the additional weight. Table 4.2.2.1 represents the factor of safety behavior with the elimination of the third bench. A screen shot of the new slope design profile can be seen in Figure 4.2.2.1.

It may be concluded upon that with the removal of the third bench, resulting in a new back slope and bench dimension of approximately $170 \mathrm{ft}$. and $60 \mathrm{ft}$. respectively the analysis yielding a factor of safety increase. The increase in the factor of safety forced the simulated failure plane to change location and showed failure at the bottom of the newly designed slope projecting the entire way to the toe of the cut. A screenshot of the analysis can be seen in the Figure 4.2.2.1, illustrating the new profile design as well as the relocation of the failure plane. This slope design 
although stable would not only meet the stability requirements stated in DD-403 it exceeds the requirement by approximately $11 \%$ thus deeming it an acceptable design consideration.

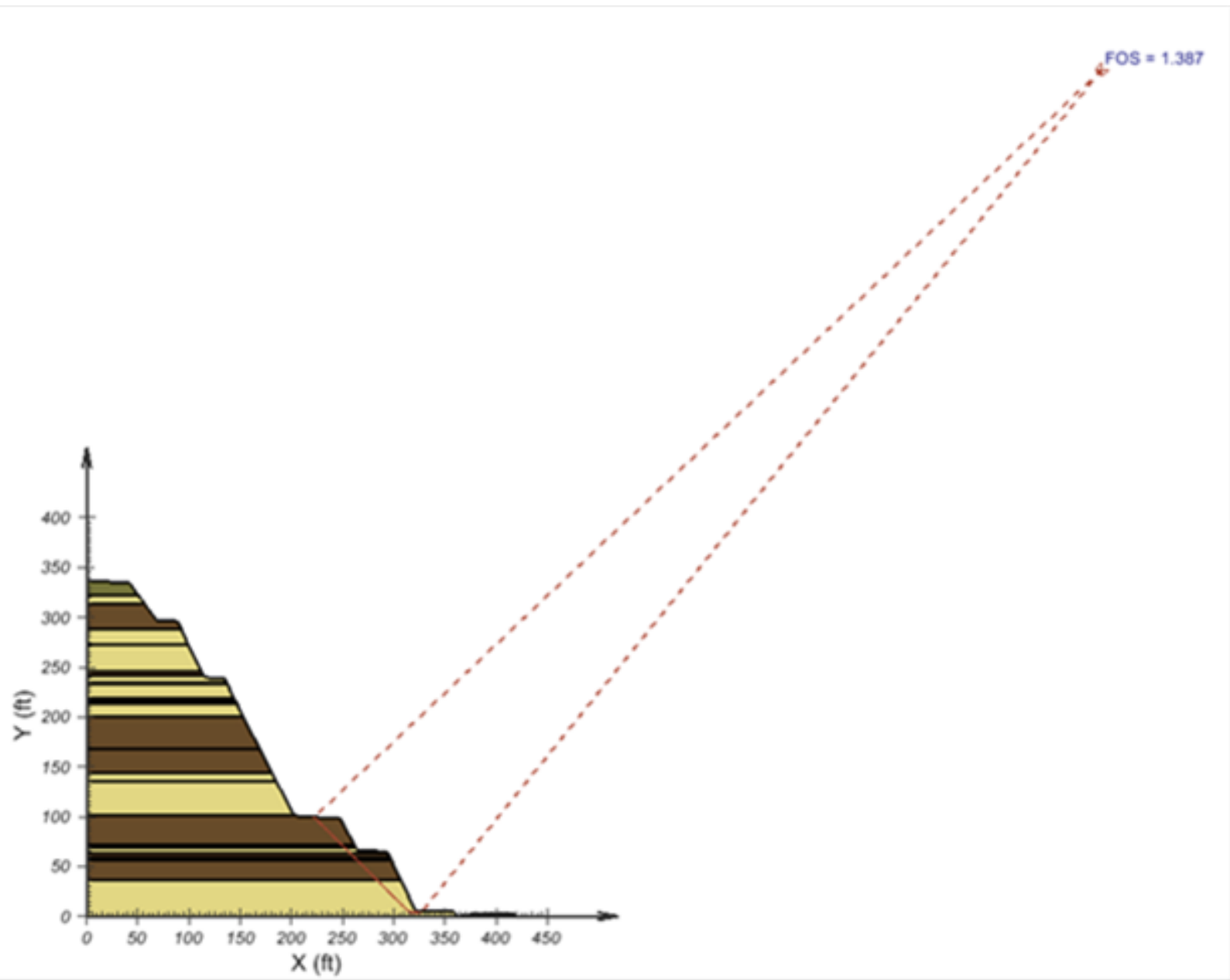

Figure 4.2.2.1: New Slope Design Trial 1 


\subsubsection{Site 1: Coalfield's Expressway Field Measurements: New Slope Design Trial 2}

This second analysis process similar to the first targeted the third bench placed directly in the siltstone layer. The bench was removed from the siltstone layer and placed directly below in a more competent sandstone layer. A screen shot has been included in Figure 4.2.3.1 to depict the new proposed slope profile. The decision to leave the sandstone layer in this design was to allow for more material to be left in place with the intent to resist the driving forces present which lead to slope failure. The new vertical height located above the new sandstone bench is approximately $100 \mathrm{ft}$. This new profile would create a back slope that is twofold larger than currently allowed within the cut slope design guide. The removal of the siltstone layer has allowed for a larger bench to be constructed in the sandstone layer, which measures approximately 50 feet horizontally. The resulting data has been listed in tabular format, located in Table 4.2.3.1.

Table 4.2.3.1: Coalfield's Expressway Field Measurements: New Slope Design Trial 2

\begin{tabular}{|c|c|c|c|}
\hline \multicolumn{4}{|c|}{ Coalfield's Expressway Field Measurements: New Slope Design Trial 2 } \\
\hline Analysis Method & Initial Factor of Safety & $\begin{array}{c}\text { Bench Reduction } \\
\text { Factor of Safety }\end{array}$ & Percent Increase \\
\hline $\begin{array}{c}\text { General Limit } \\
\text { Equilibrium }\end{array}$ & 1.254 & 1.194 & $-4.7 \%$ \\
\hline
\end{tabular}

Conclusive data was found upon the completion of the slope stability analysis, resulting in an overall decrease of the factor of safety. This result showed identical results to the first trial; lowering the overall factor of safety and relocating the simulated failure plane at the top of the back slope where the bench was removed. The cause for the decrease in the factor of safety is believed to stem from the excess sandstone material. As illustrated in Table 4.2.1.1 the sandstone is a stronger more competent material. The addition of the sandstone at the toe of the slope forces the failure to occur higher on the back slope in a heavily siltstone laminated area. Due to the fact that the redesigned slope did not meet the required factor of safety of 1.25 , this design alteration should not be considered as an acceptable design profile. 


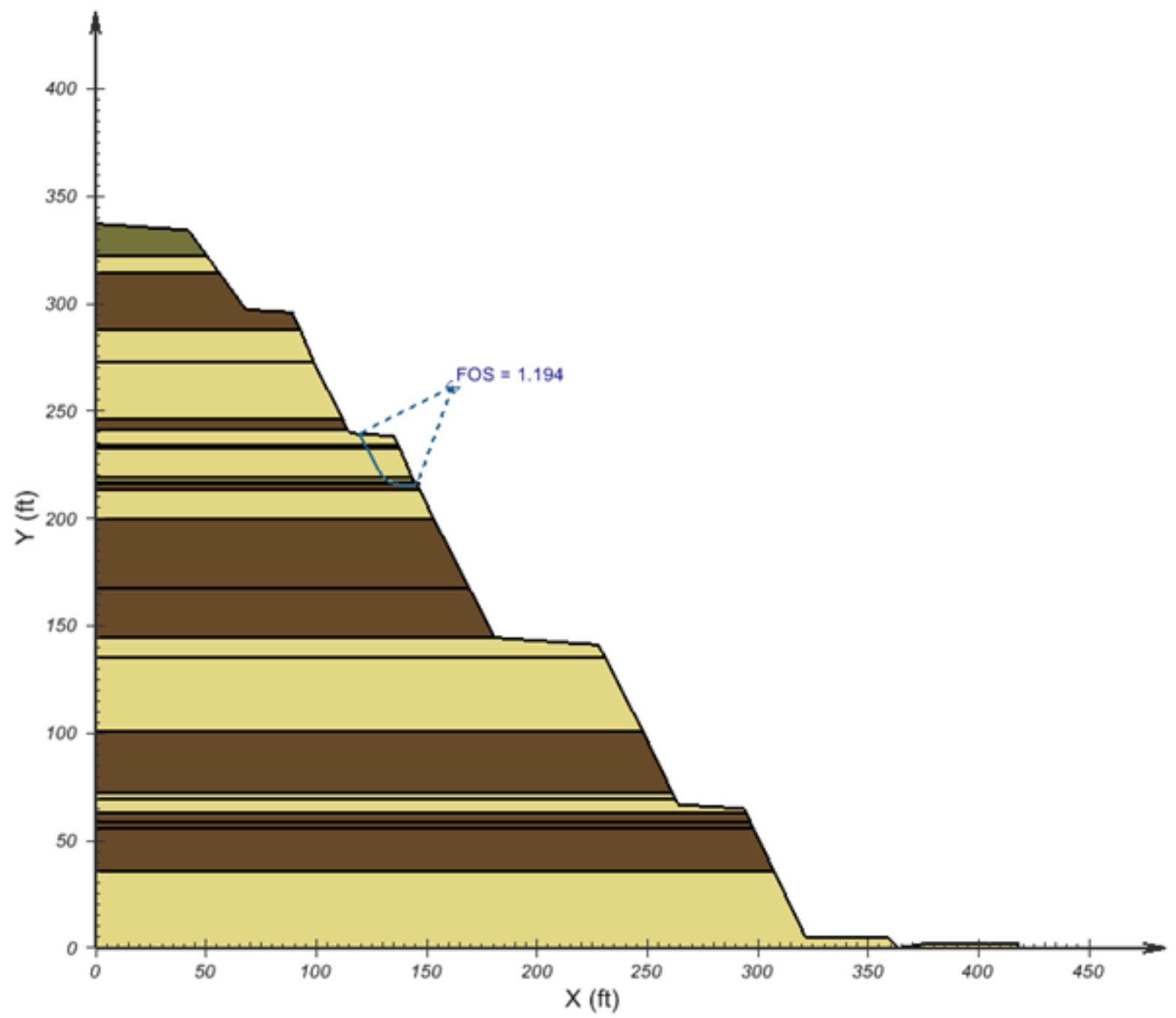

Figure 4.2.3.1: New Slope Design Trail 2 


\subsubsection{Site 1: Coalfield's Expressway Field Measurements: New Slope Design Trial 3}

The third new slope design approached the issue with respect of driving forces and the attempt to minimize the effect which can lead to slope failure. In this design third bench located in the siltstone layer was again removed to eliminate a centralized failure plane. In addition to the bench removal two new benches were proposed at the top and the bottom of the siltstone layer completely encompassing layer with sandstone abutments. The benches constructed in the sandstone layers were increased to a width of approximately 35 feet and 40 feet for the top and bottom benches respectively. It is important to note that increasing the bench widths allows for more in situ material to be left at the original location to resist the driving forces cause by the proposed failure plane.

Table 4.2.4.1: Coalfield's Expressway Field Measurements: New Slope Design Trial 3

\begin{tabular}{|c|c|c|c|}
\hline \multicolumn{4}{|c|}{ Coalfield's Expressway Field Measurements: New Slope Design Trial 3 } \\
\hline Analysis Method & Initial Factor of Safety & $\begin{array}{c}\text { Bench Reduction } \\
\text { Factor of Safety }\end{array}$ & Percent Increase \\
\hline $\begin{array}{c}\text { General Limit } \\
\text { Equilibrium }\end{array}$ & 1.254 & 1.550 & $23.6 \%$ \\
\hline
\end{tabular}

The resulting back slope vertical height yielded an approximate elevation change of 100 feet. This new design yet again exceeds the limits of the cut slope design guide on maximum vertical height as well as the minimum bench width of $35 \mathrm{ft}$., which exceeds the minimum requirement of 20 horizontal feet as stated in DD-403. The factor of safety performance with the new slope configuration is listed below in Table 4.2.4.1. A screen shot of the new proposed design can be seen in Figure 4.2.4.1.

The analysis of this profile concluded an increase in the factor of safety of the proposed slope profile. An increase in the factor of safety is believed to be a direct response of the proposed bench locations in addition to the larger bench widths. The wider benches proved to increase the resistive forces subsequently increasing the factor of safety. Due to the fact that the stability analysis yielded a new factor of safety exceeding the required 1.25 , this would be an acceptable slope design in accordance with DD-403. 


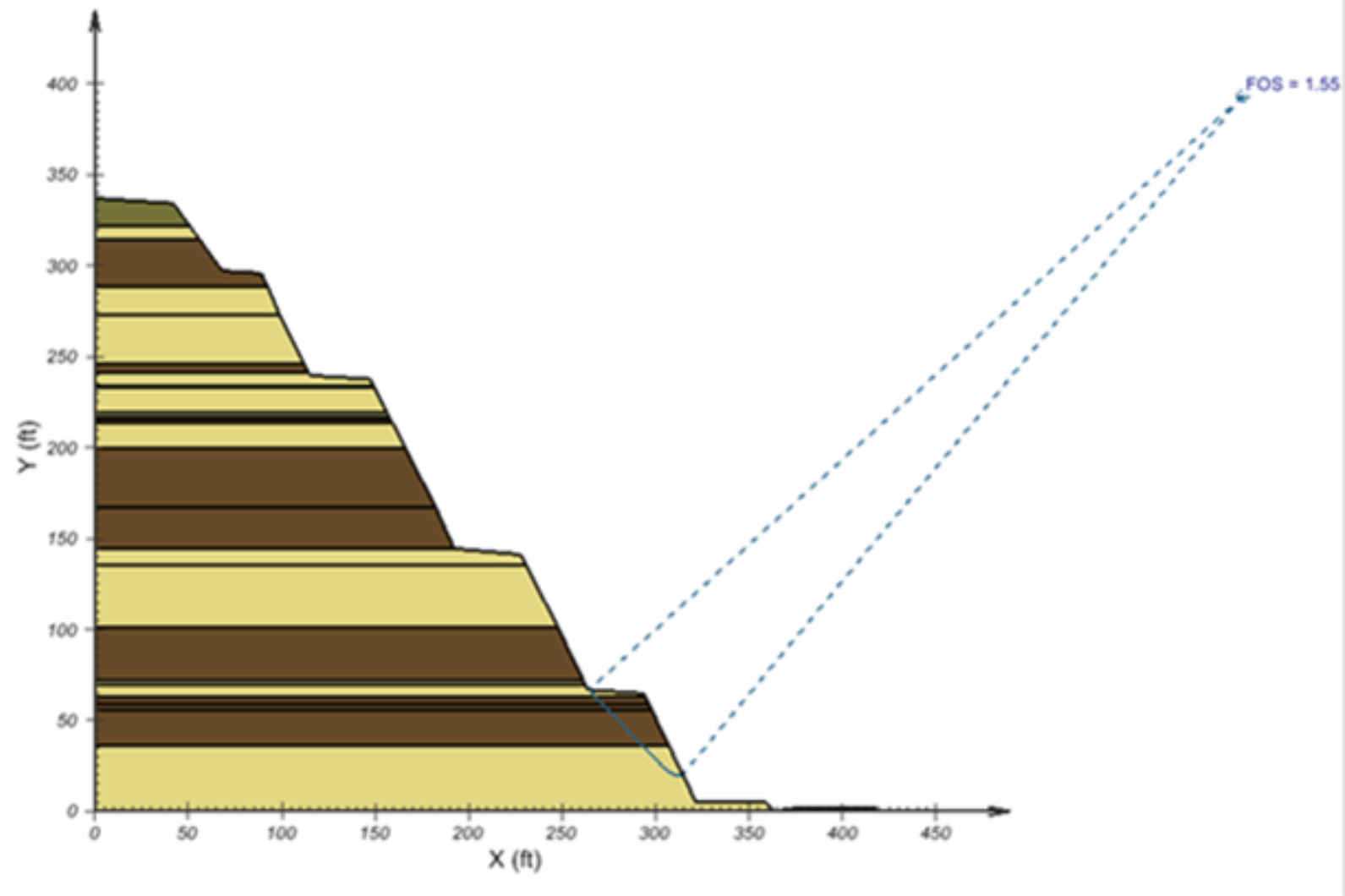

Figure 4.2.4.1: New Slope Design Trial 3 


\subsubsection{Site 1: Coalfield's Expressway Field Measurements: New Slope Design Trial 4}

The fourth and final design consisted of the removal and implementation of benches with regards to minimize the driving forces placed on the siltstone layer, similar to the approach of the third iteration presented in Section 3.6.4. The fourth bench in the original design was constructed in primarily a sandstone layer with thin intermittent siltstone layers. This bench was removed in the redesign resulting in a continuous planar section with a vertical height of approximately 115 feet. A bench was placed at the top of the siltstone layer directly beneath the sandstone and would encompass two siltstone layers which were around a total of 55 vertical feet. At the base of the siltstone an addition bench would be placed in a sandstone layer as a horizontal length of $38 \mathrm{ft}$. The goal of this design was to eliminate the bench that was previously found in the high sandstone layer and removed some weight which in turn lowers the driving forces on the siltstone layer. The addition of the bench beneath the siltstone layer was to add addition weight to this portion of the slope to push the suggested failure plane deeper, thus creating a more stable design. A screen shot of the proposed design can be seen in Figure 4.2.5.1. The following data was subsequently found through the modeling procedure and yielded the succeeding data and is represented in Table 4.2.5.1.

Table 4.2.5.1: Coalfield's Expressway Field Measurements: New Slope Design Trial 4

\begin{tabular}{|c|c|c|c|}
\hline \multicolumn{4}{|c|}{ Coalfield's Expressway Field Measurements: New Slope Design Trial 4 } \\
\hline Analysis Method & Initial Factor of Safety & $\begin{array}{c}\text { Bench Reduction } \\
\text { Factor of Safety }\end{array}$ & Percent Increase \\
\hline $\begin{array}{c}\text { General Limit } \\
\text { Equilibrium }\end{array}$ & 1.254 & 1.438 & $14.7 \%$ \\
\hline
\end{tabular}

In conclusion it can be stated that an increase in the factor of safety was once again achieved with the redesign of the slope. The redesign allowed for larger vertical heights to be reached as well as larger benches thus leaving more material in place, lowering the overall construction efforts and costs. 


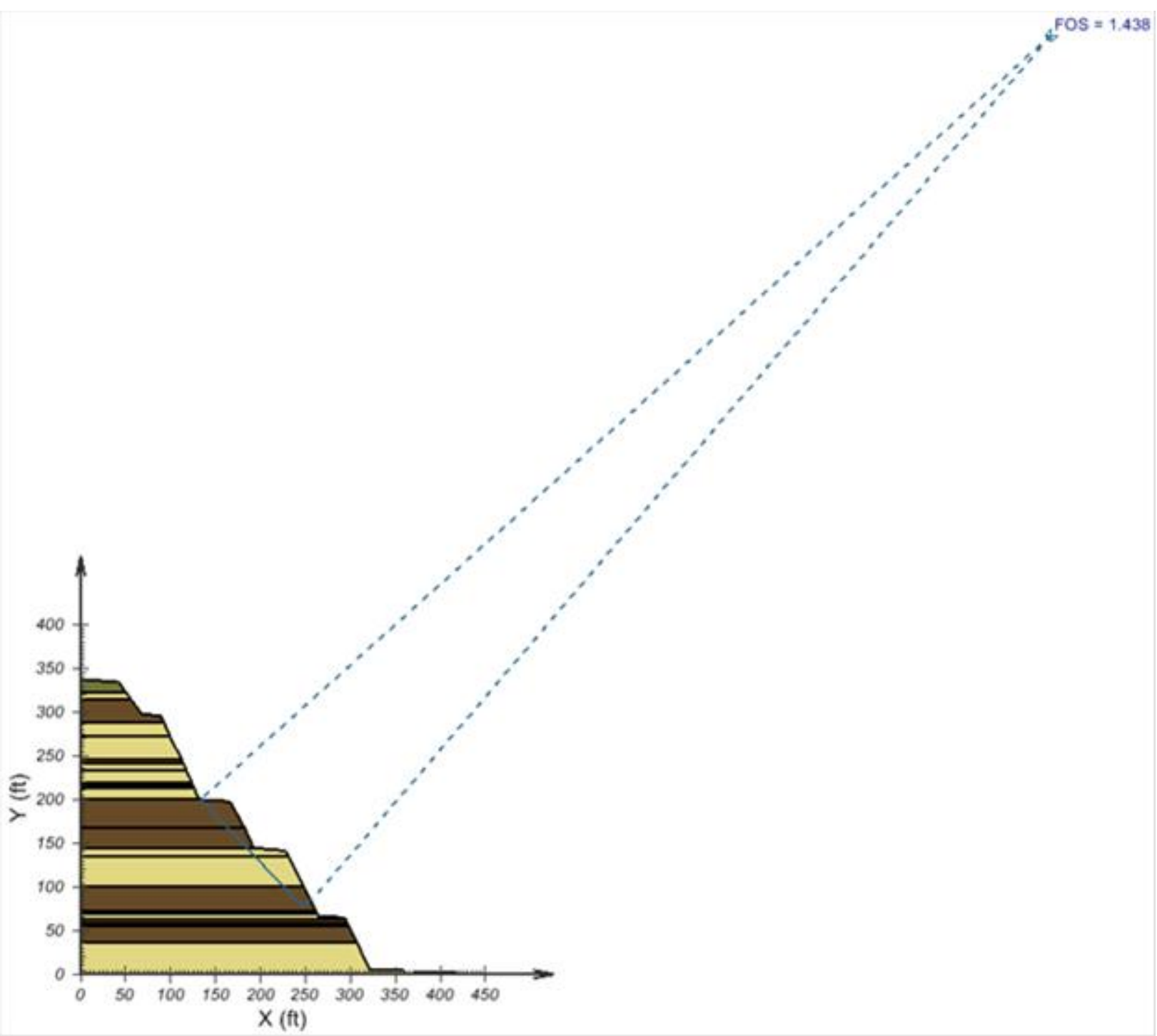

Figure 4.2.5.1: New Slope Design Trial 4 


\subsubsection{Site 1: Summary and Comparison: Coalfields Expressway: Bench Reduction}

The results table illustrates an overall comparison between the designs and the average increase that could be expected in the factor of safety given the implementation of the new design.

Table 4.2.6.1: Summary table of factor of safety influence with new slope design

\begin{tabular}{|c|c|c|c|c|c|}
\hline \multicolumn{5}{|c|}{ Coalfield's Expressway Field Measurements: New Slope Design Results } \\
\hline Analysis & $\begin{array}{c}\text { Number of } \\
\text { Benches }\end{array}$ & $\begin{array}{c}\text { Initial Factor } \\
\text { of Safety }\end{array}$ & $\begin{array}{c}\text { Bench } \\
\text { Reduction } \\
\text { Factor of } \\
\text { Safety }\end{array}$ & $\begin{array}{c}\text { Percent } \\
\text { Difference }\end{array}$ & \multicolumn{1}{|c|}{ Alteration } \\
\hline $\mathbf{1}$ & 6 & 1.254 & - & - & - \\
\hline $\mathbf{2}$ & 5 & 1.254 & 1.387 & $10.6 \%$ & $\begin{array}{l}\text { - Removal of third } \\
\text { bench }\end{array}$ \\
\hline $\mathbf{3}$ & 5 & 1.254 & 1.194 & $-4.7 \%$ & $\begin{array}{l}\text { - Removal of } \\
\text { fourth bench } \\
\text { - Relocation of } \\
\text { third bench }\end{array}$ \\
\hline $\mathbf{4}$ & 5 & 1.254 & 1.550 & $23.6 \%$ & $\begin{array}{l}\text { - Removal of } \\
\text { fourth bench } \\
\text { - Relocation of } \\
\text { third bench }\end{array}$ \\
\hline
\end{tabular}

Conclusive evidence showing the increase in the factor of safety of the slope with the reduction of benches shows that it is possible for rock cut slopes to be constructed with back slope portions exceeding the vertical $50 \mathrm{ft}$. restriction as stated in DD-403. Throughout the modeling iterations the target area was the weak siltstone area and minimizing the driving forces placed upon it. The designs allowed for bench removal at this area, in addition to planar sections existing above and below the target area. It should be noted that the new designs that allowed for larger bench widths resulted in the overall increase in factor of safety. It is believed that this was due to the nature of more material allowing for larger resistive forces caused by the extra material. Figure 4.2.6.1 illustrates the difference in all the design considerations and the proposed failure location. 
- Through the analysis it was found that vertical cut heights exceeding $100 \mathrm{ft}$. will allow for a stable slope design in a highly layered geologic arrangement.

- Bench width with and increased horizontal dimension up to $35 \mathrm{ft}$. allowed for additional in situ material to remain in place resulting in two benefits. The first of which affects slope performance is it allows for a greater resistant force, thus increasing the slopes factor of safety. The second benefit is from a construction cost aspect. As more material is left in place this lowers the excavation quantities and lowers the overall cost for cut slope construction.

- Conclusive evidence shows that with the removal of one bench and the increasing of bench widths, a factor of safety increase of approximately $24 \%$ was achieved. This performance was accomplished in slope redesign trial three. 

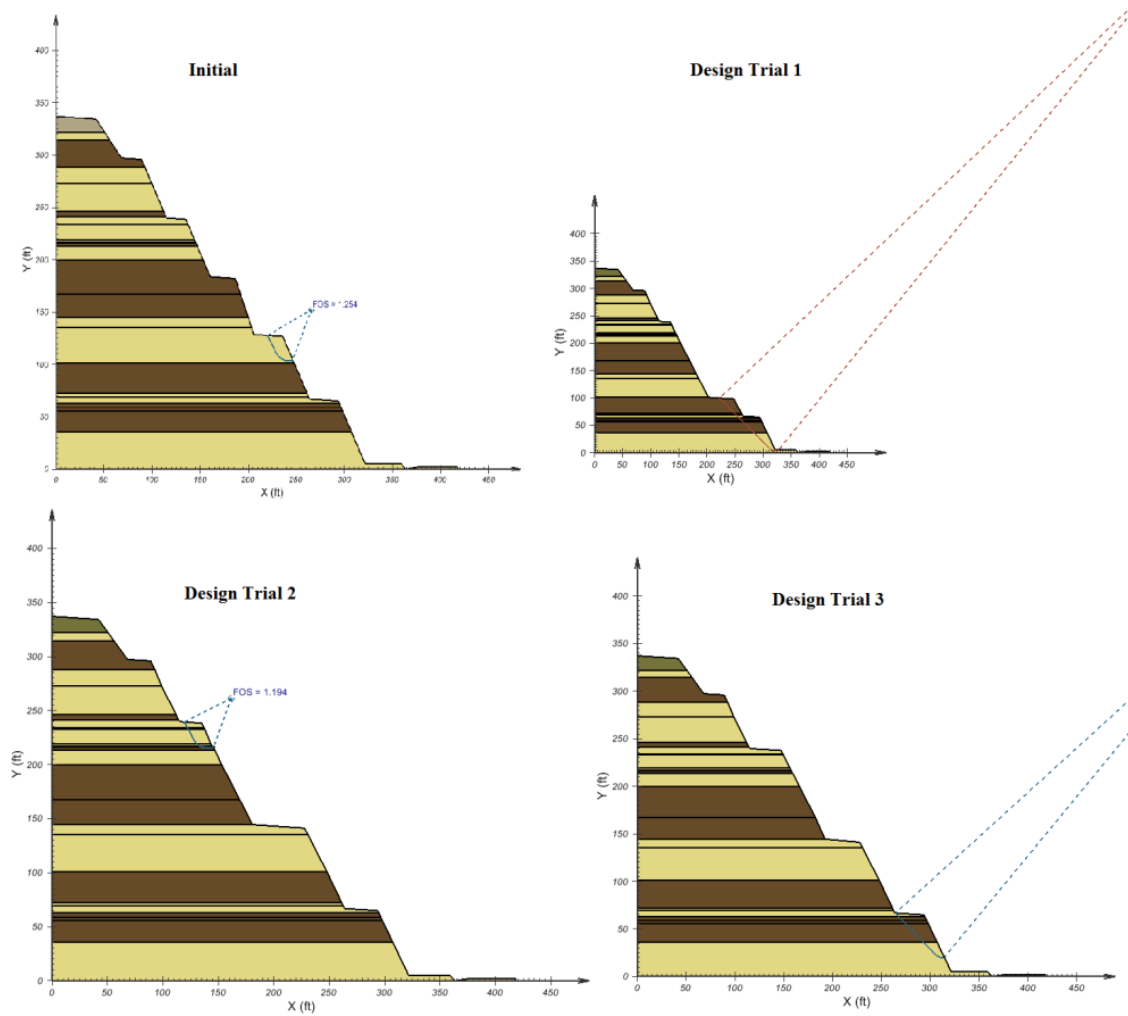

Design Trial 4

Figure 4.2.6.1: Coalfield's Expressway Design Trials

Table 4.2.6.2: Bench Reduction Summary Table

\begin{tabular}{|c|c|c|}
\hline Analysis & Number of Benches & Factor of Safety \\
\hline Initial & 6 & 1.254 \\
\hline Trial 1 & 5 & 1.387 \\
\hline Trial 2 & 5 & 1.194 \\
\hline Trial 3 & 5 & 1.550 \\
\hline Trial 4 & 5 & 1.438 \\
\hline
\end{tabular}




\subsection{Site 2: Route 48 - Corridor H: Grant and Hardy County, WV}

The site evaluation on Route 48 on the border of Grant and Hardy County was conducted on the $12^{\text {th }}$ day of September 2013. Grant and Hardy County are found in the eastern panhandle, spanning from the Maryland to Virginia boarder. The purpose of this visit was to evaluate the current performance of bench cut profiles along Route 48 and assess bench removal. Route 48 is fairly new route, with the oldest construction dating back to 1998. This route was necessary for evaluation to note the behavior of a newer bench cut slope profile. Two slopes were evaluated during this site visit, one showing no signs of failure and the other showing a large mass movement within the slope. This section of the state has a vastly different geologic composition than most of the state. West Virginia's geology is primarily comprised of sedimentary rock. The geological formations in the eastern panhandle varied greatly from hard competent limestone to sand beds. The variations existing in the geology makes for a difficult slope design process. The two slopes evaluated were constructed in predominately hard limestone, with a few inter-bedded layers throughout. The second slope in the evaluation process showed signs of failure due to geological anomalies found within the slope. A large clay seam interlacing throughout the slope has caused a portion of material to fall toward the roadway. The failure was so frequent and severe that a concrete barrier was placed at the roadways edge in the attempt to mitigate rock fall from reaching the roadway. Figures 4.3.1 - 4.3.2 show photographs obtained during the field site investigation on U.S. Route 48. 


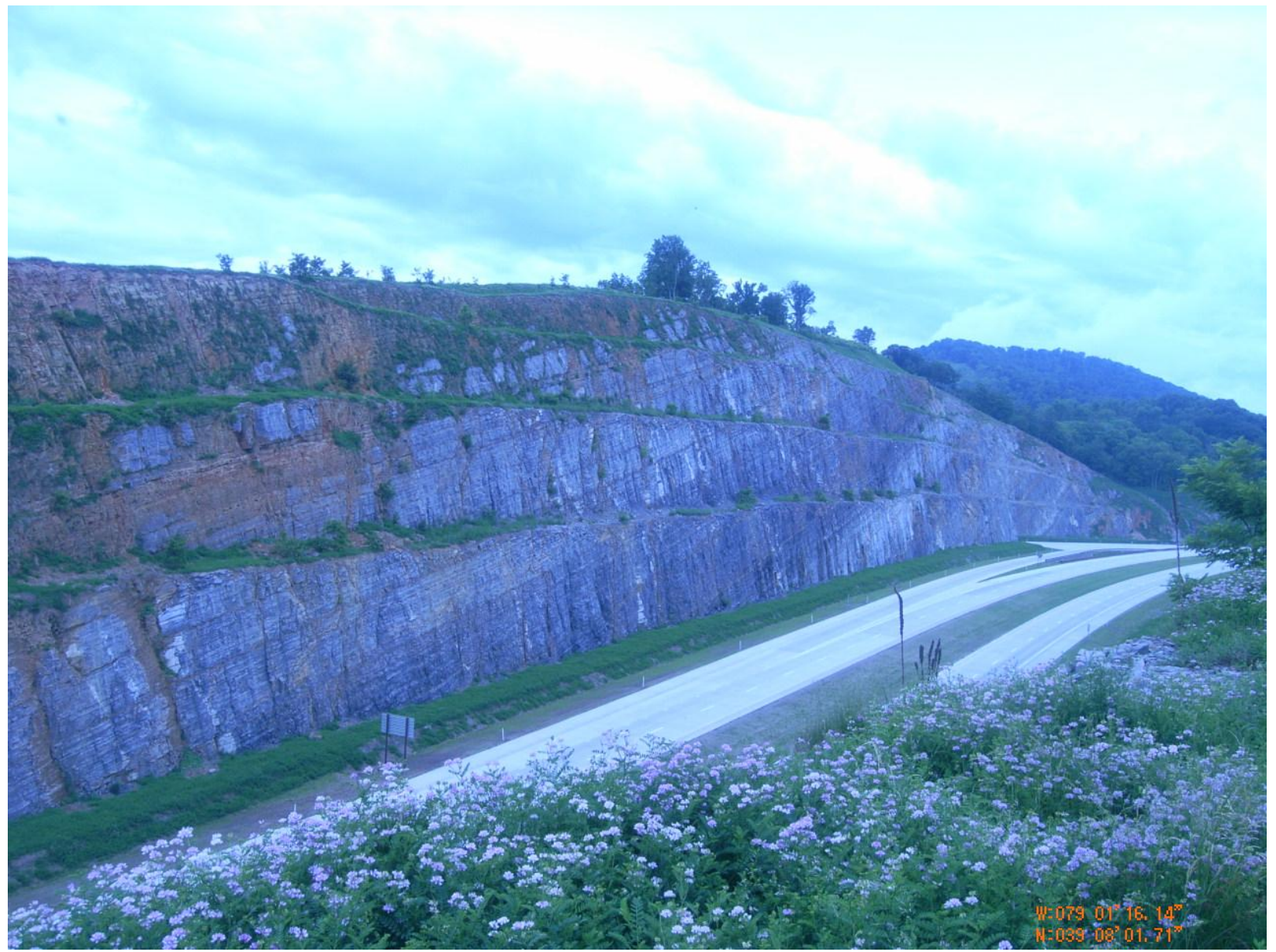

Figure 4.3.1: Slope 1 evaluated during the field visitation 


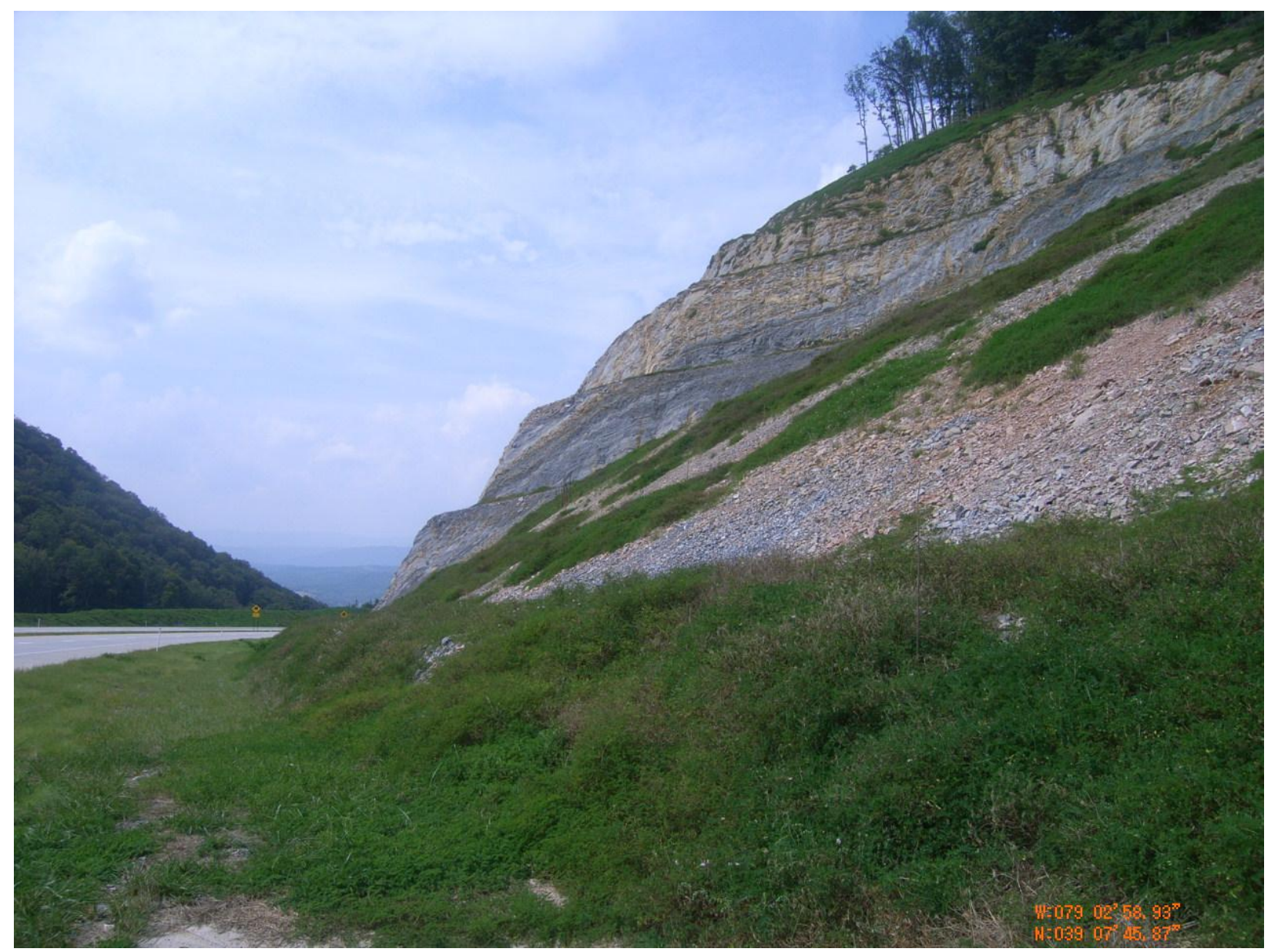

Figure 4.3.2: Slope 2 evaluated during the field visitation

The field evaluation of the site included the West Virginia University research group traversing the slopes and taking physical measurements to ensure accuracy of slope geometry. The group was able to traverse on all of the benches throughout the two slopes. The first slope that was assessed was performing very well and showed minimal signs of rock fall events on the slope or at the toe. The geological formation that was present consisted of limestone with some intermittent layers of sandstone. The structure was large blocky uniform masses with minimal sporadic fracturing of the rock. The limestone was extremely competent and was resisting weathering very well. All sign of fallen rock present on the first profile was of minimal size, it is what would be expected to be found mid slope or at toe of slope. The vast majority of debris was cobble sized ( 3 to 12 inch) with the average size around 6 inches. The second slope that was evaluated was not as structurally sound as the first that was evaluated. This area was prone to frequent rock fall events. One particular event was noted in a car size boulder reaching the roadway, prior to concrete barrier placement maintenance director (John Burns, personal communication, 2013). 
The first bench on the slope had a large mass movement sitting on it. Large clay seams were found inter-bedded around the limestone formation and was most likely the root cause for this failure. Fallen debris from this event was in the boulder classification (> 12 inches). Included in Figure 4.3.3 and Figure 4.3.4 illustrates the fallen debris on the second cut slope and the believed causation of the clay seam.

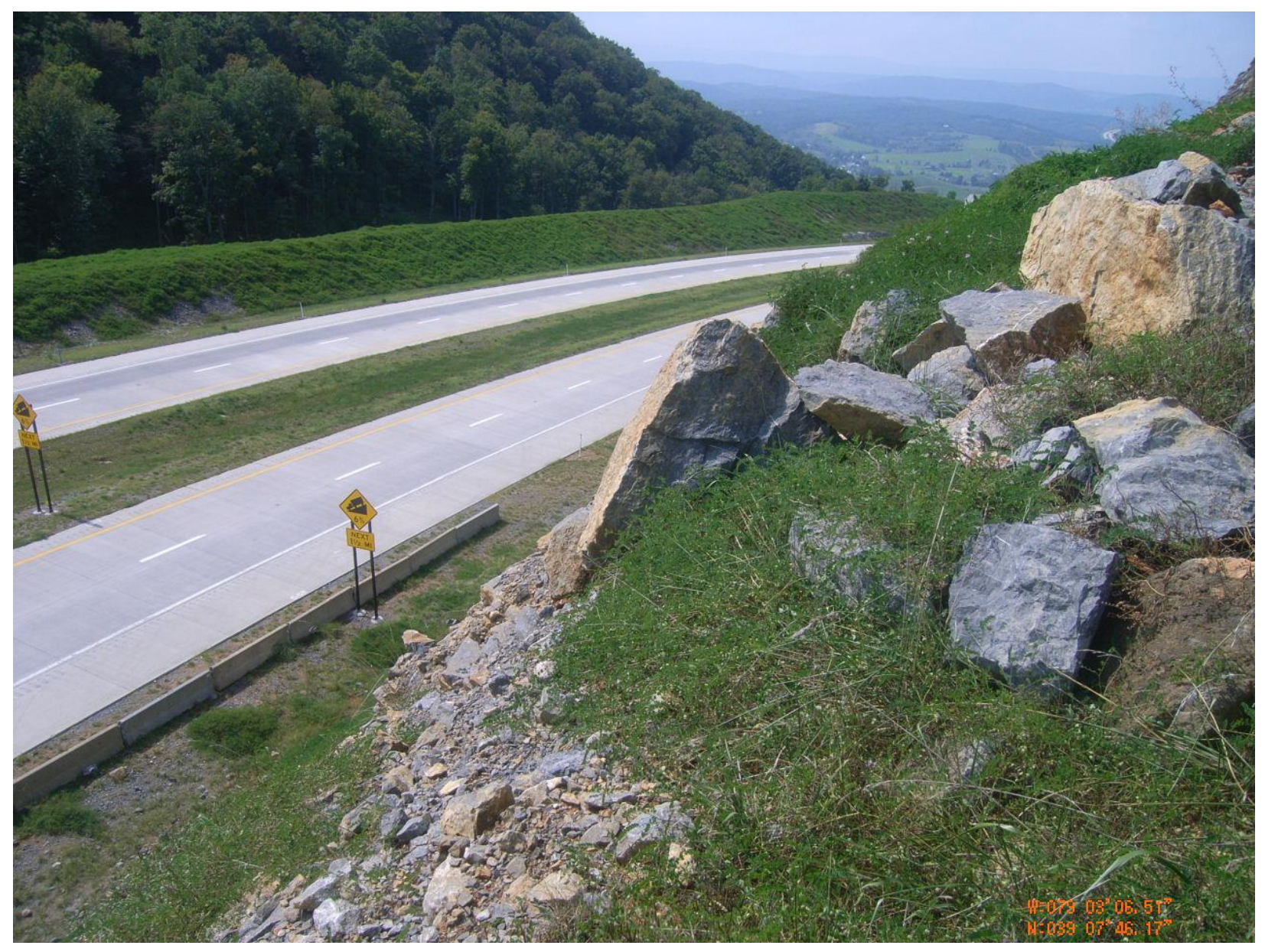

Figure 4.3.3: Fallen debris on Corridor $H$ 


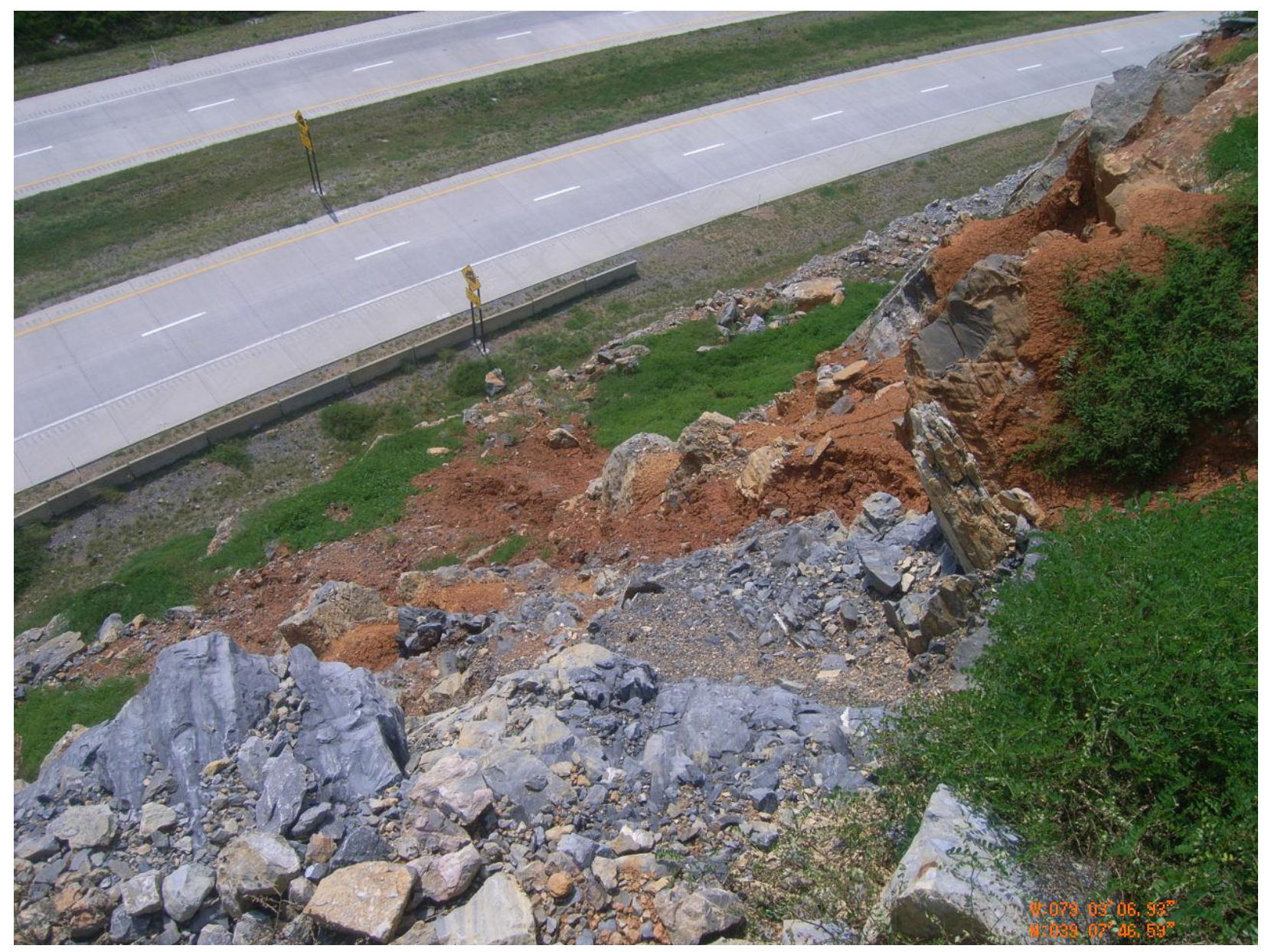

Figure 4.3.4: Clay seem leading to rock fall

The geological formations were very consistent form slope to slope with the exception of the clay seems on the second profile. Each slope contained a sighting bench at the toe. This practice is not advantageous to rock fall attenuation, and will most likely allow falling debris to reach the roadway. Both slopes showed very dense vegetation on the benches as well as sparse areas of vegetation on the back slopes.

The evaluation of two cut slopes on this route was conducted to collect a wider data base in the evaluation of a Rockfall Hazard Rating System (RHRS) stand point. The RHRS assesses cut slopes and gives a number associated to the slope regarding possible public hazard. It was also necessary to evaluate the slope with the large interbedded clay seams due to the fact it was causing rock fall events, it was important to see the mitigation practice and rock fall attenuation features used to minimize user risk. Due to the topography and land contour, this slope was not ideal for modeling purposes. The stability focus for Route 48 will be focused on the initial slope evaluated. The analysis of Corridor $\mathrm{H}$ : Route 48 was conducted identically to the procedure previously performed on Coalfield's Expressway with minor difference. Upon review of the proposed WVDOH designs it was found that the variation of planned and physical profile was minimal. A survey crew had measured the slope upon construction and the plans that were 
reviewed included the two profiles (actual and planned) which mimicked each other almost perfectly. Table 4.3.1 lists the models that were evaluated throughout the Corridor H evaluation including the redesign analysis. This also proved in the comparison of the field measurements obtained on the field exploration. The measurements were almost identical to the planned and actual profile. Due to the minimal change in the profiles the need for field measurements and planned profiles was deemed unnecessary, thus one geometric slope profile will be assessed and all redesigns will stem from this profile.

Table 4.3.1: Models conducted in the Corridor $H$ cut slope evaluation

\begin{tabular}{|c|l|l|}
\hline Model & \multicolumn{3}{|c|}{ Material Strength / Failure Criterion } \\
\hline Plan - Field Slope & Low - Hoek-Brown & High - Hoek-Brown \\
\hline Re-designed slope & $50 \%$ of maximum Strength Value - Trial 1 \\
\hline Re-designed slope & $50 \%$ of maximum Strength Value - Trial 2 \\
\hline Re-designed slope & $50 \%$ of maximum Strength Value - Trial 3 \\
\hline Re-designed slope & $50 \%$ of maximum Strength Value - Trial 4 \\
\hline
\end{tabular}

\subsubsection{Site 2: Corridor H: WVDOH Design - As-Built Measurement Geometry}

The modeling performed on Route 48 - Corridor $\mathrm{H}$ was conducted with the same intent and focus of the procedure on Coalfield's Expressway. As stated in Section 4.2 the modeling procedure was shortened due to the similarities in the field measurements and planned construction profile. Figure A1-3 in Appendix 1 presents a photograph that illustrates the designed profile graphed concurrently with the survey profile. Upon review of the WVDOH designs the slope that was evaluated in the field and the one that modeling would be based on was located at station 309+00. The WVDOH designs illustrated the original design for the slope to be intended to be constructed at a back slope angle of an $\mathrm{H}: \mathrm{V}$ ratio of $0.25: 1$ or $76^{\circ}$ with benching intervals occurring every 50 vertical feet. This information was found to be accurate upon the field measurements which yielded an average back slope angle of $75^{\circ}$ with benches occurring every 50 vertical feet. Field measured bench construction was found to mimic that of the WVDOH designs with an average bench width of approximately $20 \mathrm{ft}$. The total height of the cut slope was found to be approximately 200 vertical feet. See Figure 4.3.2.1 for a visual representation of the slope profile. 


\subsubsection{Site 2: Corridor H: WVDOH Design - As-Built Slope Stability Analysis}

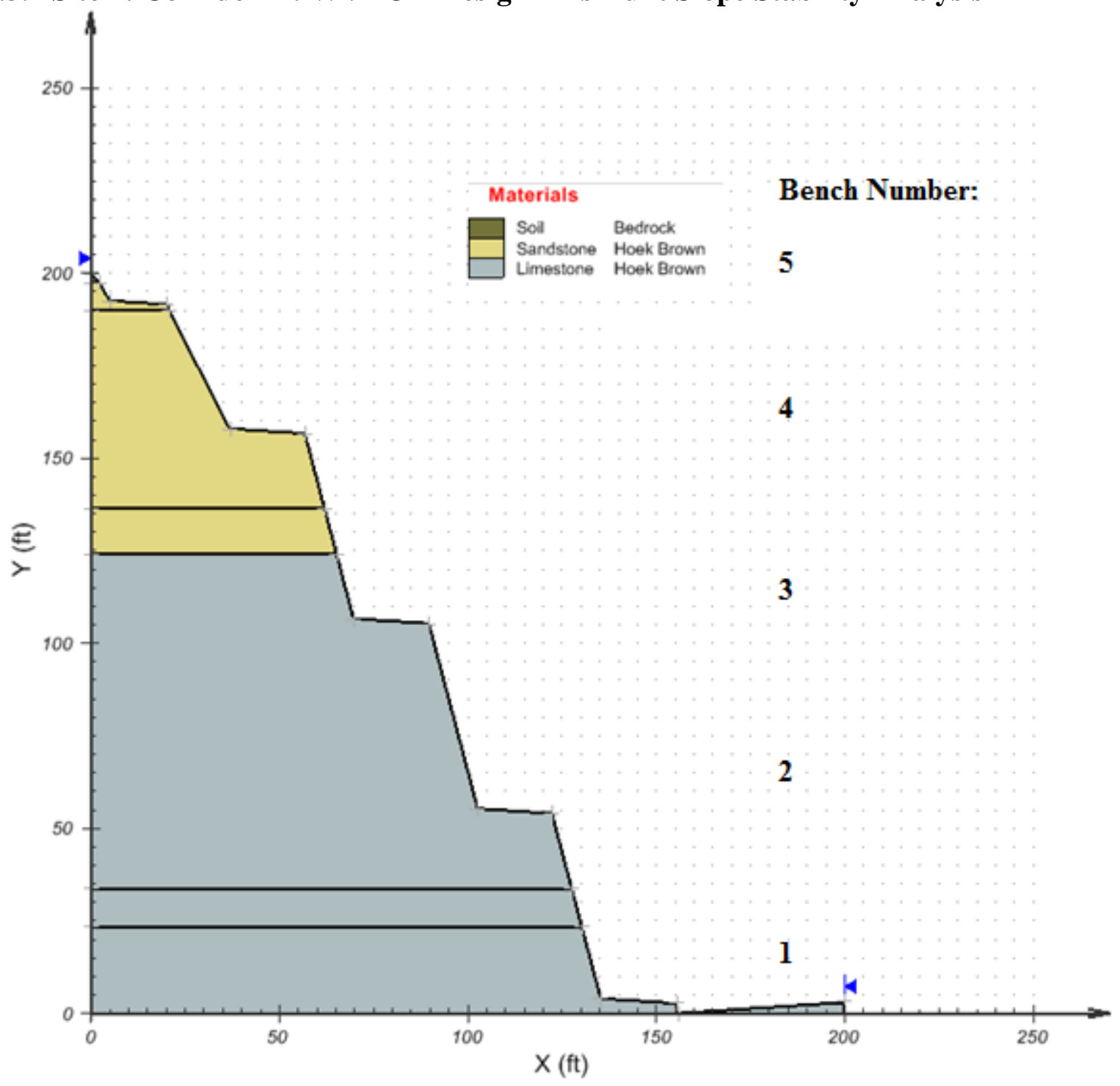

Figure 4.3.2.1: Slope constructed via WVDOH design

The geotechnical reports conducted in the primary site investigation were provided for evaluation and interpretation. It was found that a borehole had been drilled in close vicinity to the location of the cut slope inspected during the field visitation. The borehole log recorded a boring of 200 vertical feet with respective layer designation the entire depth. Table 4.3.2.1 includes the layers retrieved from the borehole log which were directly input into the modeling process, deeming for a perfect encompassment of the entire slopes material. The lithology in this portion of the state is vastly different than most of the state. Large seams of competent sandstone and limestone are found with in this region; refer to Figure 4.3.4. 
Table 4.3.2.1: Master Borehole Log for Corridor H from the crest to toe of slope

\begin{tabular}{|c|c|c|}
\hline & Master Bore Log - Corridor H \\
\hline Material & Depth (ft.) & Layer Thickness (ft.) \\
\hline Soil & $0.0-2.48$ & 2.48 \\
\hline Sandstone & $2.48-10.0$ & 7.52 \\
\hline Sandstone & $10.0-63.44$ & 53.44 \\
\hline Sandstone & $63.44-76.0$ & 12.56 \\
\hline Limestone & $76.0-165.52$ & 89.52 \\
\hline Limestone & $165.52-176.0$ & 10.48 \\
\hline Limestone & $176.0-200.0$ & 24.00 \\
\hline
\end{tabular}

The slope assessment process was conducted identically as stated in Figure 3.5.1 negating the evaluation of the Mohr-Coulomb failure criterion. Input parameters used in the evaluation process can be seen in Table 4.3.2.2.

Table 4.3.2.2: Hoek-Brown material inputs (Sjöberg, 1997) (Zhao, 2010)

\begin{tabular}{|c|c|c|c|}
\hline UC Strength (KSF) & \multicolumn{2}{|c|}{ Minimum } & Maximum \\
\hline Sandstone & \multicolumn{2}{|c|}{417.708} & 3550.523 \\
\hline Limestone & \multicolumn{2}{|c|}{626.563} & 5221.358 \\
\hline Soil & \multicolumn{3}{|c|}{ Bedrock } \\
\hline \multirow{2}{*}{ GSI } & Minimum & Maximum & \\
\hline & 23 & 75 & \\
\hline \multirow{2}{*}{$\begin{array}{c}\text { D-Factor } \\
\text { *(values decrease as blasting } \\
\text { improves) }\end{array}$} & $\begin{array}{l}\text { Minimum - } \\
\text { Poor }\end{array}$ & $\begin{array}{l}\text { Maximum - } \\
\text { Good }\end{array}$ & \\
\hline & 1.0 & 0.7 & \\
\hline $\mathbf{M i}$ & Minimum & Maximum & \\
\hline Sandstone & 4.7 & 35.5 & \\
\hline Limestone & 4 & 50 & \\
\hline
\end{tabular}




\subsubsection{Site 2: Corridor H: WVDOH Design - As-Built Slope Stability Analysis}

Results from the slope stability analysis produced vastly great factors of safety for the two cases. The calculated factor of safety for the two analyses can be seen in Table 4.3.3.1 for the HoekBrown failure criterion.

Table 4.3.3.1: Factor of Safety - Hoek-Brown Failure Criterion for Corridor $H$ Factor of Safety - Hoek-Brown Failure Criterion for Corridor $\mathbf{H}$

Analysis Method Minimum Maximum

0.658 258.7

\subsubsection{Site 2: Discussion}

The calculation of the factor of safety of the current slope performance is stated in Table 4.3.3.1. Results showed a factor of safety of 0.658 for the low parameter inputs for the Hoek-Brown failure criterion. The factor of safety is believed to be so low due to multiple reasons; two leading causes are the material strength and the constructed geometry which is not an entirely accurate assessment for the current performance of the slope. A range in material strength was obtained through a literature review on rock strengths, due to the lack of data provided in the geotechnical report. The range in the calculated factor of safety illustrates the worst and best case scenarios for this slope profile. The current performance of this cut is behaving well, thus the factor of safety is above 1.0 deeming it stable. A discrete value cannot be attached to this slope given the absence of material testing. This analysis is to illustrate the necessity and importance of site specific material testing, to ensure a safe design that meets the minimum factor of safety requirement of 1.25 . The examination of the high material strengths produced a factor of safety exceeding the requirement of 1.25 significantly. Figure 4.3.4.1 illustrates overlaid screen shots of the stability analysis, depicting the projected failure plane and minimum factor of safety calculated during the model assessment. The location of the failure plane was centralized within the sandstone portion of the slope illustrating the failure occurring in the weaker material in both considered cases encompassing benches four and five. 


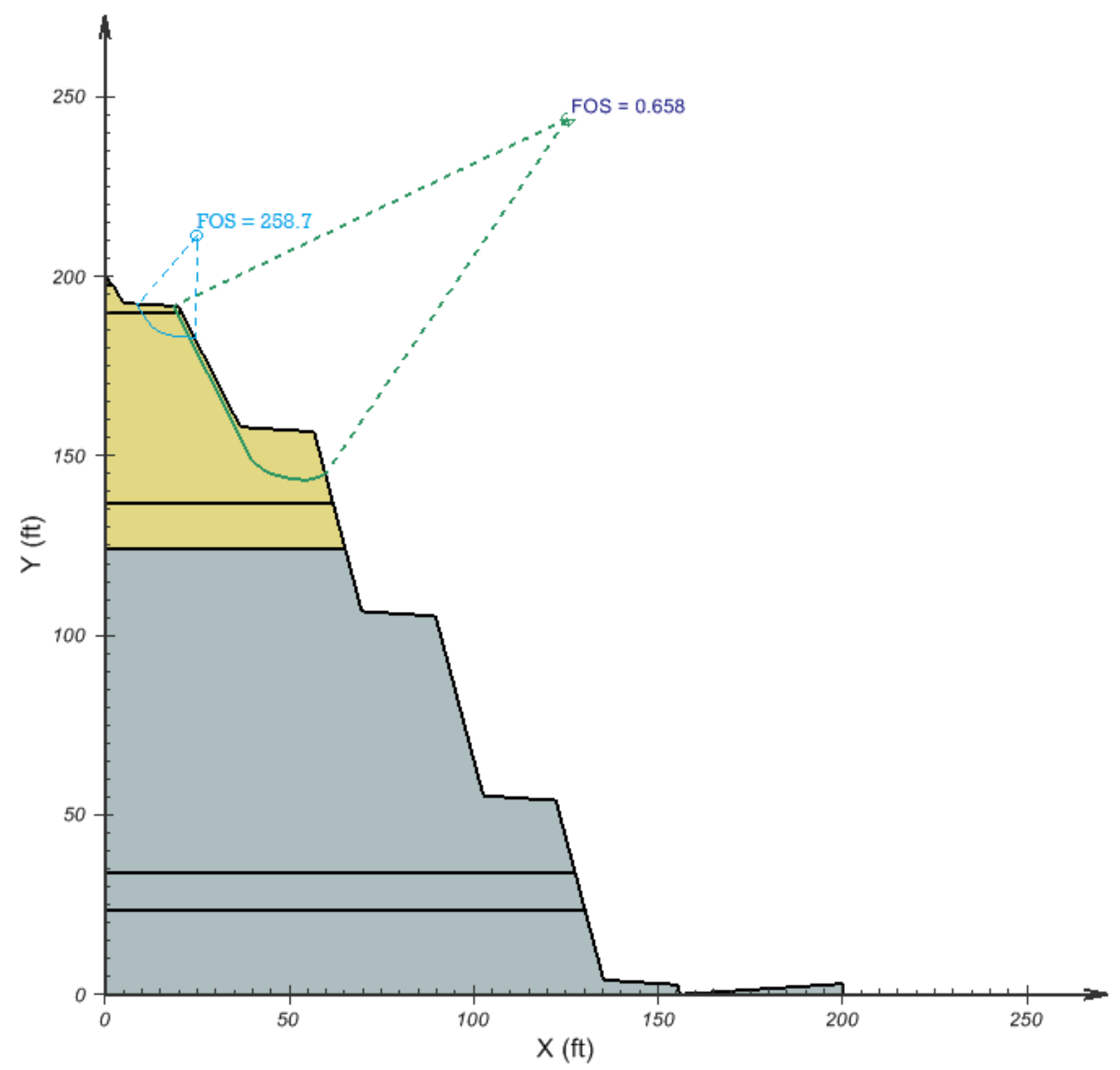

Figure 4.3.3.1: Corridor $H$ - Hoek-Brown failure criterion

\subsection{Site 2: Corridor H: Bench Reduction Slope Design}

The bench elimination was performed within the previous guidelines and criteria discussed in Section 4.2. An iterative process will be completed through this process; slope geometry will be designed, evaluated for stability, recorded and then repeated. This will allow the factor of safety response to be shown with bench reduction at various heights within the profile. As seen in Figure 4.3.3.1 the location of the proposed failure planes are primarily located within the sandstone layer, this will be one of the targeted areas in order to increase the factor or safety by pushing the failure plane deeper into the slope. It should be noted that the limestone area did not illustrate signs of a potential failure plane. The limestone area was also a targeted area in order to optimize cut profiles in competent material and minimize excavation quantities and cost. The 
red box depicted in Figure 4.4.1 encompasses the area of concern where bench elimination or material fill will occur.

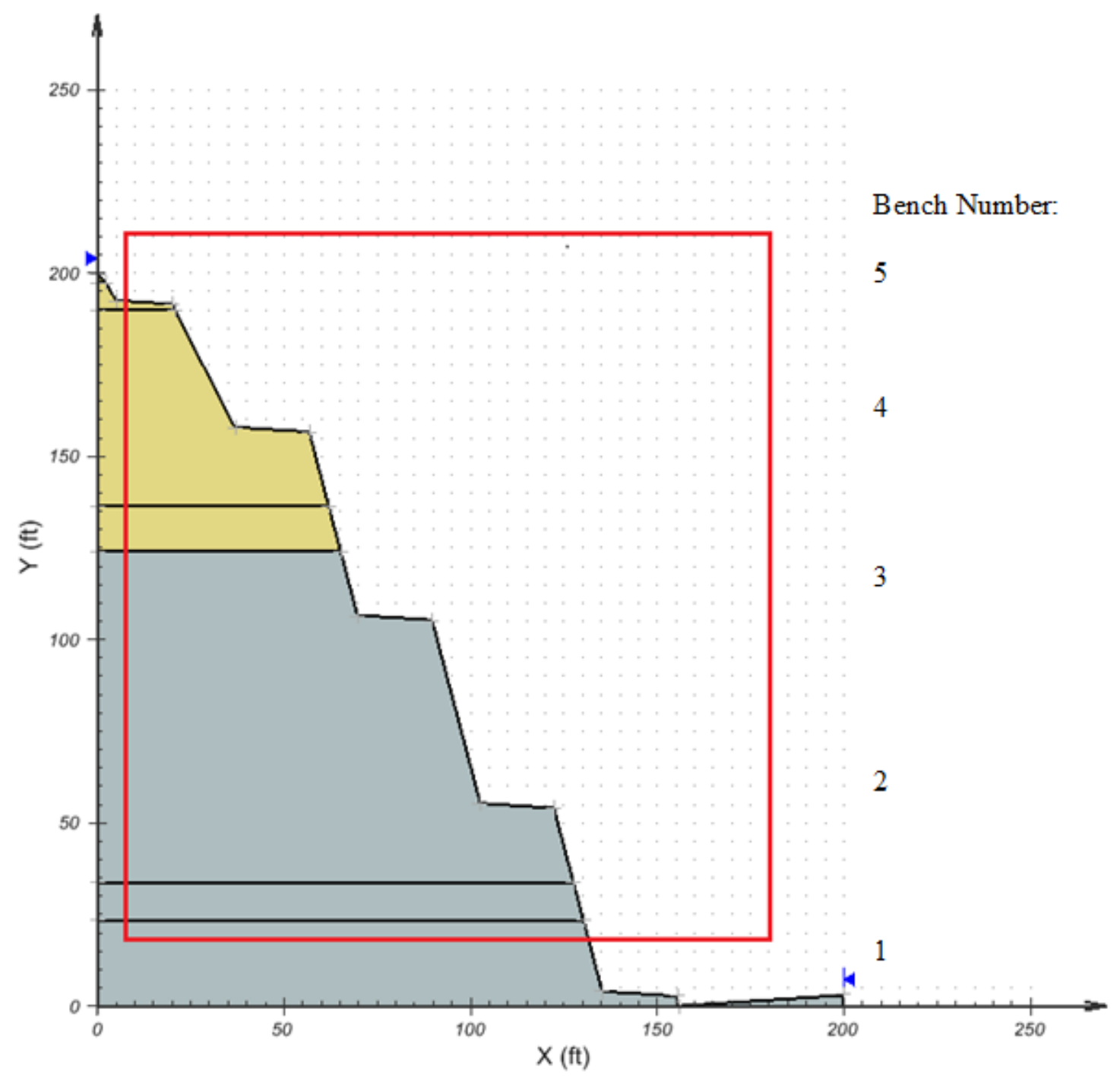

Figure 4.4.1: A screen shot of the focus area of bench elimination

\subsubsection{Site 2: Corridor H: WVDOH Design - As-Built: Initial Slope Assessment}

The initial slope assessment was conducted with the same geometry analyzed in Section 4.3.2. This analysis used the unconfined strength parameter at 50 percent of maximum value of the material, this was to ensure the preliminary factor of safety would be above 1.25 , thus illustrating the effect any bench elimination will have on the slope, be it positive or negative. This analysis procedure was conducted identically to the process discussed in Section 4.2.1. The Hoek-Brown failure criterion was input with the minimum values to promote a conservative design, whilst meeting the primary objective of increased slope performance with the implementation of continuous planar sections exceeding the current design restrictions. Table 4.4.1.1 includes a 
listing of the parameters and the respective values used throughout the bench reduction analysis on Corridor $\mathrm{H}$.

Table 4.4.1.1: Corridor H: Hoek-Brown Input Parameters (Sjöberg, 1997) (Zhao, 2010)

\begin{tabular}{|c|c|c|}
\hline \multicolumn{3}{|c|}{ Corridor H: Hoek-Brown Input Parameters } \\
\hline Parameter & Sandstone & Limestone \\
\hline $\begin{array}{c}\text { Unconfined Compressive } \\
\text { Strength (KSF) @ 50\% of } \\
\text { maximum UCS }\end{array}$ & 1984.116 & 2923.960 \\
\hline Disturbance Factor & 1.0 & 1.0 \\
\hline Geological Strength Index & 23 & 23 \\
\hline Rock Mass & 5 & 4 \\
\hline Unit Weight (lb./ft ${ }^{3}$ ) & 151.08 & 156.07 \\
\hline
\end{tabular}

The initial slope assessment analysis yielded the factor of safety results listed in Table 4.4.1.2 given the use of the previous listed parameter values. The target of the further bench reduction models will be to meet or exceed the current factor of safety of the slope. Figure 4.4.1.1 shows the proposed failure plane location derived from the initial slope assessment.

Table 4.4.1.2: Corridor H: WVDOH Design-As-Built: Initial Slope Assessment

\begin{tabular}{|c|c|}
\hline \multicolumn{2}{|c|}{ Initial Slope Assessment } \\
\hline Analysis Method & Factor of Safety \\
\hline General Limit Equilibrium & 2.090 \\
\hline
\end{tabular}

The current calculated factor of safety is significantly greater than 1.25 , which leads to the belief that the slope has been over designed with benches at 50percent of maximum material strength value. This leaves an ideal opportunity for a bench reduction procedure. 


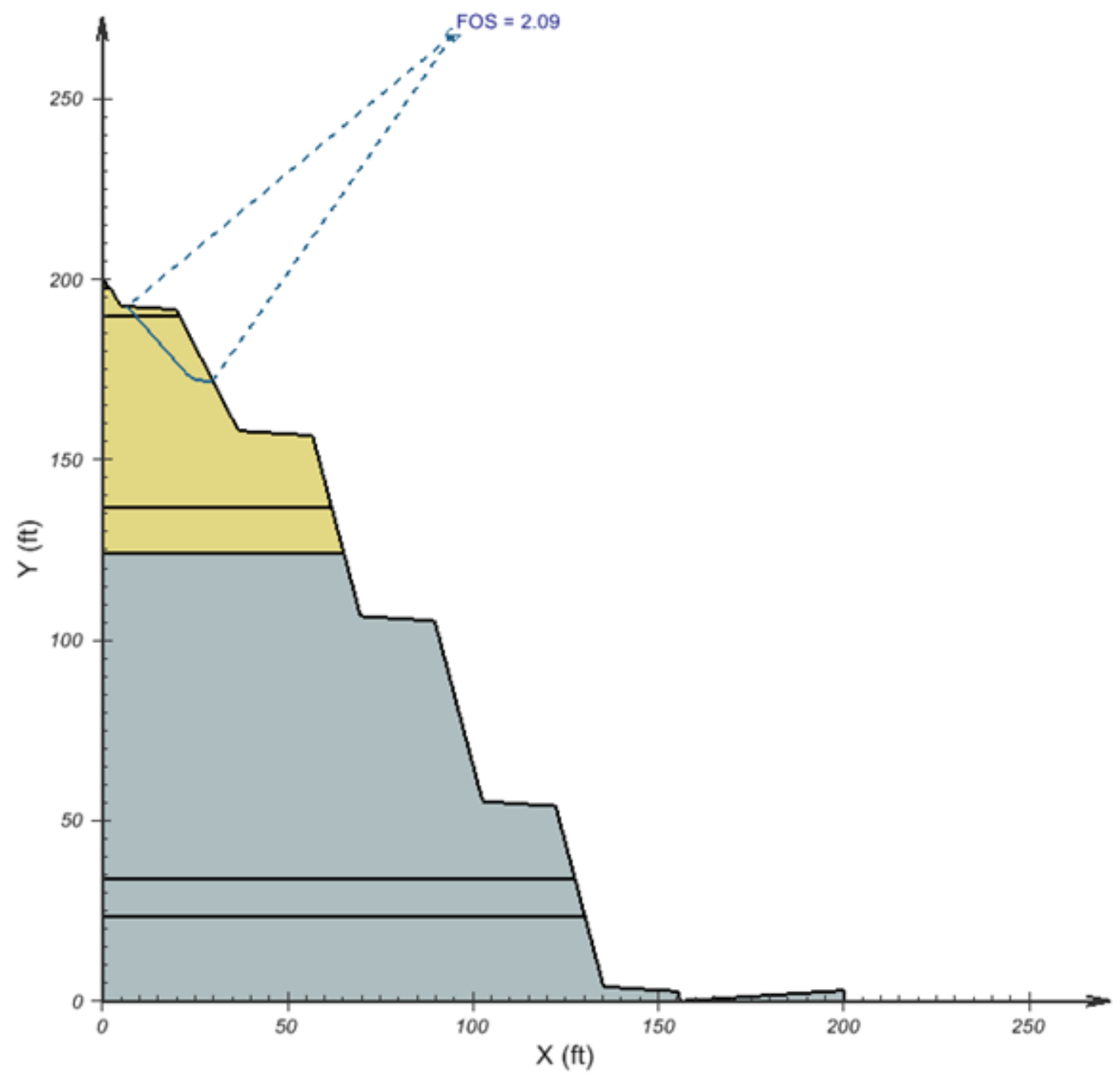

Figure 4.4.1.1: Initial Slope Assessment 


\subsubsection{Site 2: Corridor H: WVDOH Design - As-Built: New Slope Design Trial 1}

The initial slope redesign targeted the sandstone area. This area illustrated signs of failure in all three previous modeling cases; Hoek-Brown Low and High cases, as well as the initial slope assessment while using 50 percent of maximum unconfined compressive strength value. The new slope layout was designed with intent to leave more material in place so the in situ stresses would allow more resistance against the driving forces leading to failure. The redesign of the slope allowed for a new profile to consist of four geotechnical benches, including the sighting bench at roadway grade, this is a reduction of one bench from the original contour. This alteration in bench number allowed for a larger back slope of the angle located near the crest of the slope, the new back slope height was approximately $80 \mathrm{ft}$. In addition a new bench width was derived during this design of approximately $50 \mathrm{ft}$. horizontally. The new design has exceeded the criteria listed in DD-403. A screenshot of the modeled profile is illustrated in Figure4.5.2.1. The resulting stability analysis is listed in Table 4.5.2.1.

Table 4.4.2.1: Corridor H: WVDOH Design-As-Built: New Slope Design Trial 1

\begin{tabular}{|c|c|c|c|}
\hline \multicolumn{4}{|c|}{ New Slope Design Trial 1 } \\
\hline Analysis Method & Initial Factor of Safety & $\begin{array}{c}\text { Bench Reduction } \\
\text { Factor of Safety }\end{array}$ & Percent Difference \\
\hline $\begin{array}{c}\text { General Limit } \\
\text { Equilibrium }\end{array}$ & 2.090 & 1.093 & $-47.6 \%$ \\
\hline
\end{tabular}

It may be concluded on that with the new slope design a decrease in factor of safety was found due to the bench reduction. The increase in the sandstone material at the crest created enough resisting forces to overcome the driving forces leading to failure; however, it resulted in instability issues further down the slope. The new proposed failure plane initiates at the interface of the bench and back slope. This is most likely due to high stress concentration at this inflection point. The increased stresses are a direct result of the amplified material weight at the crest of the slope. Due to the decrease in the slope performance and the resulting factor of safety being less than the required 1.25 as stated within DD-403 this design should not be considered, further design profiles should be assessed. 


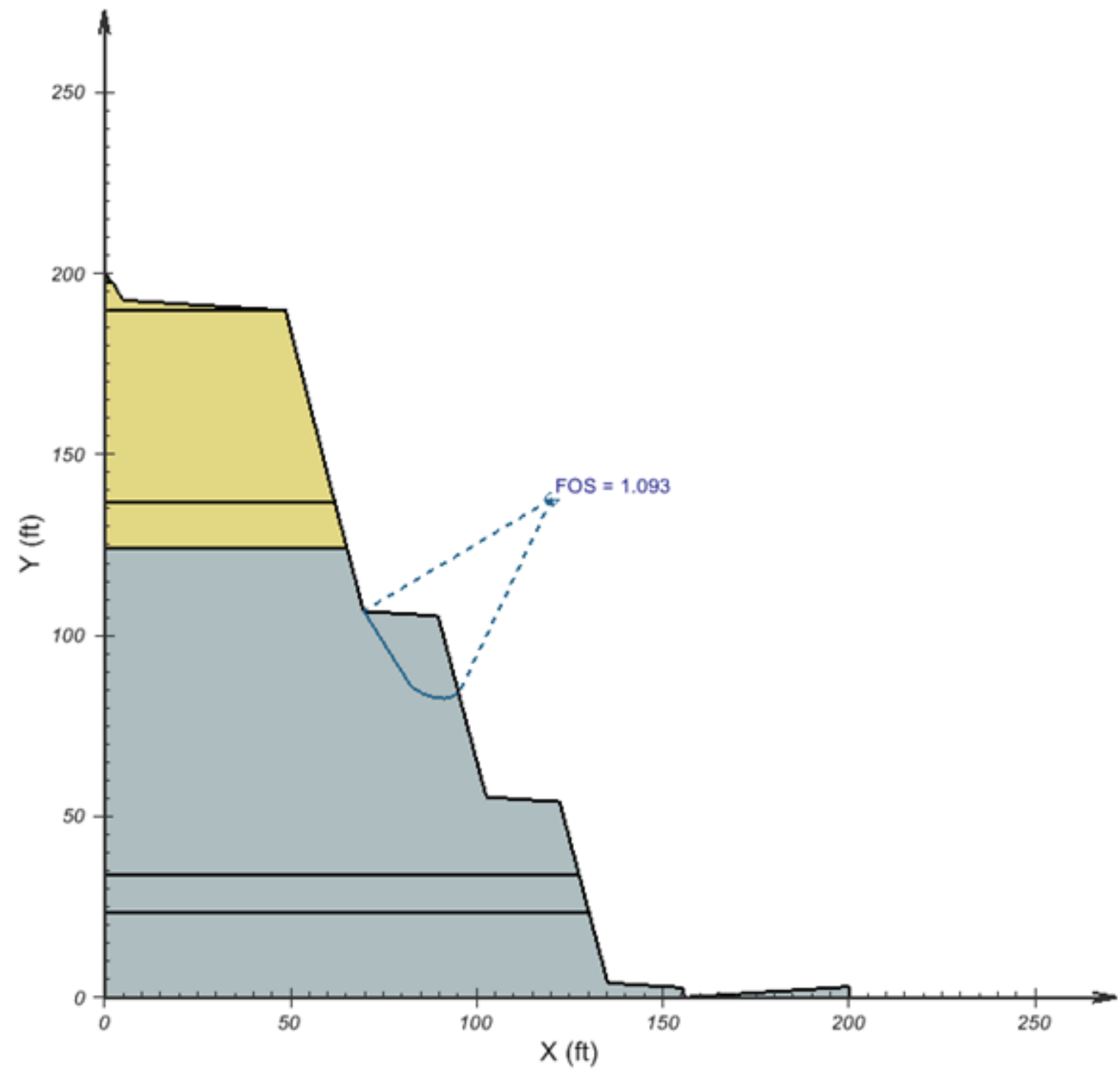

Figure 4.4.2.1: New Slope Design Trial 1 


\subsubsection{Site 2: Corridor H: WVDOH Design - As-Built: New Slope Design Trial 2}

The second design consideration within the new profile assessment will incorporate Trial 1 into the design. In addition to allowing for more sandstone material to remain at the crest, the second bench from the bottom in the limestone layer will be filled in resulting in a second larger planar back slope. The intent of this design was to allow for enough limestone material to provide resistive forces against the driving force proposed by the sandstone. The new slope design along with the newly proposed failure plane can be seen in Figure 4.4.3.1. Table 4.4.3.1 includes the data from the stability analysis.

Table 4.4.3.1: Corridor H: WVDOH Design-As-Built: New Slope Design Trial 2

\begin{tabular}{|c|c|c|c|}
\hline \multicolumn{4}{|c|}{ New Slope Design Trial 2 } \\
\hline Analysis Method & Initial Factor of Safety & $\begin{array}{c}\text { Bench Reduction } \\
\text { Factor of Safety }\end{array}$ & Percent Difference \\
\hline $\begin{array}{c}\text { General Limit } \\
\text { Equilibrium }\end{array}$ & 2.090 & 1.493 & $-28.6 \%$ \\
\hline
\end{tabular}

Similar to the first redesign, a decrease in factor of safety was found with the bench reduction. The reduction in the strength was not as severe at the first attempt, this is most likely due to the addition limestone redirecting the simulated failure plane and overcoming some of the driving forces. This design should be further evaluated with the possibility of increasing the back slope height in the limestone in the attempt to allow for more material to resist the driving force cause by failure. It should be noted that although the factor of safety is above the required 1.25 deeming it a successful trial; however, a reduction in stability was still produced, thus the profile should be considered at a design option under caution. The statement to evaluate this slope with caution stems from the issue with material testing and that extensive material tests should be conducted on a given material prior to considering this bench reduction application similar to this scenario. 


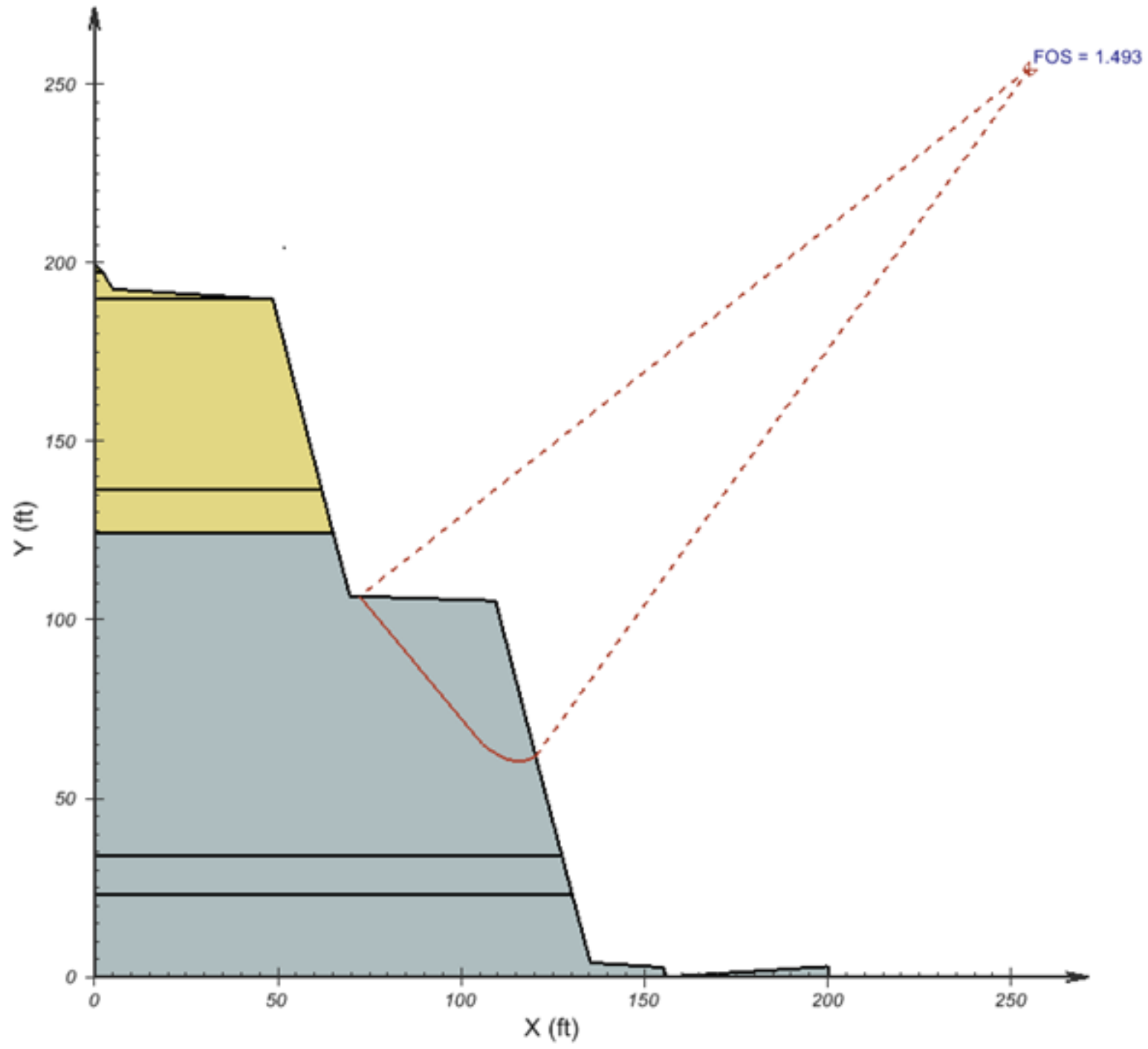

Figure 4.4.3.1: New Slope Design Trial 2 


\subsubsection{Site 2: Corridor H: WVDOH Design - As-Built: New Slope Design Trial 3}

The third bench reduction slope design was constructed similar to Trial 2, with the increased amount of limestone remaining mid-slope to resist the driving forces which lead to slope failure. In the third redesign two benches were eliminated in the limestone portion of the slope. The sighting bench was left in place, due to current department of highways practice; this resulting in a new back slope vertical height of approximately $120 \mathrm{ft}$. This new continuous back slope has allowed for a larger bench to be placed at the interface of the sandstone and limestone layer, the newly proposed bench protrudes nearly $45 \mathrm{ft}$. horizontally. The new slope design profile as well as the proposed failure plane can be seen in Figure 4.4.4.1. Results from the stability analysis are listed in Table 4.4.4.1.

Table 4.4.4.1: WVDOH Design-As-Built: New Design Trail 3

\begin{tabular}{|c|c|c|c|}
\hline \multicolumn{4}{|c|}{ WVDOH Design - As-Built: New Slope Design Trial 3 } \\
\hline Analysis Method & Initial Factor of Safety & $\begin{array}{c}\text { Bench Reduction } \\
\text { Factor of Safety }\end{array}$ & Percent Difference \\
\hline $\begin{array}{c}\text { General Limit } \\
\text { Equilibrium }\end{array}$ & 2.090 & 1.085 & $-48.1 \%$ \\
\hline
\end{tabular}

Conclusive data upon the completion of stability analysis yielded a reduction in the factor of safety. The proposed failure plane behavior this time was forced back into the sandstone layer. The intent of the design to allow for the extra limestone material to with stand the failure driving force did in fact do just that, thus redirecting the failure location. Reduction in the factor of safety has yet again led to an unacceptable design which does not meet or exceed the initial design factor of safety also dropping below the required 1.25 as stated in DD-403; this profile design should not be considered as a resign option. The failure plane appears to be at the original angle of design in the sandstone layer; further designs should be attempted to emulate this angle with intent at minimizing the driving forces the material subjects onto itself. 


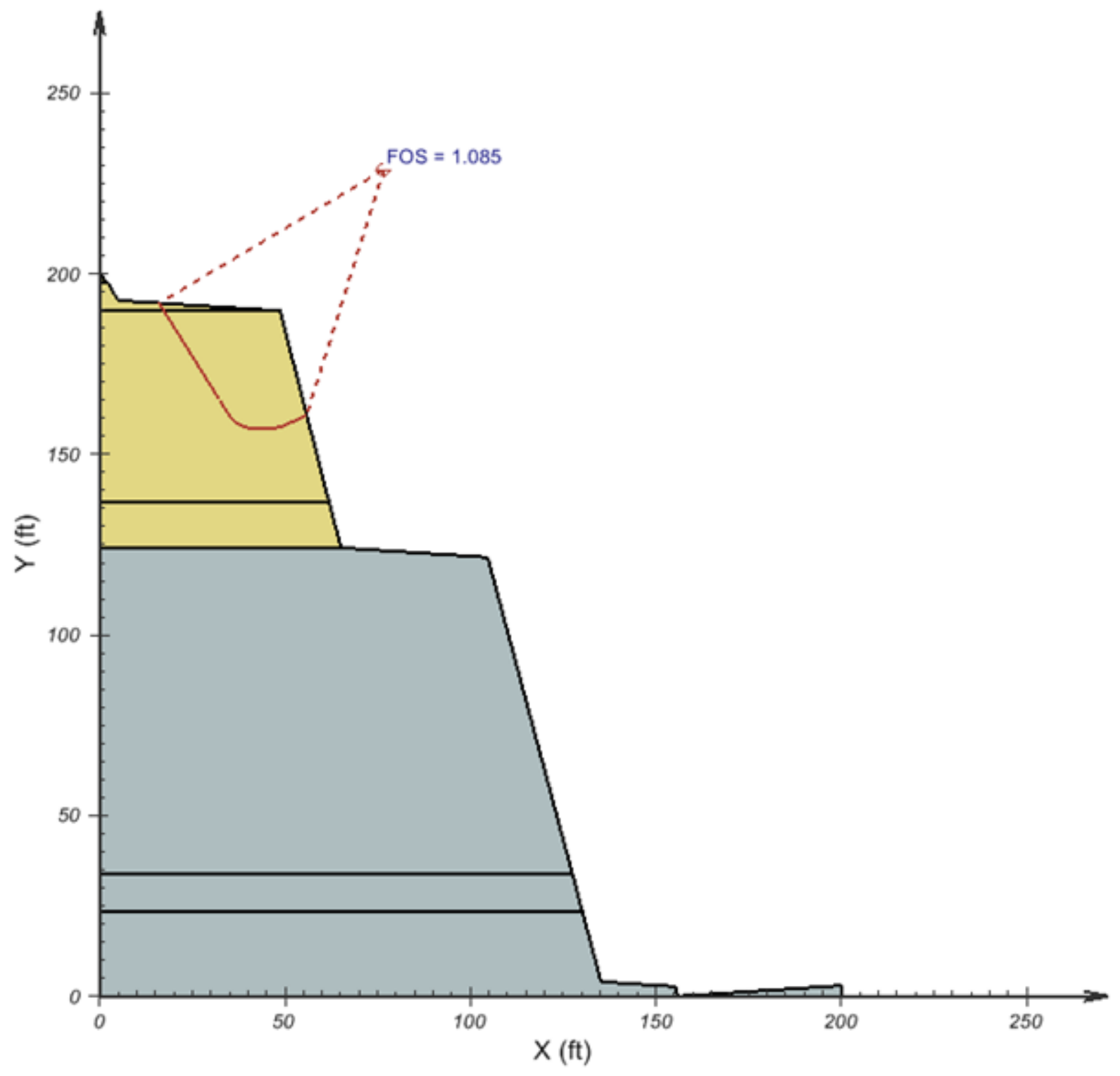

Figure 4.4.4.1: New Slope Design Trial 3 


\subsubsection{Site 2: Corridor H: WVDOH Design - As-Built: New Slope Design Trial 4}

The final slope construction was designed with the attempt to minimize excavated material by considering only one bench throughout the height of the slope. This design was completed with consideration from the third trial and the location of the suggested failure plane in that case. The limestone section was made continuously planar from the sighting bench at the roadway grade to the interface of the sandstone. This is the same concept considered in Trial 3; however, to minimize the self-weight the sandstone would undergo, the material was laid back to a lower back slope angle while keeping within the original slope boundaries. The reason for laying the sandstone back was from previous analyses and the failure plane angle. A screen shot of the constructed slope as well as the resulting simulated failure plane can be seen in Figure 4.4.5.1. The resulting factor of safety from this new slope profile is listed in Table 4.4.5.1.

Table 4.4.5.1: Corridor H: WVDOH Design-As-Built: New Design Trail 4

\begin{tabular}{|c|c|c|c|}
\hline \multicolumn{4}{|c|}{ New Slope Design Trial 4 } \\
\hline Analysis Method & Initial Factor of Safety & $\begin{array}{c}\text { Bench Reduction } \\
\text { Factor of Safety }\end{array}$ & Percent Difference \\
\hline $\begin{array}{c}\text { General Limit } \\
\text { Equilibrium }\end{array}$ & 2.090 & 1.222 & $-41.5 \%$ \\
\hline
\end{tabular}

Conclusive evidence shows a reduction in overall slope factor of safety with the removal of benches two and three and the addition of laying the sandstone portion back to a lower back slope angle. The evaluation of this slope profile redistributed the failure plane back within the limestone layer. Similar to the other design trials a reduction was yet again seen in the slope performance; this case, dropping the factor of safety below the required 1.25. This design may be considered at the geotechnical engineer's discretion as it does in fact fall beneath the required value however is close to the required 1.25 . 


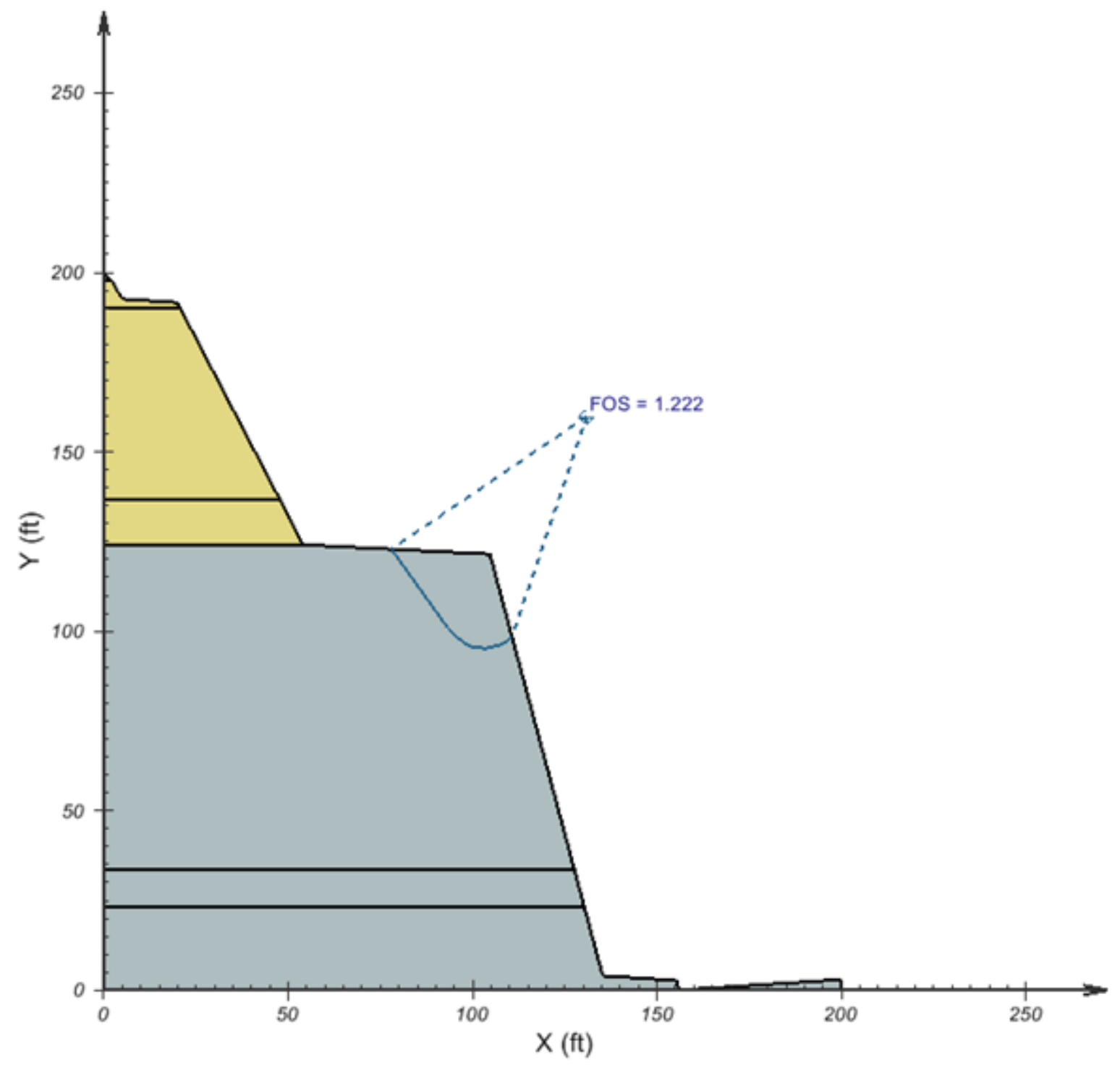

Figure 4.4.5.1: New Slope Construction Trial 4 


\subsubsection{Site 2: Summary and Comparison: Corridor H: Bench Reduction}

A final comparison of results was necessary in order to evaluate the factor of safety response through the various designs. Table 4.4.6.1 lists the result derived through the modeling process.

Table 4.4.6.1: Summary table of factor of safety influence with new slope design

\begin{tabular}{|c|c|c|c|c|c|}
\hline \multicolumn{5}{|c|}{ Corridor H: WVDOH Design - As-Built: New Slope Design Results } \\
\hline Analysis & $\begin{array}{c}\text { Number } \\
\text { of } \\
\text { Benches }\end{array}$ & $\begin{array}{c}\text { Initial } \\
\text { Factor of } \\
\text { Safety }\end{array}$ & $\begin{array}{c}\text { Bench } \\
\text { Reduction } \\
\text { Factor of } \\
\text { Safety }\end{array}$ & $\begin{array}{c}\text { Percent } \\
\text { Difference }\end{array}$ & Alteration \\
\hline Initial & 5 & 2.090 & - & - & - \\
\hline $\mathbf{1}$ & 4 & 2.090 & 1.093 & $-47.6 \%$ & $\begin{array}{l}\text { - Elimination of } \\
\text { fourth bench }\end{array}$ \\
\hline $\mathbf{2}$ & 3 & 2.090 & 1.493 & $-28.6 \%$ & $\begin{array}{l}\text { - Elimination of } \\
\text { second and fourth } \\
\text { bench }\end{array}$ \\
\hline $\mathbf{3}$ & 3 & 2.090 & 1.085 & $-48.1 \%$ & $\begin{array}{l}\text { - Elimination of } \\
\text { second and fourth } \\
\text { bench } \\
\text { - Relocation of third } \\
\text { bench }\end{array}$ \\
\hline $\mathbf{4}$ & 3 & 2.090 & 1.222 & $-41.5 \%$ & $\begin{array}{l}\text { - Elimination of } \\
\text { second and fourth } \\
\text { bench } \\
\text { - Lay back of } \\
\text { sandstone area }\end{array}$ \\
\hline
\end{tabular}

- Conclusive evidence shows bench reduction in these instances is neither beneficial nor plausible to create increased slope factor of safety. The redesign of the slope profiles yielded similar results with each outcome, some showing more of a factor of safety reduction than others. The bench reduction did in fact show the possibility to include bench removal achieving the minimum factor safety requirement of 1.25 ; however, a decline in factor of safety was the result. In this situation it is significantly important to follow the cut slope design standards as listed in DD-403 given this back slope angle.

- If continuous planar sections are of need in hard rock material, it is advised to lay the slope back at a lower back slope angle. The laying back of the slope will help with the stress distribution, thus leading to a stable slope design. While laying the slope back increases the quantity of material to be excavated it does in fact allow for a stable planar design. Figure 4.4.6.1 illustrates a side-by-side comparison of all the design trails assessed for Corridor $\mathrm{H}$. 

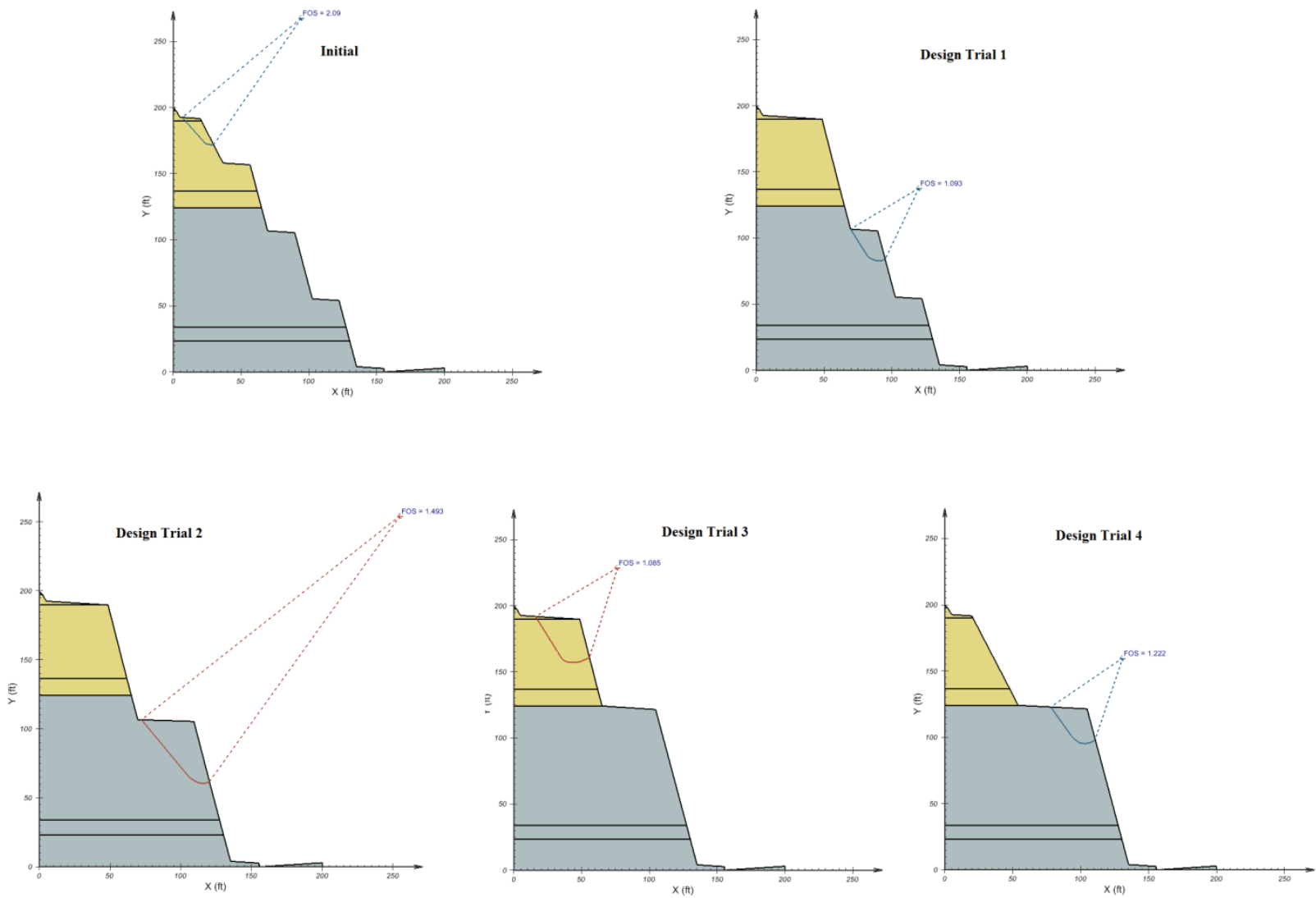

Figure 4.4.6.1: Corridor H Design Trials

Table 4.4.6.2: Bench Reduction Summary Table

\begin{tabular}{|c|c|c|}
\hline Analysis & Number of Benches & Factor of Safety \\
\hline Initial & 5 & 2.090 \\
\hline Trial 1 & 4 & 1.093 \\
\hline Trial 2 & 3 & 1.493 \\
\hline Trial 3 & 3 & 1.085 \\
\hline Trial 4 & 3 & 1.222 \\
\hline
\end{tabular}




\subsubsection{Site 2: Corridor H: Layer Sensitivity}

The completion of the Corridor $\mathrm{H}$ bench reduction analysis illustrated reduction in strength in each of the design trials. This result was not as expected due to the material strength that was assessed during this analysis as compared to the lower material strengths evaluated in the Coalfield's Expressway section. A difference in the geology difference other than material competency was the lamination of layering. The Corridor $\mathrm{H}$ borehole logs should eight layers that spanned a vertical height of $200 \mathrm{ft}$. Evaluation of the Coalfields Expressways geotechnical report showed 16 layers that spanned a $200 \mathrm{ft}$. vertical height and a total of 24 layers to cover the total slope height of approximately $370 \mathrm{ft}$. It was believed layer interaction may serve a role in the stability behavior with regards to stress paths and force concentrations. An analysis was performed on Corridor $\mathrm{H}$ to simulate a more laminated geological composition. This model took the geological finds gathered from the geotechnical report and divided the total depth into approximately 16 zones to allow more layer interface interaction during the analysis. Geometric parameters were held constant to the initial slope evaluation to solely examine the behavior geological layering may have on the factor of safety analysis. Table 4.4.7.1 lists the variable inputs and values used in the analysis. The unconfined compressive strength value used was at 50 percent of maximum value.

Table 4.4.7.1: Corridor $H$ validation material values

\begin{tabular}{|l|c|c|}
\hline \multicolumn{3}{|c|}{ Corridor H: Hoek-Brown Input Parameters } \\
\hline Parameter & Sandstone & Limestone \\
\hline $\begin{array}{l}\text { Unconfined Compressive } \\
\text { Strength (KSF) }\end{array}$ & 1984.116 & 2923.960 \\
\hline Disturbance Factor & 1.0 & 1.0 \\
\hline Geological Strength Index & 23 & 23 \\
\hline Rock Mass & 5 & 4 \\
\hline Unit Weight (lb./ft ${ }^{3}$ ) & 151.08 & 156.07 \\
\hline
\end{tabular}

Figure 4.4.7.1 illustrates the side-by-side layering difference the validation model has in comparison with the initial model evaluation. The resulting evidence from the analysis proved that layer interaction did not play a role in stability performance with the proposed failure planes occurring at identical location from the analyses. This validation illustrates that material strength is the sole driving factor in slope stability and geological composition with regards to layering has no effect on the structural integrity of the slope. 

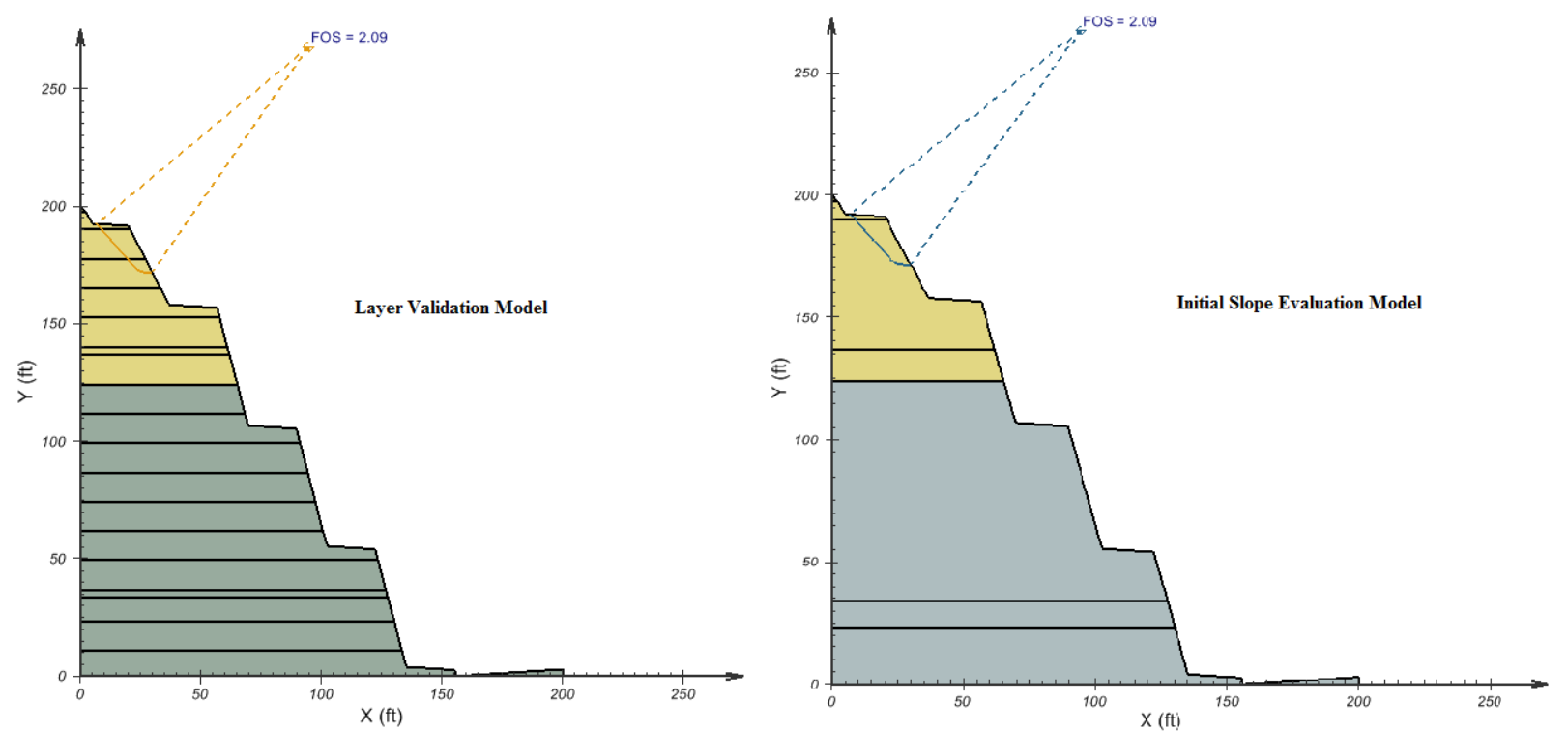

Figure 4.4.7.1: Layer validation failure plane comparison 


\subsection{CONCLUSIONS AND RECOMMENDATIONS}

The purpose of this research was to address the feasibility and practicality of continuous planar slope profiles designs to be implemented with the design directives currently used by West Virginia Department of Highways. The key tool used in this evaluation was finite element modeling software in addition to field visitations and the completion of a literature review. The following conclusive evidence of the research is as follows:

Through the use of the modeling software SoilVision Systems ${ }^{\mathrm{TM}}$ particularly the SVSlope ${ }^{\circledR}$ module the following guidelines, findings, and recommendations were derived:

- Extensive sub-surface exploration should be conducted within the given area of a proposed rock cut slope. As illustrated in the modeling there are wide ranges with regards to strength of a given material. Unconfined compressive strength tests should be performed on the extracted material that is obtained through borehole drilling. Tests should be conducted on each of the materials where a substantial layer is encountered. In addition testing to acquire the unit weight should also be conducted. Test samples taken at each material layer will allow increase the accuracy of a design, to ensure an undesirable weak material is properly addressed in the design.

- Use of the initial back slope design charts should be used to derive on the acceptable angle to meet the required factor of safety of 1.25 given the predominant materials unconfined compressive strength

- The use of finite element software with the capability of evaluating the Hoek-Brown failure criterion should be used in slope design and stability assessment. Evaluation of a rock material as Mohr-Coulomb criterion is not beneficial in the design and should not be a practice, due to the theory and input parameters. The Hoek-Brown criterion take into consideration the effects blasting will have on the material. Blasting can lead to facture propagation on the exposed rock face leading to slope instability, this should be modeled to ensure a conservative design. In regards of the other criterion parameters (i.e. GSI and Rock Mass Index) estimation or assumed values should be done so on the lower end of the data range. The method of slices to be used during the stability should be done so to encompass the factor of safety calculation in regards to moments and forces. The General Limit Equilibrium does in fact consider both in the evaluation, if the Simplified Bishop's method is desired; it should be coupled with the Simplified Janbu the same coupling must be done if the Simplified Janbu method is the preferred method. 
- Through the design flow chart conformation it was found that the most sensitive back slope angle occurs at approximately $60^{\circ}$. While holding all parameters constant and exclusively altering the geometry, the stability results behave in a non-linear fashion with the inflection point occurring around $60^{\circ}$.

- The use of continuous planar sections throughout the slope should be evaluated and considered given stability requirements have been met. The iterative process should be performed until a desirable design has been met with respect to the designer's approval. The design should be economically practical and allow for safe construction practices. It should be noted that not all benches can be removed, there has to be at least one bench for construction practices (Aaron Wentz, personal communication, 2013).

- The slope stability evaluation results showed that it is possible to place continuous planar cut section with a slope profile and have an increase in the factor of safety, given certain stipulations. When benches are eliminated the designer can increase bench widths to allow for large material volumes to resist driving forces. This is an iterative process; several designs should be evaluated during this course.

- The bench reduction process conducted on U.S. Route 121 yielded the elimination of one geotechnical bench which lead to the increase is slope factor of safety in three of the four redesign cases assessed. Trial three of the reduction process showed an increase in stability by approximately $24 \%$. This would not only allow for a greater structural integrity is will allow for lower excavation quantities to be left in place, lowering the overall construction cost.

- Benches removed in situations where the back slope angle will exceed $0.5: 1$ or $63^{\circ}$ should be done with caution and consultation with several designers should take place. As seen in the Corridor $\mathrm{H}$ modeling a reduction was seen in all the design considerations. It should be noted that a bench reduction analysis may provide a factor of safety which exceeds the minimum requirement of 1.25; however, is a reduction from the initial evaluation. This design should be openly discussed if it is to be used. One must make sure that the appropriate testing has been performed to ensure with certainty that the bench reduction design will in fact provide a safe slope design. It is best to negate this option until it is the last resort of slope design. If continuous planar sections are sought, the back slope angle of the slope should be laid back, thus lowering the stresses caused by moments and forces. This will require additional material excavation and subsequently the addition of right-of-way.

- Rock cut slope profiles containing a continuous planar section exceeding $50 \mathrm{ft}$. vertically or multiple sections should allow for some type of rock fall attenuation structure (i.e. fence, 
ditch, larger benches mid slope) or device to minimize the chance for debris to reach the roadway surface thus posing a direct threat to users.

- Layering on lamination of the geologic layer does not affect the stability performance of a rock cut slope. Material strength is the sole factor in determining the factor of safety; whether it is laminated with infinite layers or is one solid unit.

The geology found within West Virginia allows for continuous planar sections exceeding $50 \mathrm{ft}$. vertically thus lowering excavation quantities. This will allow for various design alternations to be available for cut slope design. The reduction in material excavation will lead to lower project costs. A reduction in construction cost will allow for more projects, maintenance, or rehabilitation of current structures throughout the state.

Continuous planar sections are possible to be constructed given if the proper steps and considerations previously listed are followed. This will require extensive material testing of samples obtained through subsurface exploration. If the required right-of-way does not permit slopes exceeding 0.5:1 to be laid back to allow for planar cut, extreme caution should be used in the a bench reduction design.

With the current rock cut slope design guide restricting continuous planar sections, this research has addressed the problem soundly illustrating the possibility for a new design approach to be set in practice. This research was limited to two geographic regions within West Virginia. Weak and hard materials were assessed during this project, and through finite element software, illustrated the feasibility of designing and implementing continuous planar sections within rock cut slopes in weak sedimentary rock and competent limestone. 


\section{REFERENCES}

Das, Braja M. (2006). Principles of Geotechnical Engineering $\left(7^{\text {th }}\right.$ ed.). Canada: Nelson Education Ltd.

Federal Highway Administration: Central Federal Lands Highway Division. (2011). Context Sensitive Rock Slope Design Solutions (Publication No. FHWA-CFL/TD-11-002). Lakewood, CO.

Federal Highway Administration: Central Federal Lands Highway Division. (2012). CRSP-3D User's Manual: Colorado Rockfall Simulation Program (Publication No. FHWACFL/TD-12-007). Lakewood, CO.

Federal Highway Administration: Central Federal Lands Highway Division. (1991). Rock Blasting and Overbreak Control. (Publication No. FHWA-HI-92-001). Lakewood, CO.

Fredlund, M. (2009) SVOffice ${ }^{T M}$ 2009. Available from http://www.soilvision.com/svoffice2009download.php

Fredlund, D.G., Krahn, J., Pufahl, D.E. (1981). The Relationship between Limit Equilibrium Slope Stability Methods. Proceedings of the International Conference on Soil Mechanics And Foundation Engineering, Vol. 3. 409-416.

Hoek, E., Carranza-Torres, C., Corkum, B. (2002) Hoek-Brown Failure Criterion. Retrieved from http://www.rockscience.com/assets/files/uploads/7715.pdf.

Hoek, E., Marions, P., Marions, V. (2005) The Geological Strength Index: Applications and Limitations. Retrieved from http://www.rockscience.com/assets/files/uploads/7715.pdf.

Holtz, R., Kovacs, W., Sheahan, T. (2011) An Introduction to Geotechincal Engineering (2 ${ }^{\text {nd }}$ ed.) Pearsons Education, Inc.

Idleman, M. "Site Location Map" 2014.JPEG

Kulbacki, M. “Clay seam: U.S. Route 48” 2013. JPEG

Kulbacki, M. “Corridor H plan photograph” 2014. JPEG

Kulbacki, M. "Fallen rock on bench: U.S. Route 121" 2013. JPEG

Kulbacki, M. "Fallen rock on bench: U.S. Route 48" 2013. JPEG

Kutschke, W. (2013, December 1). Risk and Performance of Rock Cut Slope. Geo-Strata, 17, 24-30. 
Lin, G., Ord, A., Roberts, P., Zhang, Y. (2006) Numerical modeling of deformation and fluid flow in the Shuikoushan district, Hunan Province, South China. Elsevier, Volume 3 (1-4), 261-278.

Mohr-Coulomb Failure Criterion. Retrieved May 22, 2014. Retrieved from https://www.rocscience.com/help/rocdata/webhelp/rocdata/Mohr-Coulomb_Criterion.htm

Ohio Department of Transportation. (2011). Rock Slope Design Guide. Columbus, OH.

Sjöberg, J. (1997) Estimating Rock Mass Strength using the Hoek-Brown Failure Criterion and Rock Mass Classification. Internal Report: Division of Highways, (SE-971 87 Lulea, Lulea University of Technology).

West Virginia Department of Transportation, Division of Highways. (2006). Design Directives Guide for Design in Cut Sections Through Bedrock. Charleston, WV: WVDOH.

West Virginia Geological Survey. (2011). Geologic Map of West Virginia. Retrieved from http://www.wvgs.wvnet.edu/www/maps/geomap.htm

Zhao, J. (2010). "Chapter 4: Properties of Rock Materials.” Rock Mechanics for Civil Engineers. Swiss Federal Institute of Technology. 


\section{APPENDIX I}

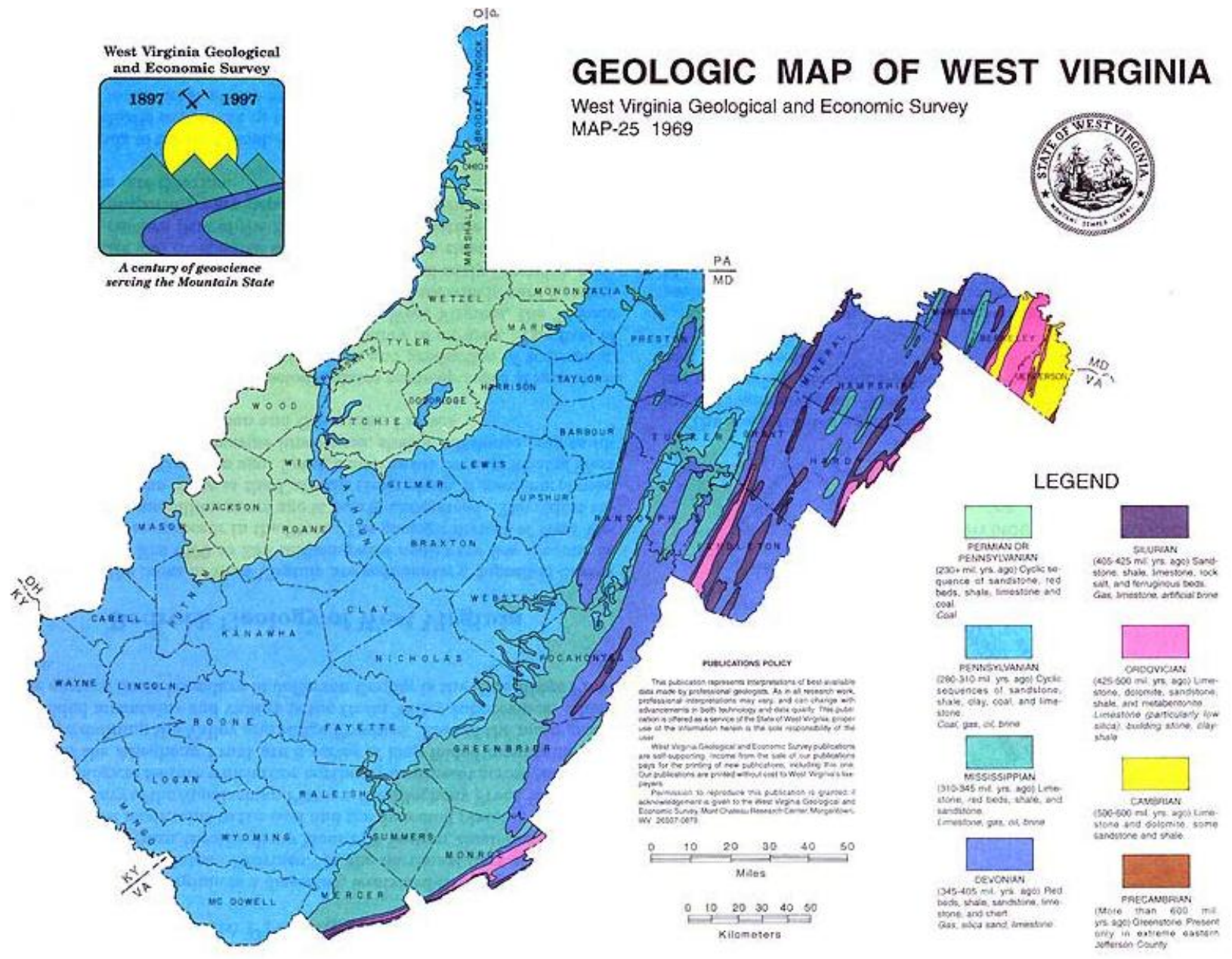

Figure A1-1: Geologic Map of West Virginia 


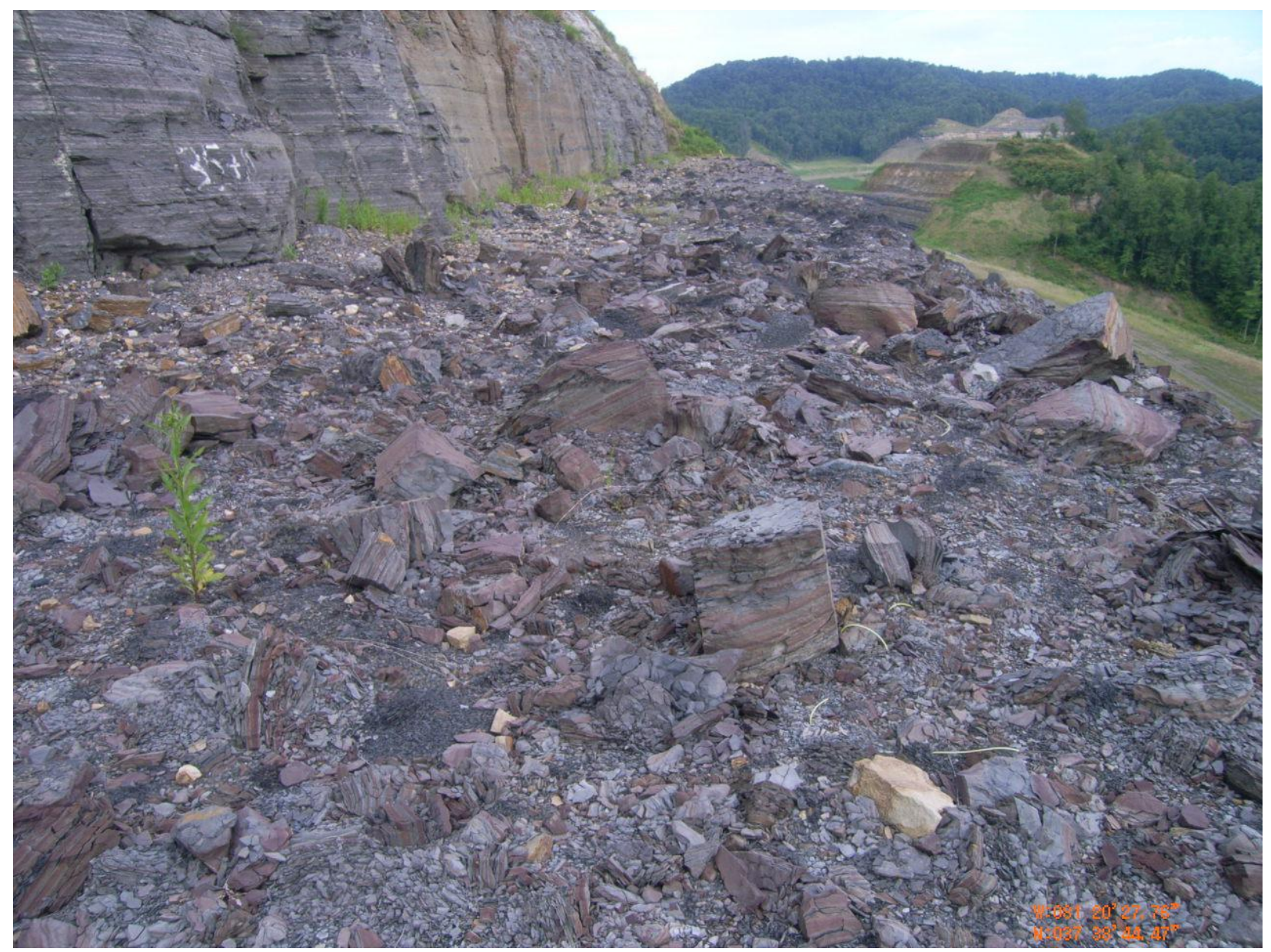

Figure A1-2: Filling of bench on Coalfield's Expressway majority of debris was siltstone 


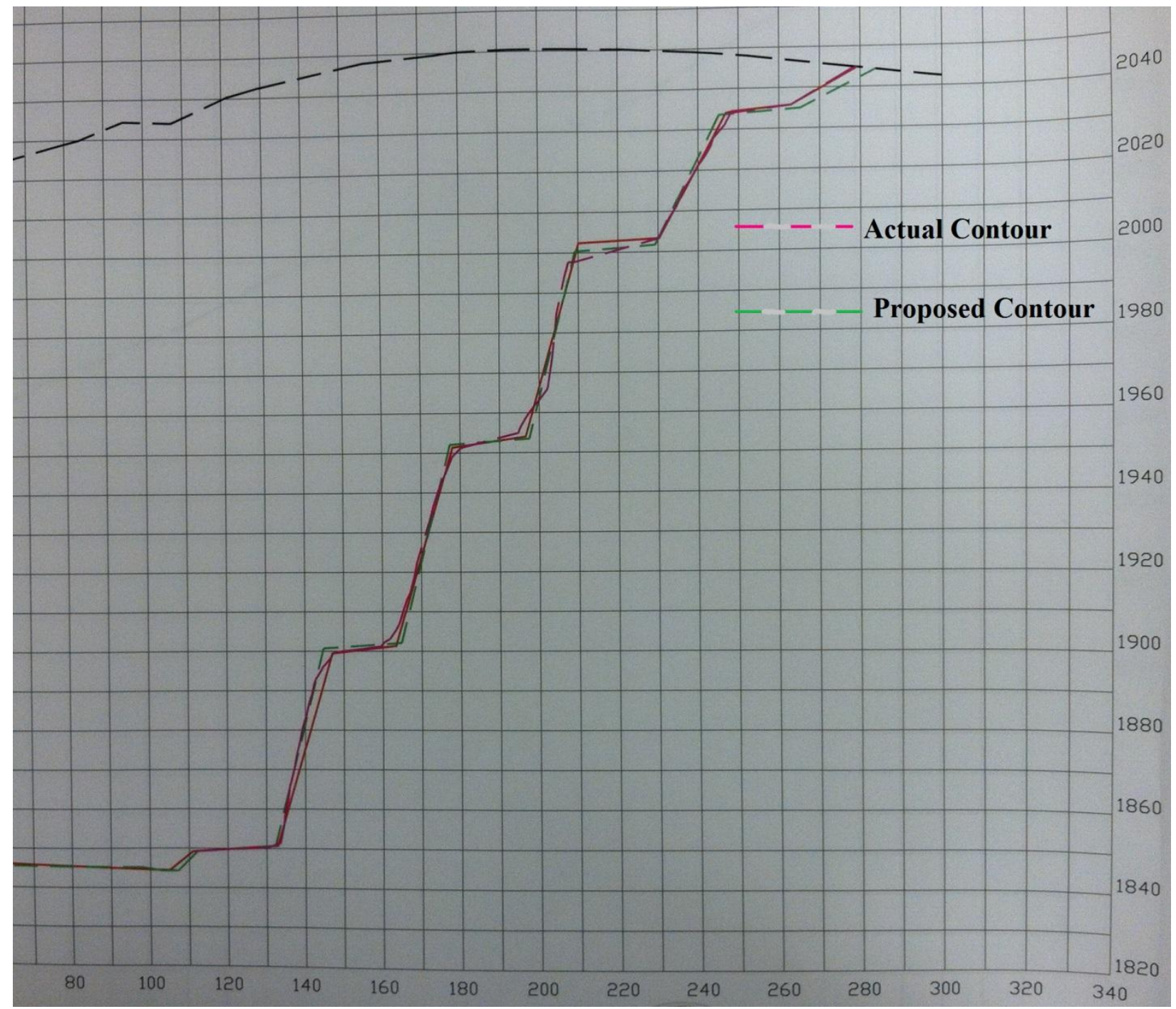

Figure A1-3: Photograph from Final As-Built Plan Corridor-H 


\section{APPENDIX II}

\section{TUTORIAL GUIDANCE DOCUMENT: NEW ROCK CUT SLOPE DESIGN}

This document provides a step by step breakdown on the process of using the flow charts and design charts developed throughout this report for new rock cut slope design. The process in new rock cut slope design can be broken into a two part procedure: 1.) Initial selection of the back slope angle, based on current DD-403 design requirements, 2.) Iterative Bench Reduction Process.

Keywords: back slope angle, failure plane, horizontal:vertical (H:V), unconfined compressive strength

\section{Initial Back Slope Selection}

The following format is step by step procedure on the use of the flow chart and design charts listed below. This design process is intended for rock cut slope construction and should not be used in the analysis or design of a soil media. All terms used (i.e. flow chart and design charts) are linked with the following figures. There are four design charts based upon four difference back slope angles: $1 \mathrm{H}: 1 \mathrm{~V}, 0.75 \mathrm{H}: 1 \mathrm{~V}, 0.5 \mathrm{H}: 1 \mathrm{~V}$, and $0.25 \mathrm{H}: 1 \mathrm{~V}$ design table one through four respectively.

- Subsurface exploration and recovery must be conducted with the extraction of rock cores. The cores must be recorded to note the depth, layer thickness, and any additional pertinent notes.

- Recovered material must be laboratory tested to achieve an unconfined compressive strength value that can be specified to each rock type.

- Testing should be conducted on each zone where a substantial layer or the most prevalent material is found. This will ensure accuracy later in the design process

- The initial back slope angle must be designed to the most prevalent material encountered from the subsurface exploration.

- The designer must compare the unconfined compressive strength values obtained in the laboratory testing to the design charts listed below. The strength of the material obtained through testing should be found on the $\mathrm{X}$-axis on Design Chart 1 . Once the material unconfined compressive strength value is found on the chart, the designer should track vertically and encounter the material in which they are evaluating. If the portion of the material they encounter falls below the required factor of safety condition of 1.25 , the designer should consider a shallower back slope angle until the minimum requirement is met. If the found value lies above the required factor safety of 1.25 , the design may proceed to Design Chart 2. 
- The designer should compare the unconfined compressive strength to the values listed on the $\mathrm{X}$-axis of Design Chart 2. Once the material unconfined compressive strength value is found on the chart, the designer should track vertically and encounter the material in which they are evaluating. If the portion of the material they encounter falls below the required factor of safety condition of 1.25 , the designer should design to the back slope angle listed on Design Chart 1. If the found value lies above the required factor safety of 1.25 , the design may proceed to Design Chart 3.

- The designer should compare the unconfined compressive strength to the values listed on the X-axis of Design Chart 3. Once the material unconfined compressive strength value is found on the chart, the designer should track vertically and encounter the material in which they are evaluating. If the portion of the material they encounter falls below the required factor of safety condition of 1.25 , the designer should design to the back slope angle listed on Design Chart 2. If the found value lies above the required factor safety of 1.25 , the design may proceed to Design Chart 4.

- The designer should compare the unconfined compressive strength to the values listed on the X-axis of Design Chart 4. Once the material unconfined compressive strength value is found on the chart, the designer should track vertically and encounter the material in which they are evaluating. If the portion of the material they encounter falls below the required factor of safety condition of 1.25 , the designer should design to the back slope angle listed on Design Chart 3. If the found value lies above the required factor safety of 1.25, the design may proceed with the back slope angle listed on Design Chart 4. 


\subsection{Flow Chart and Design Charts}

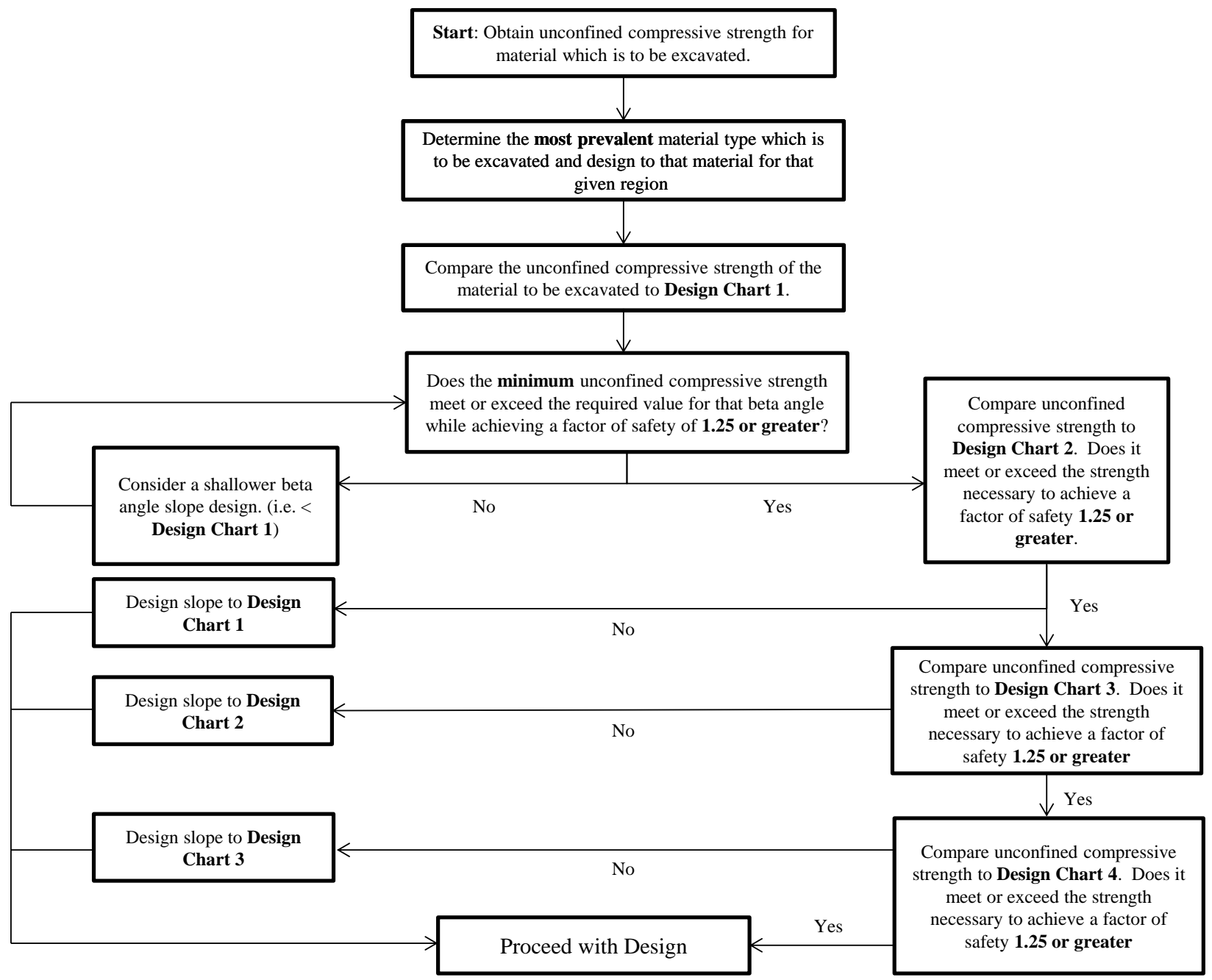

Figure 1.1.1: New Slope Design Flow Chart 


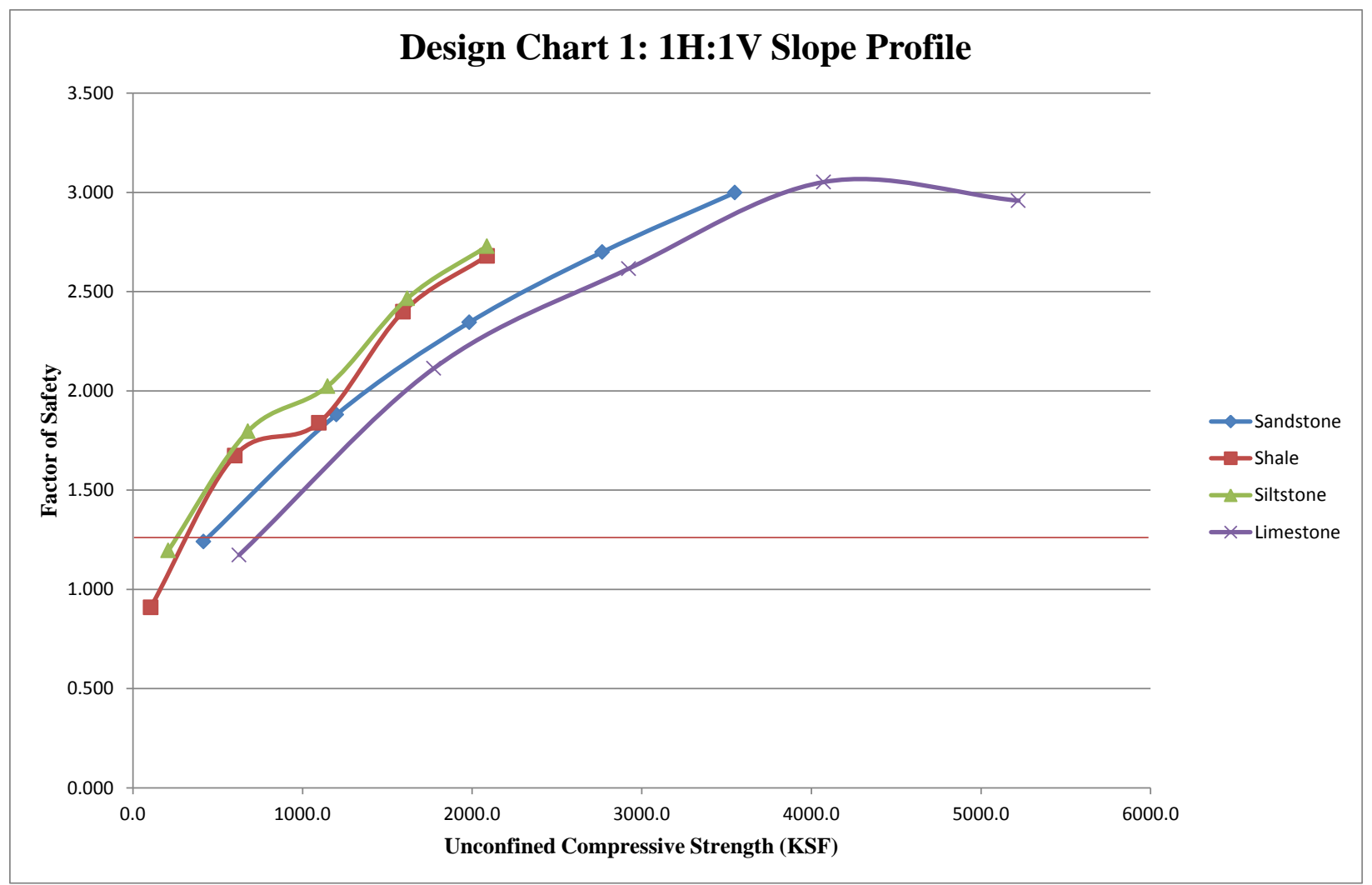

Figure 1.1.2: Design Chart1

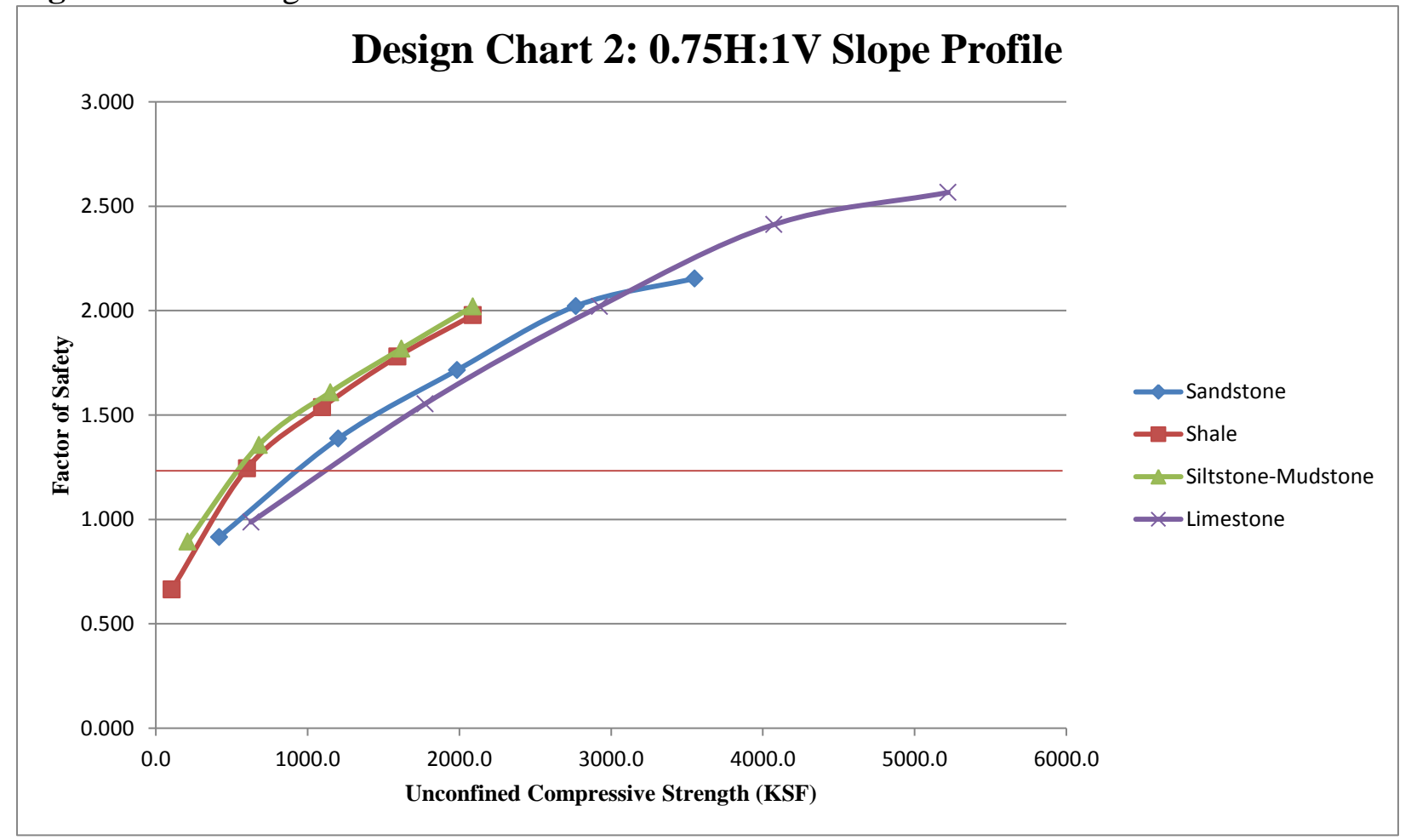

Figure 1.1.3: Design Chart 2 


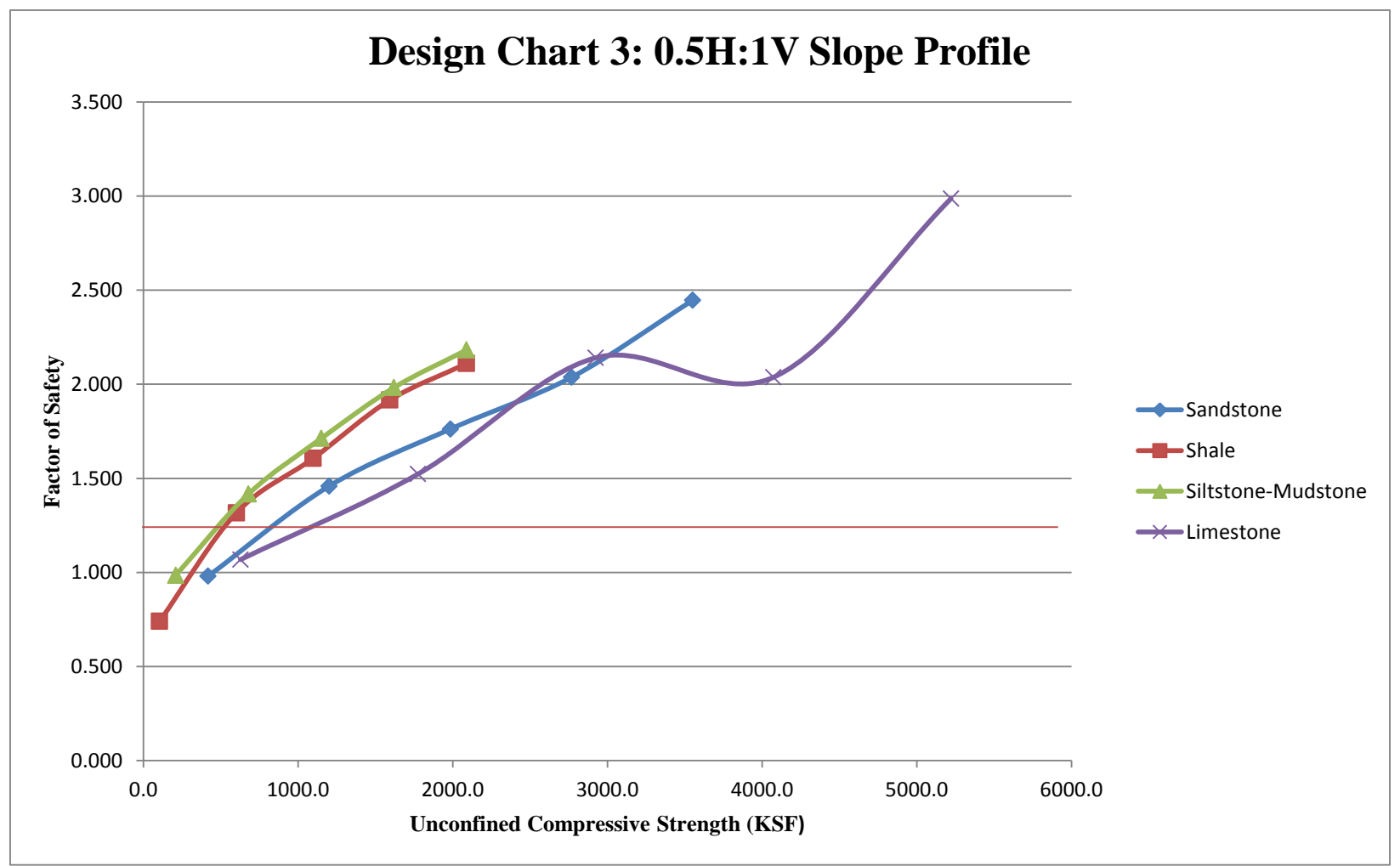

Figure 1.1.4: Design Chart 3

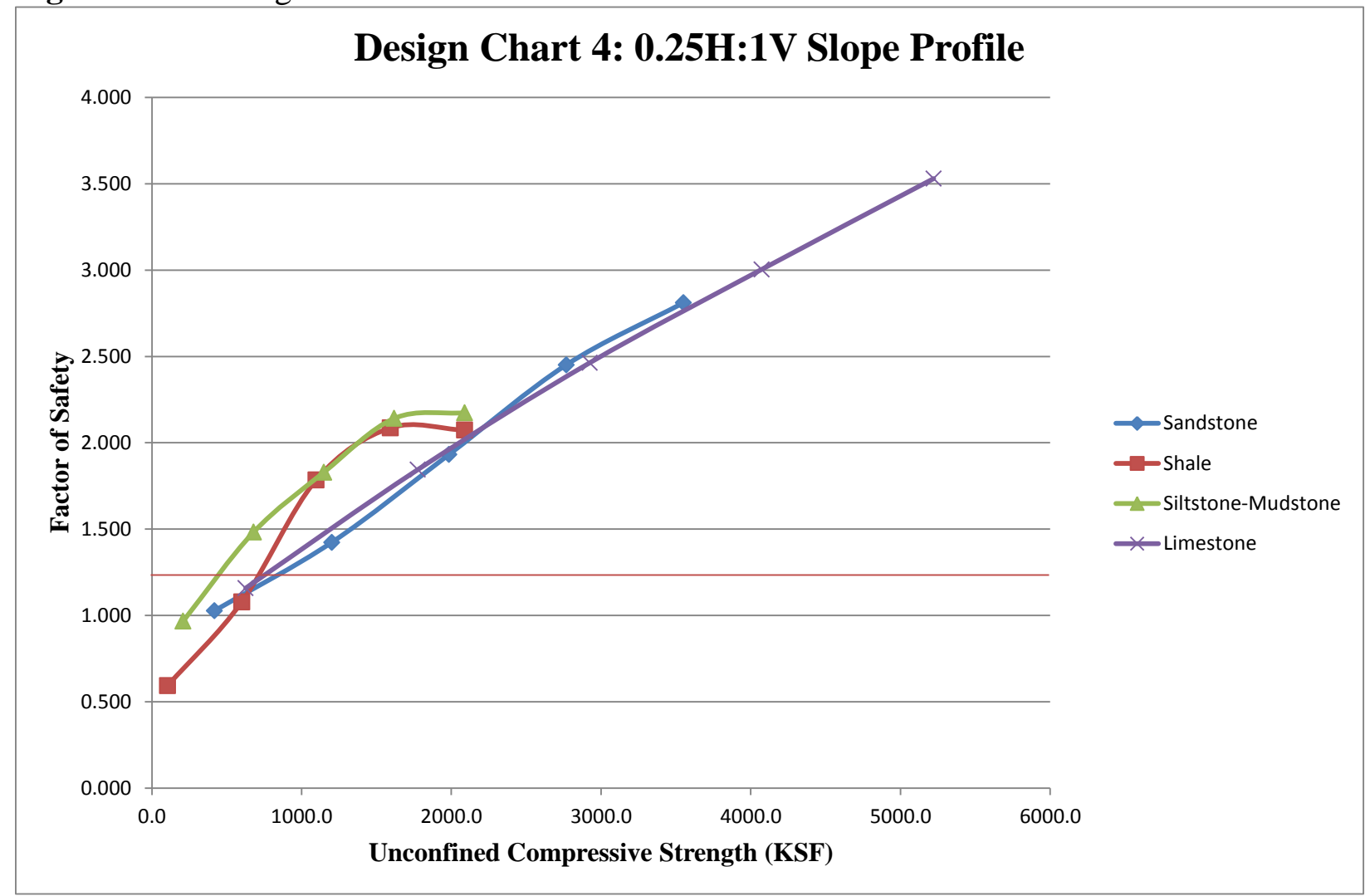

Figure 1.1.5: Design Chart 5 


\section{Bench Reduction Analysis}

This portion of the tutorial guide couples the previously obtained back slope angle through section 1 and pairs it with the bench reduction criteria and analysis procedure. The bench reduction ideology was based upon findings from literature review (Section 2.0) as well as physical recordings taken from past field observations. Engineering judgment on bench reduction should include but not limited to the consideration of the following key points and Table 2.1. Figure 2.1 provides a flow chart in which the analysis procedure follows.

\section{Bench Reduction Criteria:}

- If a thick, massive, stable erosion resistant layer rests above a thin, weak, erodible layer, then a bench may not be required in that location unless the bedding plane of a massive layer will induce slope instability leading to failure.

- If the layer or layers above a significantly thick erodible layer are not massive and do not appear to have the capacity to withstand the cantilever stresses that may be included by erosion of the erodible layer below it, then a bench should be included at that location.

- Erosion will occur in highly erodible sedimentary rock layers when exposed to surface climate. It is impractical to vary slope angles to mitigate the problem. Benching should be used to attenuate the undercutting issues caused by the erosion of these layers.

- Benching to reduce undercutting of rocks should be included at any location where a significant thick erodible layer exists which will induce rock fall.

- Surface runoff should be routed away from the face of the slope as quickly as possible by including drainage above and on the sides of each cut slope.

- Surface runoff should be routed away from the face of the cut slope by sloping benches away from the face. The benches should be sloped to route surface runoff to the ditches on the sides of the slope.

- If the strata found in the boring logs are sloped to benefit the drainage of the slope, then the drainage structure for surface runoff should be designed to follow the slope of the strata.

- A back slope at the crest of a slope is recommended at sites where it is practical to reduce surface runoff on the face of the slope. 
- In some scenarios when significant property damage or human life is at risk, alternatives such as grouting, concreting, or netting may be considered to reduce the erosion rate on highly erodible layers

Table 2.1: Bench Reduction Criteria

\begin{tabular}{|c|c|}
\hline \multicolumn{2}{|c|}{ Bench Assessment Criteria } \\
\hline Modeling Findings & Physical Observations \\
\hline Proposed failure plane location & Excessive rock fall accumulation \\
\hline SVSlope ${ }^{\circledR}-$ Factor of Safety & Excessive erosion \\
\hline CRSP - Rating & Competency of geology \\
\hline
\end{tabular}

The physical observations recorded used to aid in the bench reduction process should be from past experiences and eye witnessed or recorded happenings. The reduction process should consider and compare similar geological recordings from past designs and the behavior of the slope over time. Bench reduction with regards to numerical modeling should consider the previously listed: 1.) Failure plane location of the original assessment, 2.) Factor of safety results from initial assessment, 3.) Colorado Rockfall Simulation Program (CRSP) assessment. Note that the CRSP assessment will not be addressed in this tutorial, it is out of the scope of this research based upon stability. See section 2.5.3 of this report for a further explanation of the CRSP software. 


\section{Bench Reduction: Numerical Modeling}

Similar to the initial back slope angle procedure, the bench reduction analysis follows a flow chart process as well as a stability modeling software. The process for bench reduction is listed in the following steps:

- The designer must take the previously determined back slope angle obtain in section one of this document.

- Upon review of the selected back slope angle, does the angle exceed 0.5H:1V?

- If the designer answers the question with a YES, does right-of-way allow for the slope to be laid back? It was found through analysis that back slopes exceeding $0.5 \mathrm{H}: 1 \mathrm{~V}$ provide difficultly to the bench reduction procedure whilst trying to exceed the original factor of safety assessment. If no additional right-of-way is obtainable the designer must initially design and assess the slope within the guidelines listed in DD-403. If additional right of way is obtainable, lay the slope back to a shallower angle. The designer should lay the slope back and run a slope stability analysis constructed within the restraints of DD-403; bolded below. Does the initial assessment yield a factor of safety which exceeds the minimum requirement of 1.25? If the designer can answer YES, proceed with the bench reduction based upon the criteria listed above and the location of the failure planes. If the design answers the question with NO, they must lay the back slope angle back to increase the opportunity to meet the factor of safety requirement

- If the designer answers the question with a NO. They shall proceed to an initial slope evaluation. The initial slope assessment should evaluate the slope based upon construction practices previously listed in DD-403:

\section{○ Minimum bench width: $20 \mathrm{ft}$.}

\section{○ Bench slope (away from slope face): $15 \mathrm{H}: 1 \mathrm{~V}$}

$\circ$ Maximum Vertical Height: 50 ft.

- Does the initial assessment yield a factor of safety which exceeds the minimum requirement of 1.25? If the designer can answer YES, proceed with the bench reduction based upon the criteria listed above and the location of the failure planes. If the design answers the question with NO, they must lay the back slope angle back to increase the opportunity to meet the factor of safety requirement. 
- Once all question were able to be answered with respect to the initial assessment of the slope profile exceeding the required factor of safety of 1.25. Begin with an iterative bench reduction process by examining the location of the failure plane from the initial assessment and reduced benches throughout the slope. This iterative process should be evaluated multiple times and it is up to the designer's discretion of the levels of iterations taken.

- On completion of the iterative design procedure do any of the bench reduced redesign models possess a factor of safety that meet or exceed the initial assessment result? If the designer can answer the question with YES, select the design in which works best or is most applicable in the given situation and continue with the design. If the designer answers the question with a $\mathrm{NO}$, the iterative process may be completed again or the designer may proceed with the initial design based upon traditional bench cut profile DD-403 practices. 


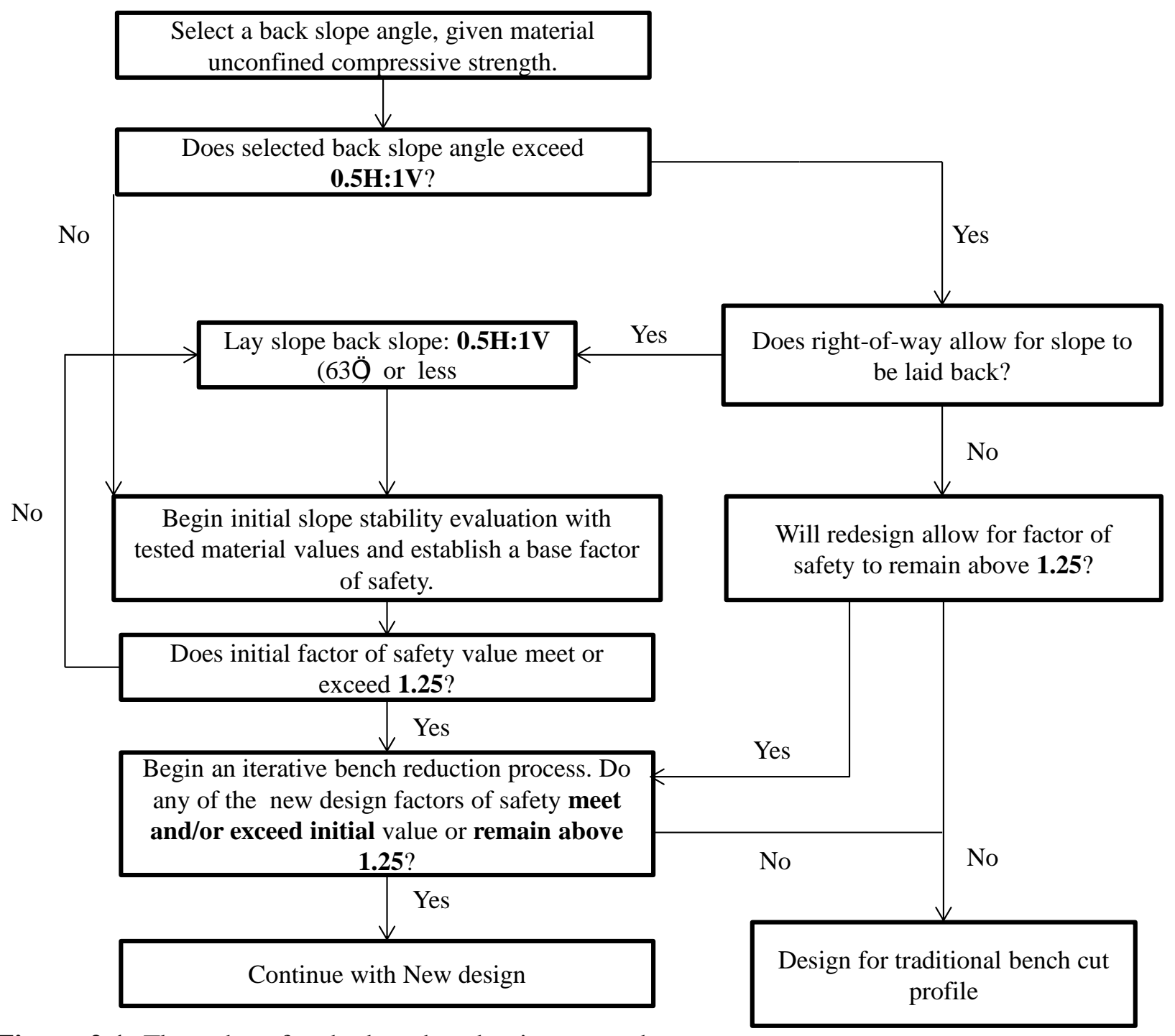

Figure 2.1: Flow chart for the bench reduction procedure

\section{CONCLUSION AND RECOMMENDATIONS}

The intent of this process is outline the procedure that should be taken in the analysis of initial back slope design and reducing benches on a rock cut slope. There is not a definitive answer that can state which benches may be removed for each individual back slope angle. This process is to provide guidance to the designer based on previous finds through literature and numerical modeling. The process of bench reduction is a case by case procedure; the contents of this document are to aid in the practice. Bench reduction should be completed on engineering judgment in addition with the aid of numerical modeling and physical finds and past experiences. 